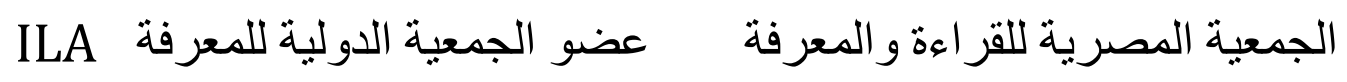

\title{
روية مستقبلية لتمويل البحث العلمي بالتعليم الجامعي بالمملكة العربية السعودية في ضوء خبرات بعض لبول الدول
}

$$
\text { إعداد: - (n) }
$$

دكتور/علي فهران محمد القحطاني 


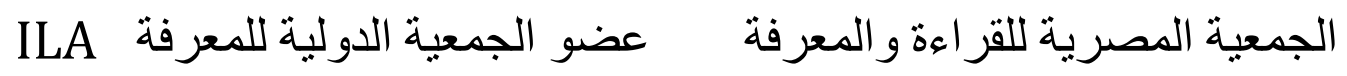


ILA الجمعية المصرية للقز اءة والمعرفة عضو الجمعية الدولية للمعرففة

\section{تمهيد:}

يموج العلم بصفة عامة - والعالم العربي بصفة خاصة - بالعديد من المتغيرات التي

أدت إلى العديد من التحديات وقد أسهمت هذه التحديات في تزايد الاهتمام بالبحث العلمي نتيجة لتزايد طموحات المجتمعات المختلفة في النمو والتقدم،فبدأت هذه المجتمعات بالبحث عن الأساليب العلمية لإيجاد الحلول لمشكلاتها، لذا انتشرت مراكز البحث

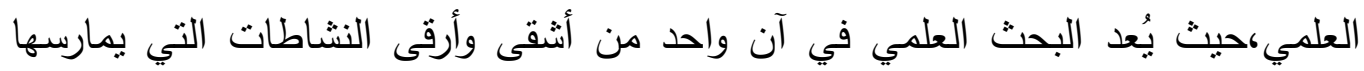
العقل البشري على الإطلاق.

وفى هذا الصدد يشير واقع البحث العلمي في الوطن العربي إلى إنه مازال غير قادر على تلبية احتباجات التقدم والمعاصرة ومواكبة التطور ، فالموازنات المعتمدة لغايات البحث العلمي في معظم الدول العربية محدودة وشحيحة إذا ما قورنت بالنسب المخصصة للبحث العلمي في أمريكا أو في الدول الغربية ،وفى هذا السياق مازال الحديث عن البحث العلمي لإني لم يتجاوز مرحلة الأماني حيث ينظر إليه على أنه جهد حكومي في حين أن الدعم الحقيقي للبحث العلمي يأتي من الحاجة إلى التطور والابتكار وبإسهام الثركات

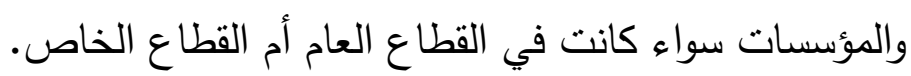

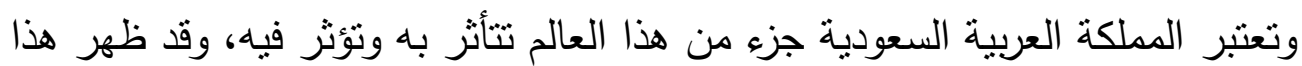
التأثير فيما شهدته المملكة من تزايد الاهتمام بالبحث العلمي نتيجة لنزايد طموحات

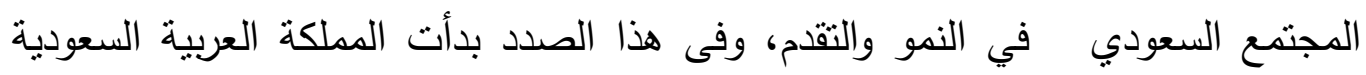
بالبحث عن الأساليب العلمية لإيجاد الحلول لمشكلاتها، لذا انتشرت مراكز البحث العلمي، كما تزايد اهتمام المؤسسات العلمية والتربوية بتتمية كفايات البحث العلمى وذللك لإن لإن مشكلات الحياة اليومية تتطلب تفكيراً علمياً ومنهجاً عملياً لحلها. ويمثل تمويل البحث العلمي محورا هاما فى ظل ما تمر به معظم دول العالم بأزمات اقتصادية تؤثز بشكل مباشر على تمويل البحث العلمي ، الأمر الذي أدى إلى قيام العديد من الدول بتنبى سياسات تمويلية تهدف إلى تخفيف العبء الملقى على الحكومات فى 
ILA الجمعية المصرية للقر اعة والمعرفة عضو الجمعية الدولية للمعرفة

تمويل التعليم العالي والبحث العلمي ، منها مشاركة الطلاب وبعض الهيئات ومؤسسات

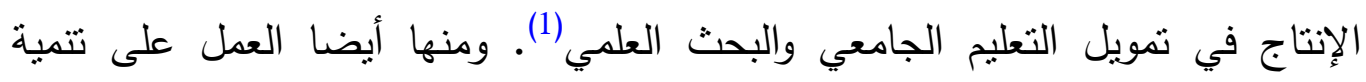

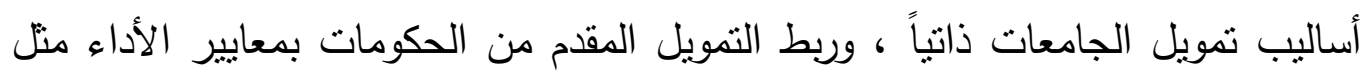

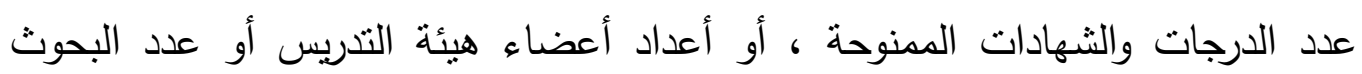

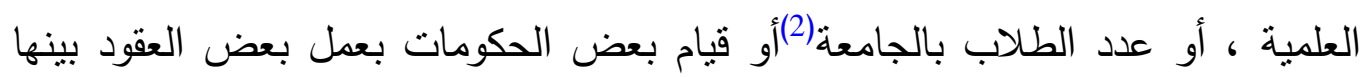

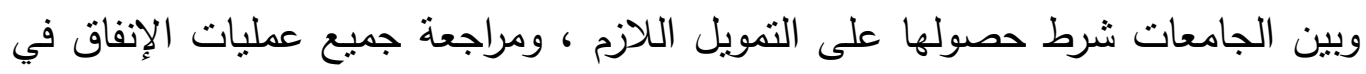

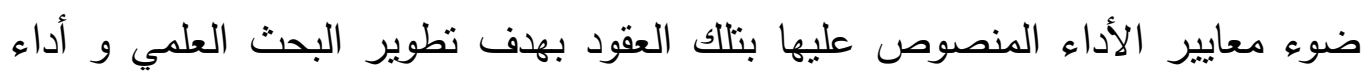

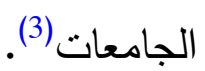

ويعد البحث العلمي أهم الوظائف الأساسية للجامعات، بل إنه المرتبة الثانية في

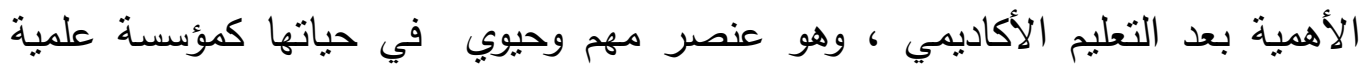
وفكرية ، حيث إنه من المقاييس الدالة علي الدور القيادي للجامعات في المجالات العلمية

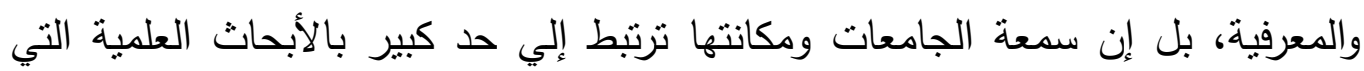
تنتجها وتتشرها (4)

(1) Holtta, Seppo; The Funding Of Universities In Finland : Towards Goal Oriented Government Steering, European, Journal Of Education, Vol. 33, No.1, 2008, P.55.

(2) Ashorth, Kenneth; H; The Texas Case Study, Change, Vol. 26, No.6, Nev/Dec, /2004, P.8.

(3) Hebel, Sara;Virginia Plan Of Fers Fiscol Stability, But The Attached Strings Worrg Colleges, Chronicle Of Higher Education, Vol. 46, No.24, 2000, P42.

(4) جمـال الدهشـان: العلاقـة الإسـتراتيجية بـين البحث العملـي الجـامعي والصـناعة" الواقـع والآفـاق المستقبلية"، نـدوة التخطيط الاستراتيجي للتعليم العـالي، كليـة التربيـة ، جامعـة طنطا ، 11 مايو

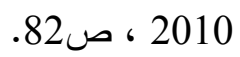


ILA الجمعية المصرية للقراعة والمعرفة عضو الجمعية الدولية للمعرفة

كما أدركت كثير من الدول وجودها وكيانها وتطورها وقوتها جميعها مرهونة بما تتجزه في مجال البحث العلمي، فأخذت ترسم لذللك الخطط وتقيم المراكز والمؤسسات

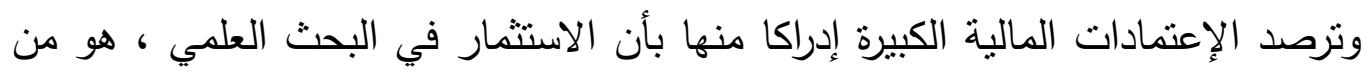

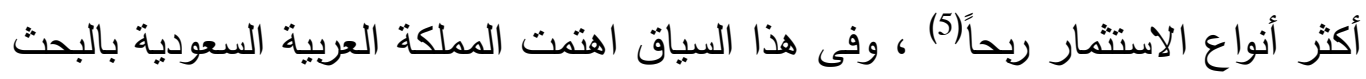

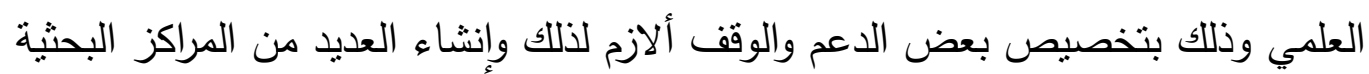

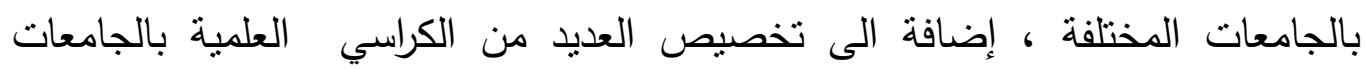

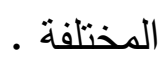

ويثير برنامج الأمم المتحدة الإنمائي إلى نسابق الدول المنقدمة فيما بينهما لرصد الموازنات

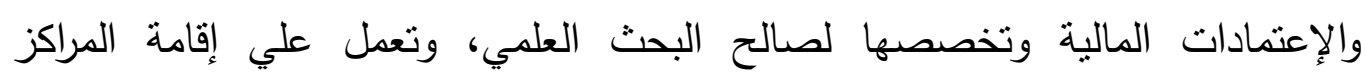

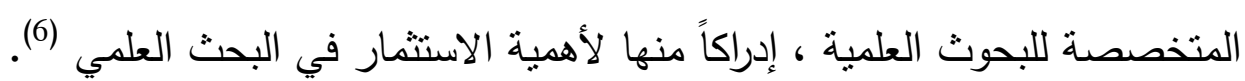

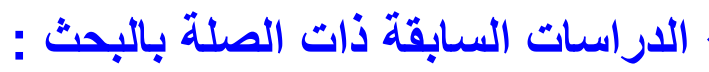

وقد قام الباحث بعرض الدراسات السابقة قبل مشكلة البحث وذللك للاعتماد

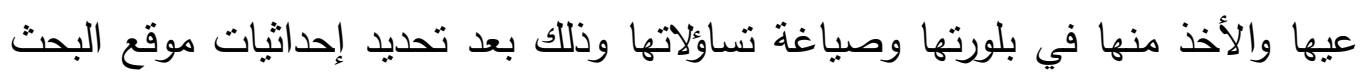

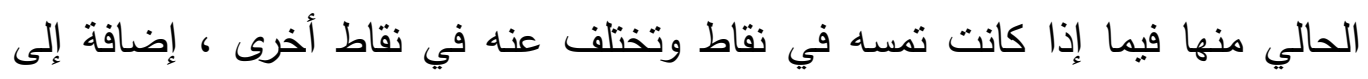
أوجهه الاستفادة كنها ـ الذان. وفى هذا الصدد أثنار منير واصف : (2001)(7) إلى أن التعليم العالي والبحث

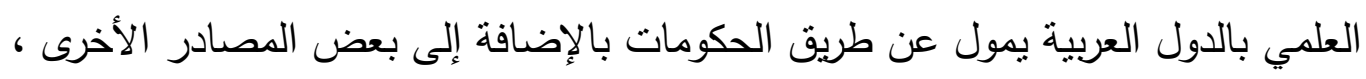

(5) عبد الله المجيدل وسالم شماس: معوقات البحث العلمي في كليات التربية من وجهه نظر أعضاء

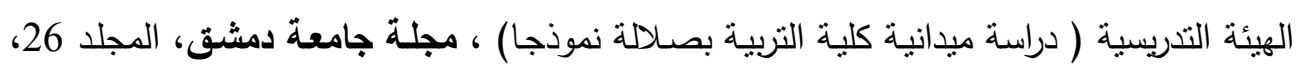

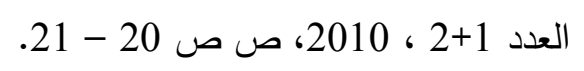

(6) برنامج الأمم المتحدة الإنمائي: تقرير المعرفة العربي، نحو تواصل معرفي منتج، الأداء العربي في

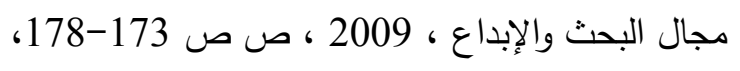


ILA الجمعية المصرية للقز اءة والمعرفة عضو الجمعية الدولية للمعرففة

وأن هناك عدداً من العوامل تؤثر في تمويل التعليم العالي بهذه الدول ، منل العوامل

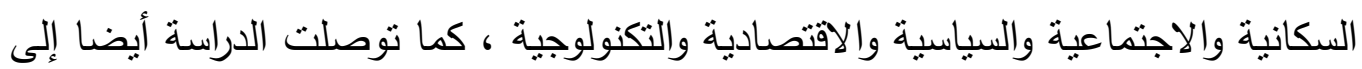

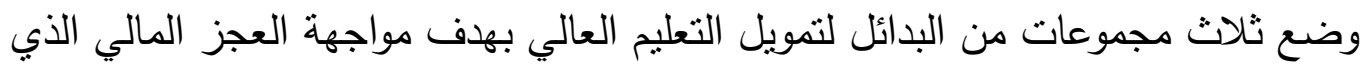
يواجه الجامعات العربية ؛ وذلك بسبب تزايد أعداد الطلاب ، والارتفاع المستمر في كلفة

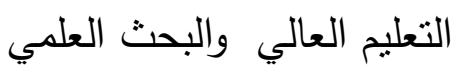

كما يؤكد براينBrian, Salter, And Others : 2000 (8) على أن التمويل الخاص

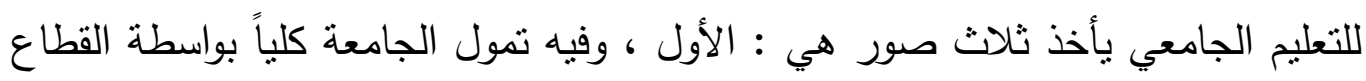

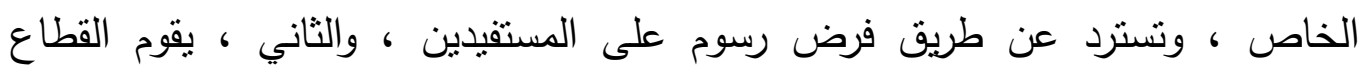
الخاص بتمويل التعليم وتكلفته تسترد عن طريق بيع الخدمات التي تقدمها الجامعة بشكل

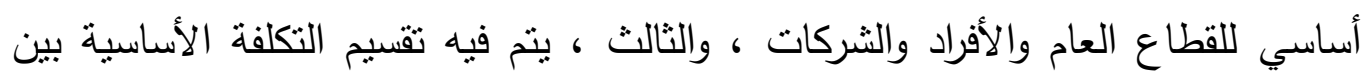

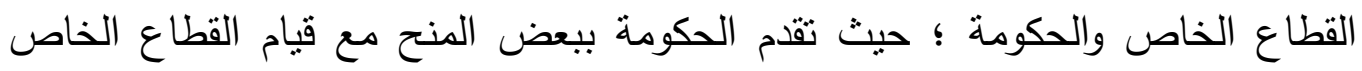

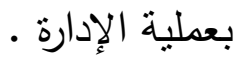

فى حين أكد ممدوح الصدفي محمد وآخران : (2002) (9) على ضرورة تبنى الدولة بدائل للتمويل منها :ضرورة قيام الدولة بإصدار تشريعات وقوانين جديدة تتيح للجامعات آثرات

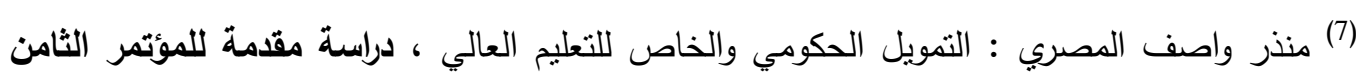

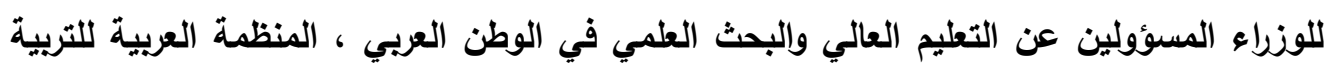

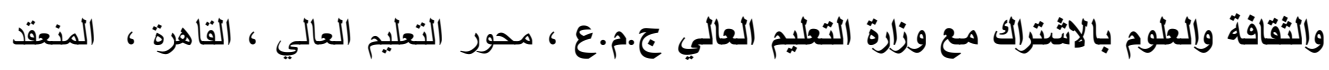
في الفترة من 24-27 ديسمبر 2001م .

(8)Brian, Salter, And Others: Managing The Private Finance Intiative, Perspective, Vol. 4, No.3, 2000, (9)مدوح الصدفي محمد وآخران : تمويل التعليم الجامعي في جمهورية مصر العربية بدائل

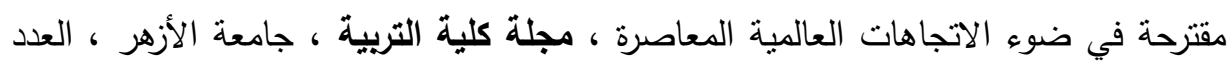

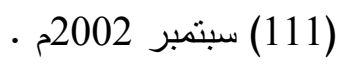


ILA الجمعية المصرية للقراعة والمعرفة عضو الجمعية الدولية للمعرفة

مزيد من الحرية للتصرف في مخصصاتها المالية واستتمارها بالأسلوب الذي ينمى مواردها ،و مساهمة جميع مؤسسات الدولة والجهات المستقيدة من خريجي الجامعات في الإنفاق والتمويل للتعليم الجامعي فى مصر ،وضرورة الاستفادة من عوائد الأوقاف الأهلية فى تمويل التعليم الجامعي ، فى حين تتبنى الجامعة التمويل الذاتي منتل: و العمل على التى تطوير المراكز البحثية فى كل جامعة بحيث تسهم فى خدمة المجتمع من خلال التعاقد مع لئي

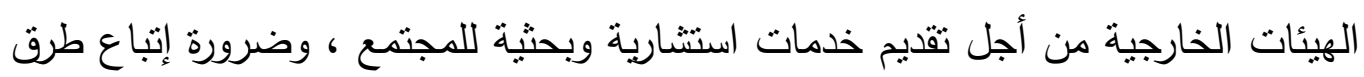
حديثة فى تحقيق خدمة تسويق نتائج الأبحاث والمبتكرات والأعمال العلمية من خلال التخطيط السليم للبحث العلمي، وتعزيز ذلك يتطلب الاستفادة من خبرات بعض الدول المتقدمة في هذا المجال .

وقد أثشار بين 2001م (10): إلى أن تمويل البحث العلمي فى كل من استراليا وبلجيكا يعتمد تمويل المنح الدراسية بها بشكل أساسي على عدد الطلاب ، وتعد الدانمرك

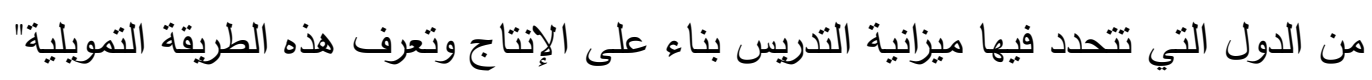
بالعداد" ، وفى فرنسا واليابان تحدد المنح الدراسية بناء على عدد الطلاب وعدد المدرسين الإني والوحدات التعليمية ، وفى ألمانيا يتم التفاوض على المنح الدراسية للتدريس والبحث بين

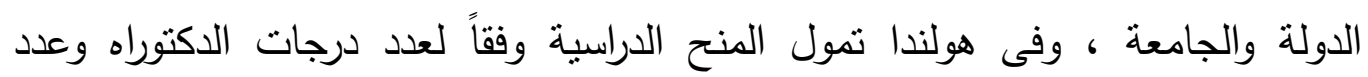

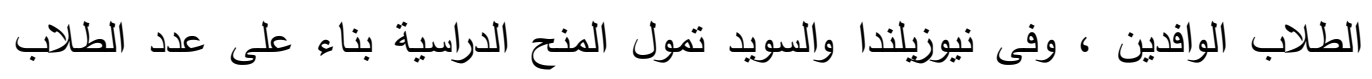
المقيدين في نظام اليوم الكامل ، وفى المملكة المتحدة كانت الأنشطة التدريسية حتى فترة قريبة تمول من قبل مجالس تمويل التعليم العالي ، وفى حين أن الولايات المتحدة

(10)Ben, Jongbloed And Hans, Vossensteyn Keeping Up Performances : An International Survey of Performance - Based Funding In Higher Education, Journal of Higher Education Policy and Management, Vol. 23, No.2, 2001. 
الجمعية المصرية للقراعة والمعرفة عضو الجمعية الدولية للمعرفة ال

الأمريكية تمول الأبحاث الرئيسية بناء على عدد الطلبة المقيدين ، ومن ثم فان الجامعات

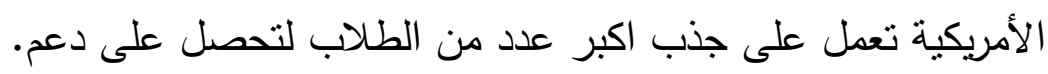
فى ضوء التعرف على واقع تمويل التعليم الجامعي والبحث العلمي بولاية كلورا دو

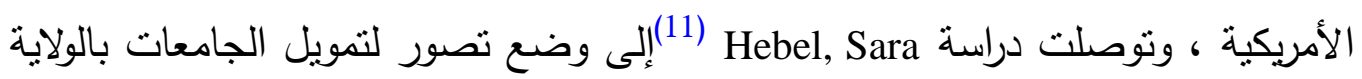

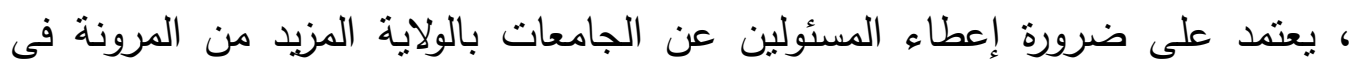

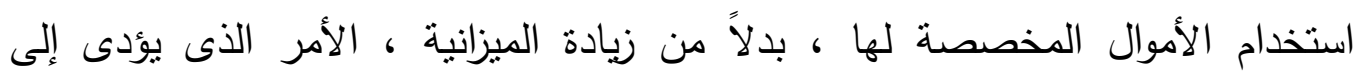

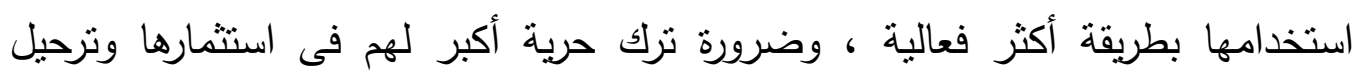

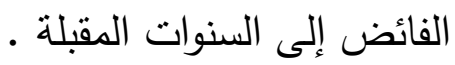

و أكد :John Hagan2002 مستويات تمويل التعليم الجامعي فى بريطانيا غير كافية لتحسين الجودة والمنافسة العالمية

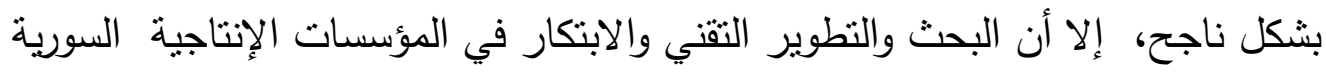

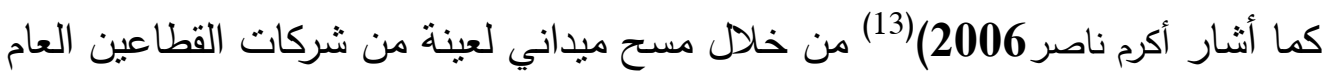
والخاص،وضعف الكوادر وندرة تخصيص ميزانية للنطوير إلا في حالات قلبلة ، وغياب

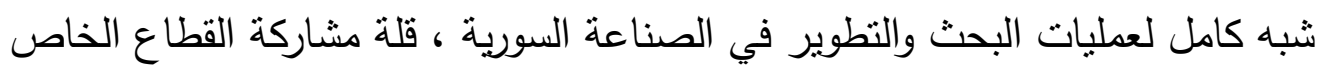
في تمويل البحث العلمي في الجامعات السورية.

(11)Hebel, Sara; Colorado Institutions Seek To Escape Limits On Spending, Chronicle Of Higher Education, Vol.48, No.39, 2002.

(12)John Hagan; More Money For More Rope: The Taylor Report and The Funding Debate, Perspectivers, Vol. 6, No.1, 2002.

(13) أكرم ناصر / صفوان الأخرس / وبثير بريز : البحث والتطوير النقني والابنكار في المؤسسات

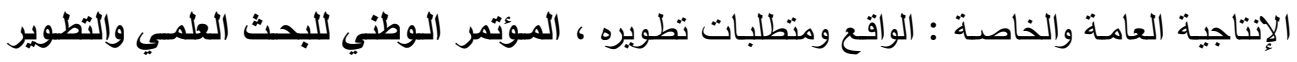

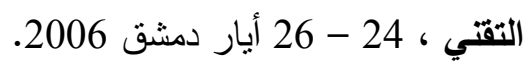


ILA الجمعية المصرية للقز اءة والمعرفة عضو الجمعية الدولية للمعرففة

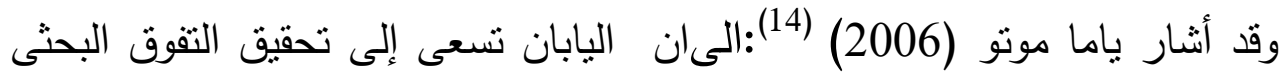
والابتكارى على المستوى المتتافس عالميا، وذلك من خلال نوفير الإمكانات المادية

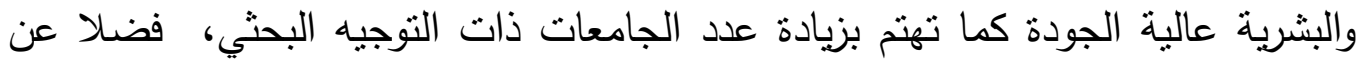
زيادة كفاءة الباحثين والتوجه إلى النشر العلمي النوعي الكثيف، كما اهتمت بزيادة المنح التنافسية وتتجيع الباحثين الثبان ودعمهم ماديا ومهاريا، وفى هذا السياق اكدت دراسة الثيا رفقي (2006) (15): على اقتراح خطة بحثية شاملة وإدارتها على المستوى الوطني ومنها:التدريب والتأهيل المستديم والمتتبع والمواكب للمستجدات العالمية ، وإنشاء المراكز المتخصصة فى البحث العلىى، وتوفير الظروف المناسبة للباحثنيهوتحديث التثريعات الجامعية،وتتجيع القطاع الخاص لإنشاء مراكز الأبحاث والإنفاق عليها ،وتسويق نتائج البحوث وتعميم جدواها، وذللك لان الخطط البحثية من شأنها زيادى التمويل فقد أكدات

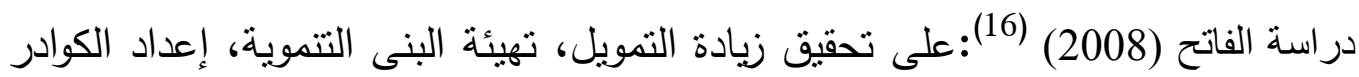
إعدادا مستديما، تعديل الأنظمة وإعطاء بعض الحرية للبحث العلمي، تحسين الظروف المعيشية والأكاديمية لرجال البحث العلمي.

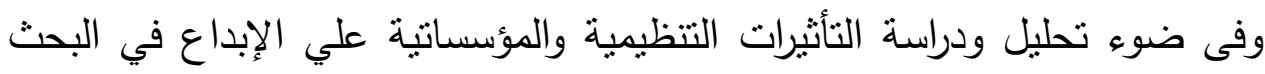

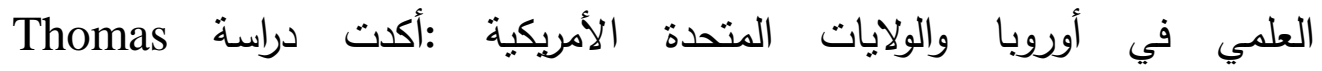

$\left({ }^{14}\right)$ Shinichi Yamamoto (2006), 'Academic Research in Japan, The future of academic research - OECD Expert Meeting Vienna.

(15) عادل عوض رفقى:"خطة بحثية لتطوير البحث العلمى"، مجلة اتحاد الجامعات العريبة،الأردن،

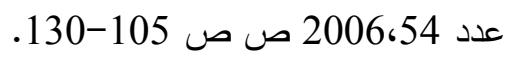

(") رشيد الفاتح :" استراتيجية البحث العلمى فى جامعة دمشق"، مؤتمر البحث العلىى مشكلاته وآفاق تطويره، 22-24 أبريل 2008، الرياض. 


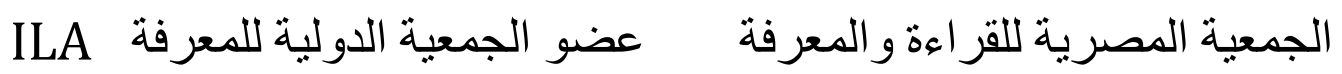

2009:Heinz

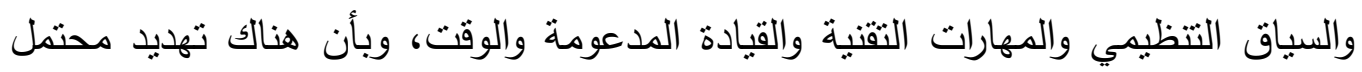

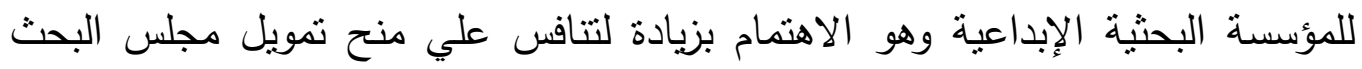

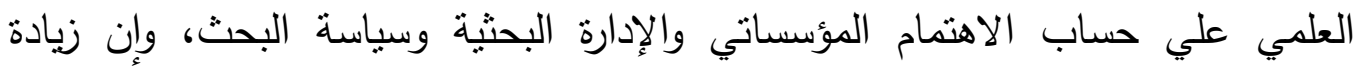
الحوافز والدكافآت خلال العمل تؤدي إلي تبادل مثمر في البحث العلمي.

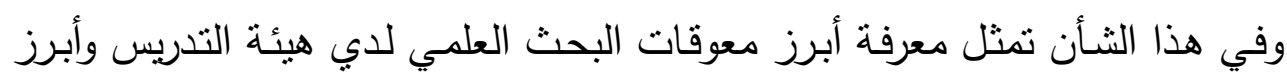
عوامل النهوض بالبحث العلمي، والتعرف علي آليات ربط البحث العلمي بمنطلبات خطط

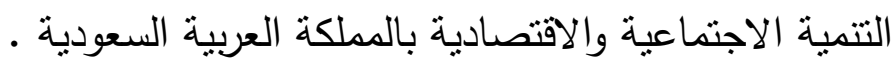

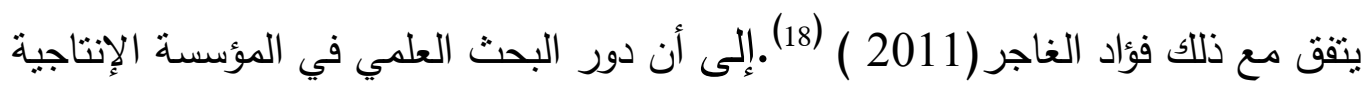

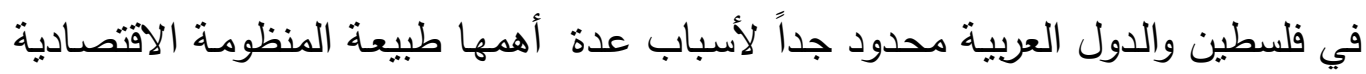

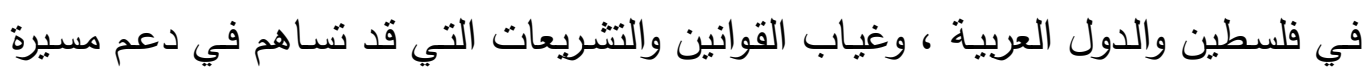

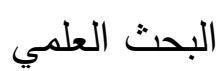
وفى ضوء استمرار مسلسل الغموض الذي يجتاح البحث العلمي بالدول العربية اشتار سالم (2011) (19) أن البحث العلمي يعانى من غموض مفهوم المشـاركة وصـعوبة قياسـها،

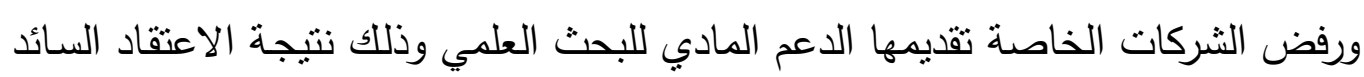

$\left.{ }^{17}\right)$ Thomas Heinz, philip Shapira, Juan Rogers \& Jacqueline Senker: Organizational And Instiutional Influences On Creativity In Scientific Research, Research policy, Vo138, Issue 4, 2009,pp 610 - 623.

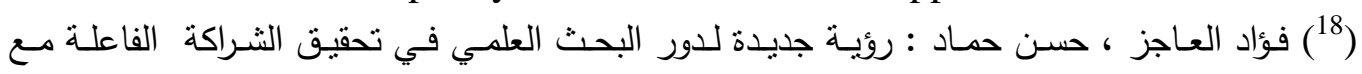

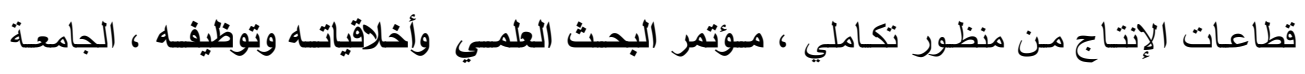

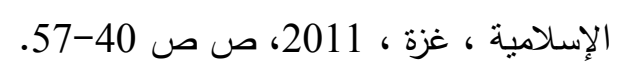

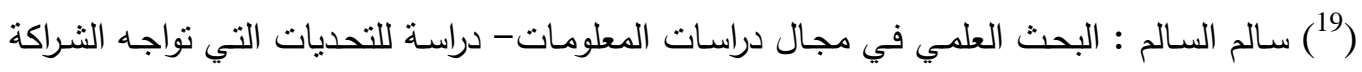

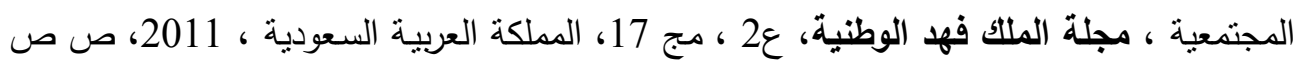
.201-180 


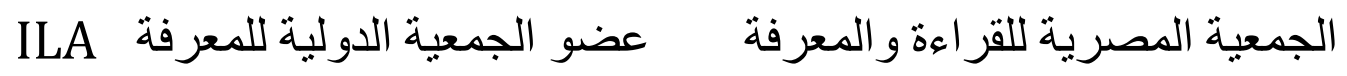

بأن البحث العلمي من مسؤولية الدولة وعدم القناعة بأهمية المشاركة، وضعف الإحساس

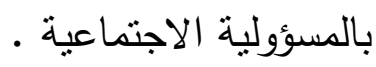
ويتقق معه أثر 2012 (20) إلى أن أثنر تمويل البحوث العامة والخاصة علي الإنتاج العلمي

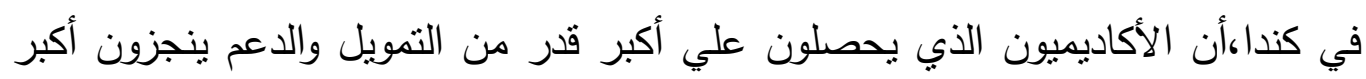

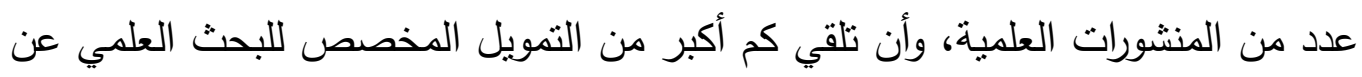

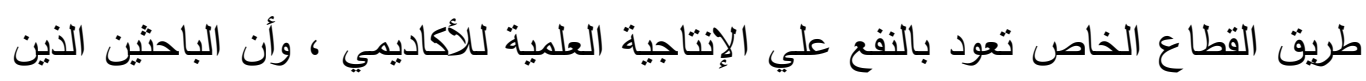

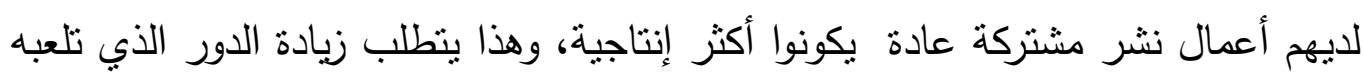

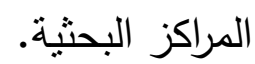

في هذا الصدد ويشير Clausen, Tommy \& Fagerberf, Jan: الدور الذي تلعبه مراكز البحوث في كل من المطلكة المتحدة والولايات الدتحدة الأمريكية

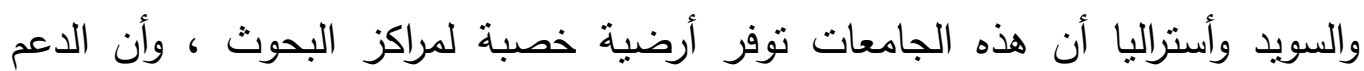

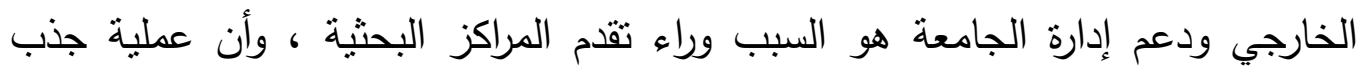
التمويل لمراكز البحوث هو ضروري للاستمرار في قدرة مراكز البحوث علي تقديم المعرفة

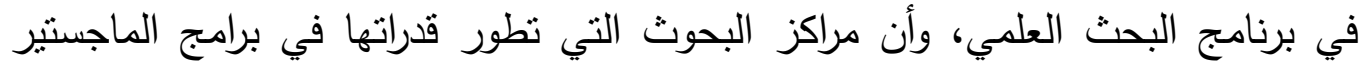

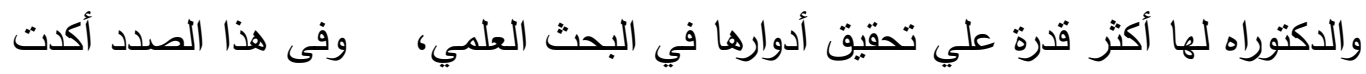
سعاد الحارثي (2012 ) (22): على ضرورة تحقيق الترابط بين البرامج البحثية ومنطلبات البرات

$\left({ }^{20}\right)$ Catherine, Beaudty \& Sedki Allaoui : Impact of public and private Research Funding on Scientific production: The Case of Nanotechnology, Research policy, Vol41,2012,pp1589-1606

$\left({ }^{21}\right)$ Clausen, Tommy \& Fagerberf, Jan \& Gulbrandsen, Maguns: Mobilizing For Change: Astudy of Research Untis in Emerging Scientific Fields, Research poliey, Vol41,Issue 7,2012,pp1249-1261.

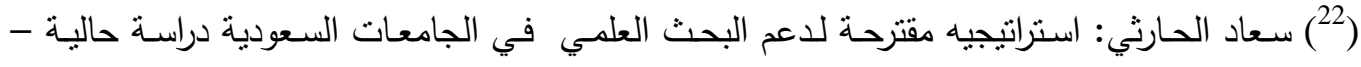

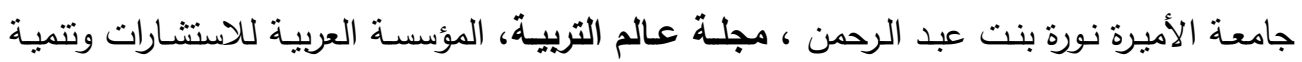

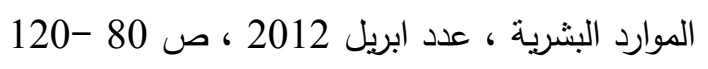


ILA الجمعية المصرية للقراعة والمعرفة عضو الجمعية الدولية للمعرفة

الدولة لتتموية المستقلية ، وتدويل البحث العلمي الجامعي السعودي ، تحسين أداء

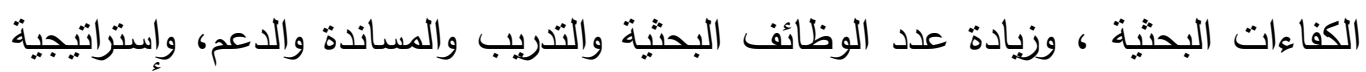

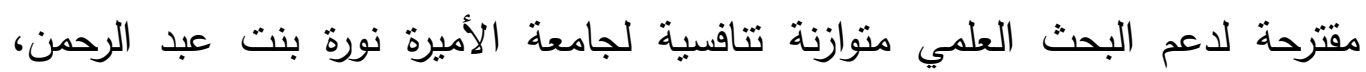

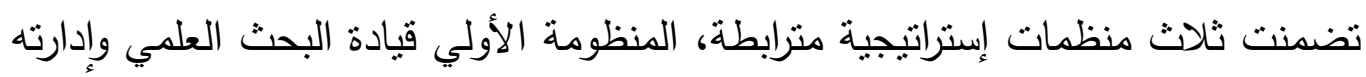

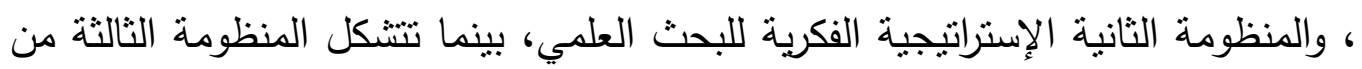
المؤسسات التتفيذية للبحث العلمي في الجامعة.

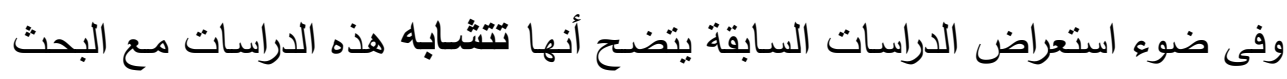

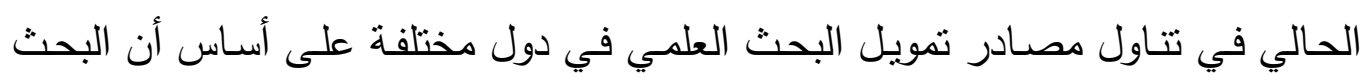

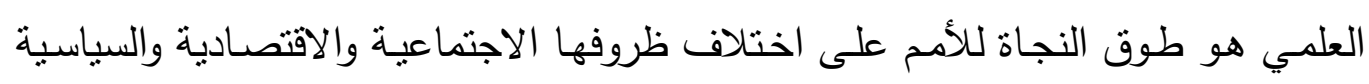

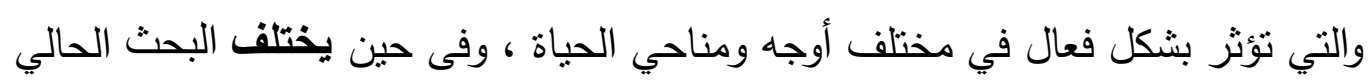

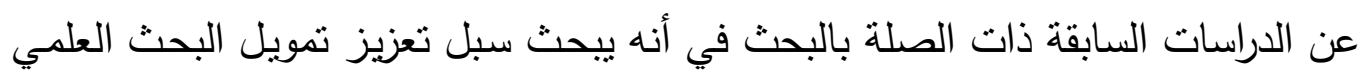

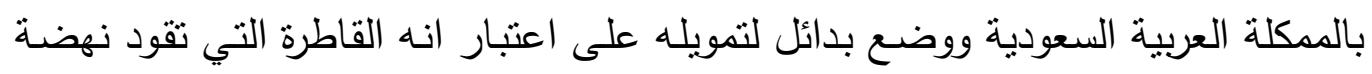

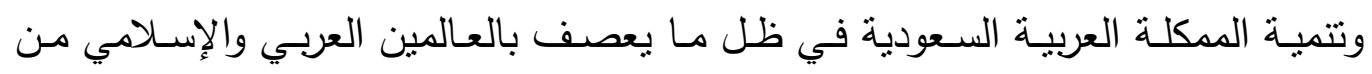
تغيرات وتحديات ، في حين بستفيد البحث الحالي من الدراسات السابقة في بلورة مشكلة

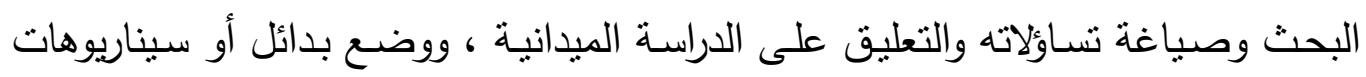

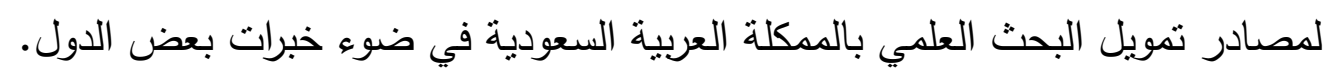

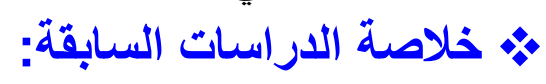

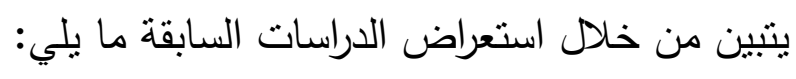

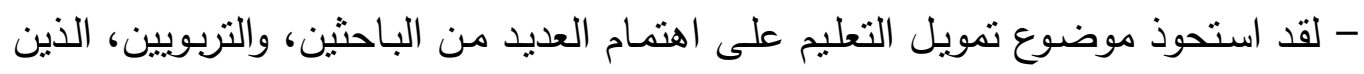
تناولوا هذا الموضوع بالبحث من جميع الجوانب.

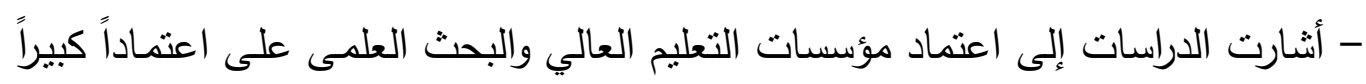

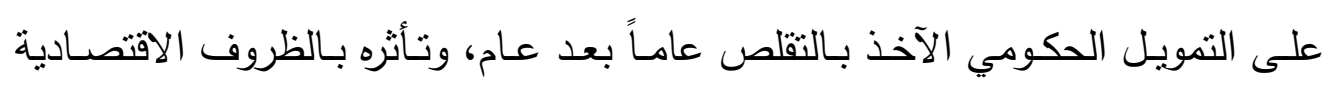

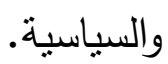




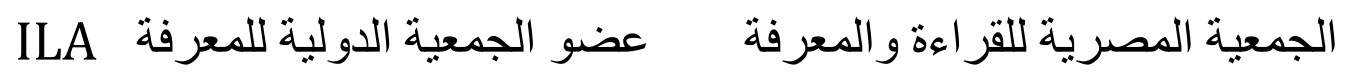

- أشـارت الدراسـات إلى ضـآلة الدعم الحكومي للجامعات والبحث العلمي، وإلى ضرورة

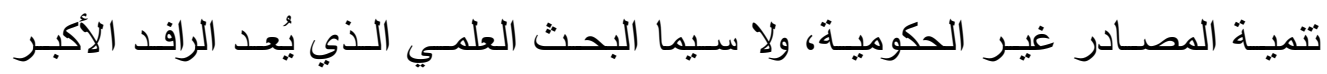
للجامعات في دول العالم المتقدم.

- ضـرورة مشـاركة القطاع الخـاص والمجتمـع المحلي والأهـالي في دعم وتتويع مصـادر تمويل الجامعات.

ويأني هذا البحث لبيان أهم مشكلات التمويل التي يعاني منها البحث العلمي بالت بالممكلة العربية السعودية، والمقترحات التي من شأنها تطوير مصادر هذا التمويل له.

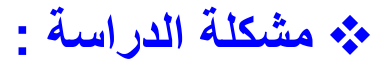

انبثقت مشكلة البحث من الحاجة الملحة للنهوض بالبحث العلمي في الوطن العربي بصفة عامة والمملكة العربية السعودية بصفة خاصة لمواكبة التطور الحضاري العالمي لئي

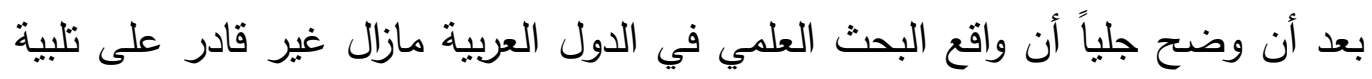
احتياجات التقدم والمعاصرة لأسباب عدة من أهمها ضعف التمويل الرسمي وتندي مساهمات القطاع الخاص. وقد أثتبت الدراسـات السـابقة أنه على الرغم من الجهود المبذولة لتطوير البحث

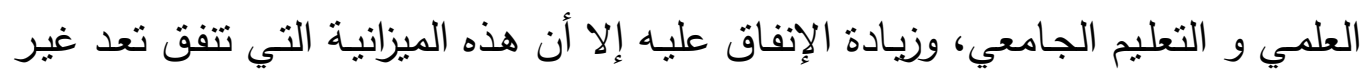
كافية، ومن أسباب هذه الإشكالية ما يلي : - - نقص الموارد المالية اللازمة للبحث العلمي، خاصة في ظل ارتفاع تكلفة هذا النوع من التعليم وتقلص مصـادر تمويله التقليدية وعدم توافر مصادر بديلة في الوقت الحاضر لمجابهة الاحتياجات المستقبلية. - - ضعف ارتباط الأبحاث العلمية المنجزة بأهداف وسياسات خطة التتمية الاقتصادية

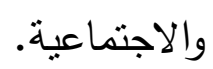


الجمعية المصرية للقر اعة والمعرفة عضو الجمعية الدولية للمعرفة ال

- - غياب القوانين والتتريعات التي قد تساهم في دعم مسيرة البحث العلمي ، وضعف

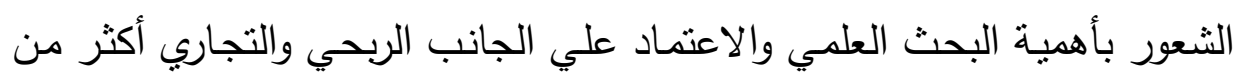
الاعتماد علي الجانب النطويري للصناعات.

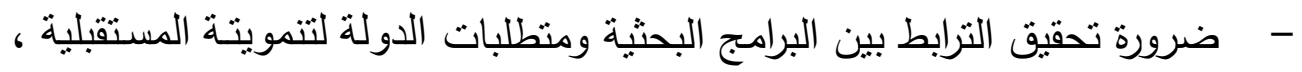
وتدويل البحث العلمي الجامعي.

وتأسيسا على ما سبق تتبلور مشكلة البحث الحالي في التبائي التساؤل الرئيس التالي: وتتبلور مشكلة البحث في التساؤل الرئيس التالي ما الروئة مستقبلية لتمويل البحث العلمي بالتعليم الجامعي بالمملكة العربية السعودية

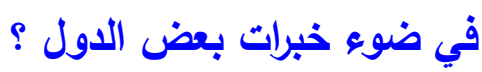
والإجابة على هذا التساؤل تنطلب الإجابة على الاس علئة الفرعية التالية

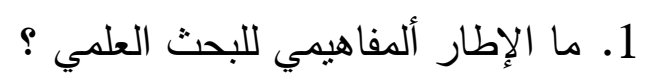

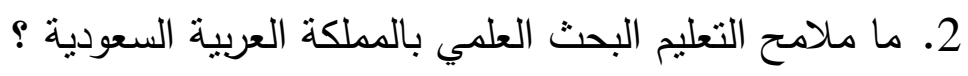

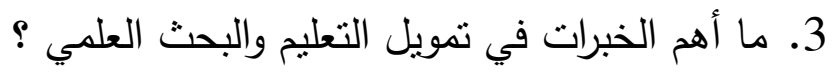

4. ما محاور الرؤية المستقبلية لتمويل البحث العلمى لتمويل البحث العلمي بالتعليم

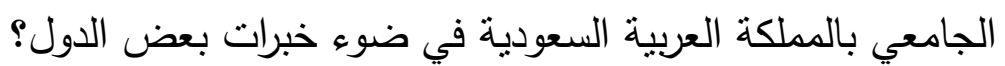
تتبلور أهداف البحث فيما يلي :

1) تعرف الإطار المفاهيمى للبحث من الماهية والأهداف وغير ذلك 2) وضـع رؤية مستقلية لتمويل البحث العلمي بالتعليم الجامعي بالمملكة العربية السعودية في ضوء خبرات بعض الدول المنقدمة .

3) تعرّة ملامح وأبعاد الواقع الحالي للبحث العلمي بالممكلة العربية السعودية.

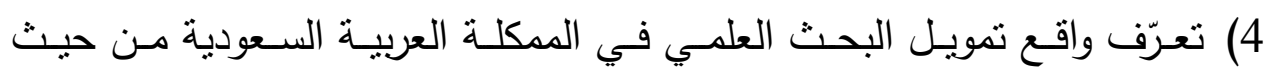
المصادر الدختلفة الحكومية والقطاع الخاص. 


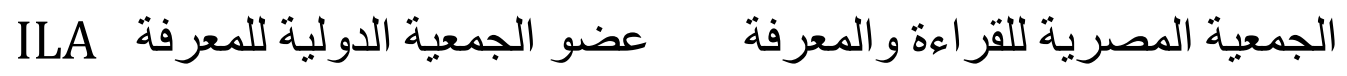

5) دراسة خبرات بعض الدول في تمويل البحث العلمي.

6) تعرّف المعوقات التي تقف وراء عدم تطور البحث العلمي في المدكلة العربية

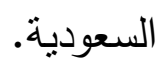

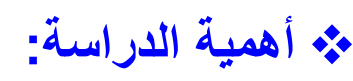

تكمن أهمية البحث الحالي في: آهمة الرالة:

1) تتاوله قضية هامة من قضايا التعليم وهي البحث العلمي وسبل وتمويله

والبحث العالمية وهى قضية التمويل وسبل تعزيز مصادرة في ضوء الاستفادة من النابل

خبرات بعض الدول.

2) هذه الدراسة دعوة إلى التعامل الواعي مع البحث العلمي، لأن تقدم المجتمعات في بلدي

عصرنا الحالي يقاس بما تحققه من إنجازات علمية وتقنية.

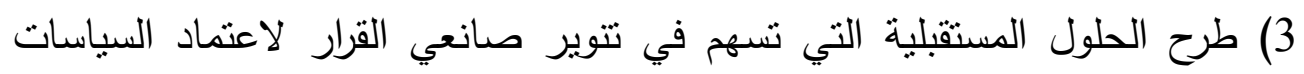

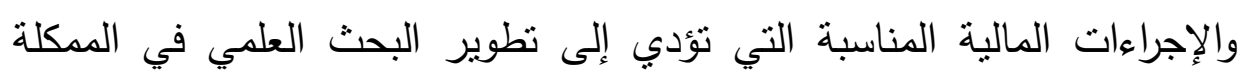

$$
\text { العربية السعودية. }
$$

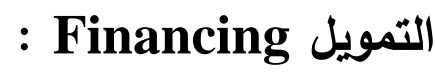

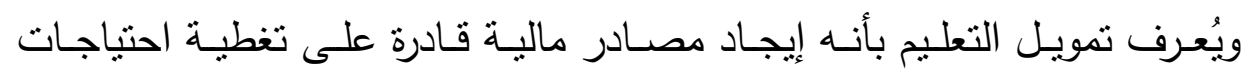

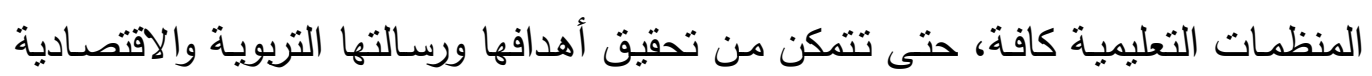
والعلمية والدراسية والاجتماعية (23).

يعرف التمويل بأنه مجموع الموارد المالية المرصودة للمؤسسات التعليمية ، لتحقيق أهداف محددة وإدارتها واستخدامها بكفاءة عالية (24).

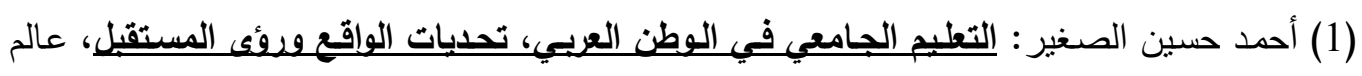


ILA الجمعية المصرية للقز اءة والمعرفة عضو الجمعية الدولية للمعرففة

البحث العلمي ويقصد بالبحث العلمي: عملية استقصاء وتتقيب وتحرى من أجل إثراء المعرفة وتطويرها بالإضافة إليها، وإغنائها، وزياداتها من خلال التحليل والنقد، والاستتناج بالثكل الذى بسهم بتحقيق إضافة جديدة إلى المعرفة(25).

كما إن روبرت (Robert) يرى البحث العلمى عبارة عن مجموعة من الجهود المنظمة التى يقوم بها الإنسان مستخدماً الأسلوب العلمى وقواعد الطريقة العلمية فى سعيه لزيادة سيطرته على بيئته واكتشاف ظواهرها وتحديد العلاقات بين هذه الظواهر (26)

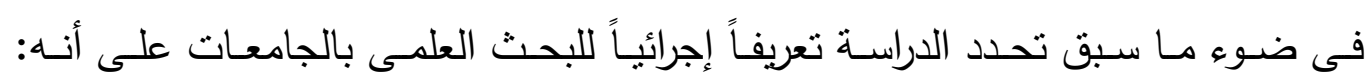

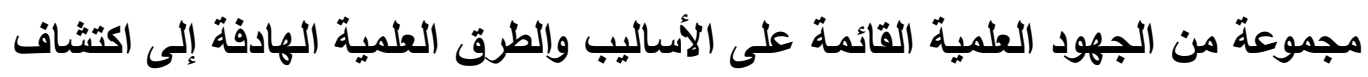
الحقائق والمعارف والتأكد من صحتها من ناحية، وإيجاد الحلول لمختلف المشكلات التى تواجه الإنسان في حياته من ناحية آخرى. تمويل البحث العلمي:

يقصد بتمويل التعليم بأنه الوظيفة الإدارية التي تختص بعمليات التخطيط للأموال ،

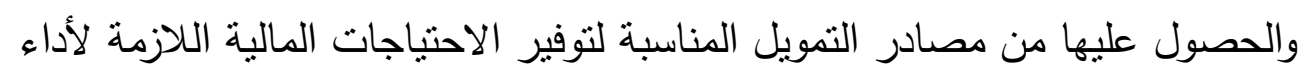

الأمم المتحدة : برنامج الأمم المتحدة الإنمائي ، تقرير التنمية البشرية ، 1990م ، ص

(25) صـلاح سـالم زرنوقة: البحث العلمي والتتمية فى مصر ، قضـايا التنميـة، ع28، مركز دراسـات

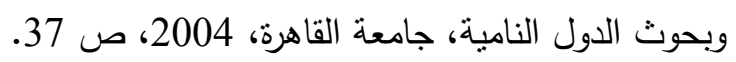

(26) Robert Heorner: Research In Special Education: Scientific Methods and Evidence - Based Practices Education, 2005, P4, www: Uorgon.edu/ Grantmatters/pdf/DR/ Research- in- Sped. 


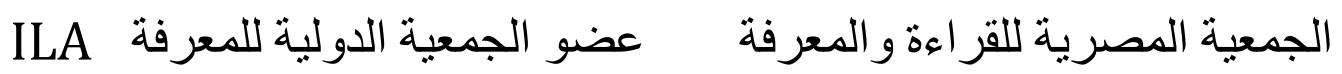

الأنشطة المختلفة ، بما بساعد على تحقيق أهداف هذه الأنشطة ، وتحقيق التوازن بين الرغبات المتعارضة للفئات المؤثرة فى نجاح واستمرار المنظومة (27).

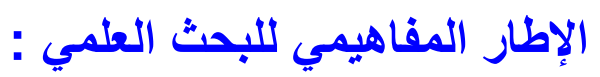

نظراً للدور الكبير الذي يلعبه البحث العلمي كمقياس للتقدم، وعلى الرغم من أن البحث العلمي أخذ مكاناً إلى جانب التدريس وخدمة المجتمع بالجامعات، إلا إن تعريفه مازال

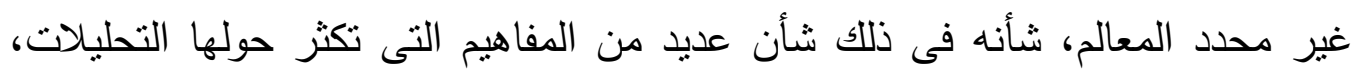
ويعود ذللك إلى اختلاف وجهات نظر الباحثين واهتماماتهم البحثية من جهة، وطبيعة المؤسسات التى يعملون

: أهداف البحث العلمى بالجامعات والمؤسسات العلمية

تتعدد أهداف البحث العلمي بالجامعات والمؤسسات العلمية وأهمها ما يلى (28): - توفير قاعدة معلومات عن الموارد والظروف الطبيعية مما يساعد على دفع جهود التنمية.

- تعميق العلاقة بين الجامعة ومراكز البحوث والمؤسسات الإنتاجية المهتمة بقضايا البحث العلمي والتقدم الثقافي.

- - تقديم خبرات الجامعات واستشـاراتها ومخرجات عملياتها البحثيـة لمشـاريع التتميـة المحلية.

وبناء على ذلك يعتبر البحث العلمي من أهم وظائف الجامعات، لأنه أحد العوامل

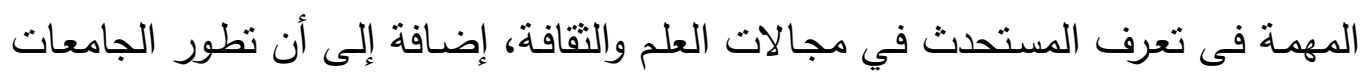

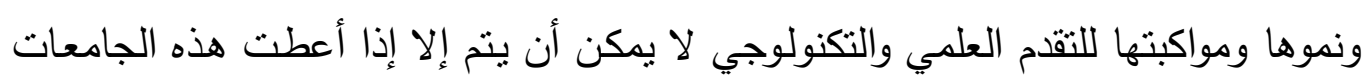

محمد عثمان حميد : أساسيات التمويل الإداري واتخاذ قرارات الاستثمار ، القاهرة ، دار

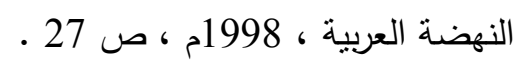

(28) محمد الصطوف: آفاق البحث العلمى العربى وإثـكاليات صناعة القرار ، مـؤتمر إدارة وتمويـل

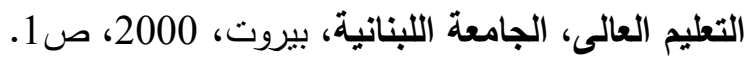
487 


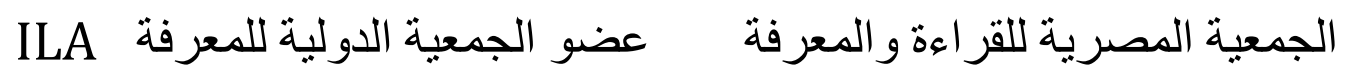

أهمية كبرى للبحث العلمي، فهو السبيل إلى معالجة المشكلات وتتمية المجتمعات، ومن هنا نظهر أهمية البحث العلمى. البه.

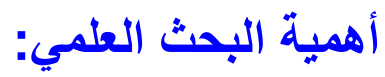

يعد البحث العلمي فى نظر الكثيرين من أهم وظائف الجامعات، لأنه أحد العوامل المهمة فى خلق المعرفة وتطويرها وتحقيق التقدم العلمي والتقني، فالتقدم الذي يشهده العالم فى كثير من البلدان المتطورة كان نتيجة للأبحاث العلمية الرائدة، كما أن تقدم أى دولة من

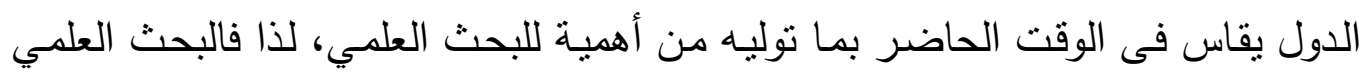
عصب نهضـة الأمم، والمجتمع الذي يطمح الوصول إلى ما وصلت إليه الدول المتقدمة

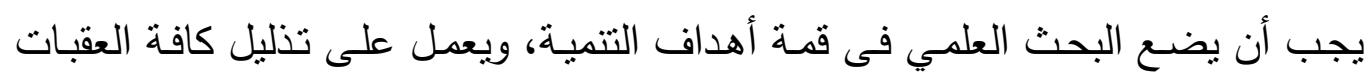
التى تعترض تحقيق هذا الهدف. كما يعتبر البحث العلمي(29) الوسيلة الأساسية لتحقيق التتمية المتكاملة للمجتمع،

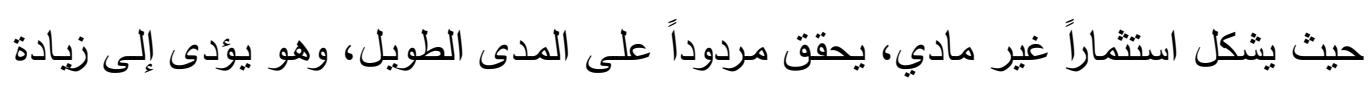
النمو الاقتصادي، ويمكن المؤسسات من مواجهة تحديات البيئات التتافسية.

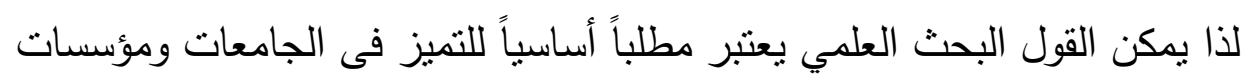
التعليم العـالي ومراكز البحـوث، خاصـة أمسام التغيرات المتسـارعة بفعل ثورة المعلوماتيـة وتكنولوجيا الإعلام والاتصـال، لذا صنف البحث العلمي بالجامعات إلى بحوث أساسية وبحوث تطبيقية.

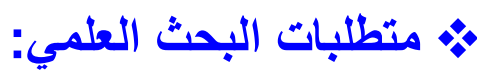

إن البحث العلمي يقتضى توفر العديد من المقومات والمنطلبات التى تتيح تحققه بصورة فعالة وتتمثل فى: توفير المناخ العلمى الملائم للإبداع، وتوفر الأدوات والأجهزة

(29) عمار عمارى، ليلى قطاف: الجامعة الجزائرية "الواقع والآفاق"، الملتقى الأول حول إثكالية التكوين

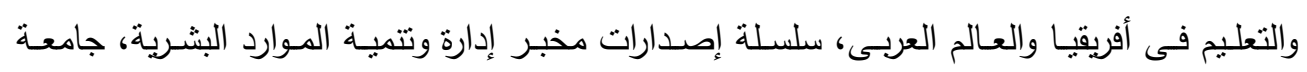

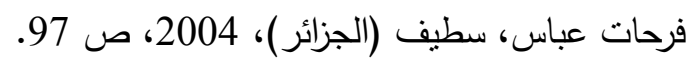
488 
الجمعية المصرية للقراعة والمعرفة عضو الجمعية الدولية للمعرفة ال

اللازمة للبحث العلمى، وإدارة البحث العلمى، الاستثمار فى البحث العلمى، تمويل البحث

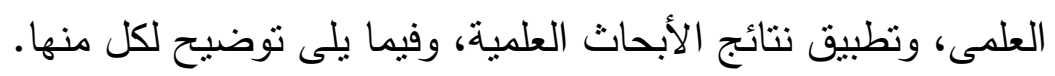

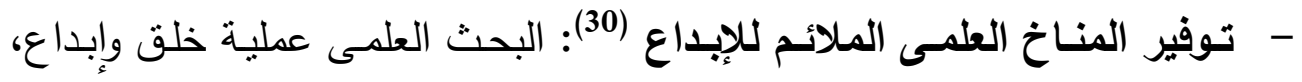

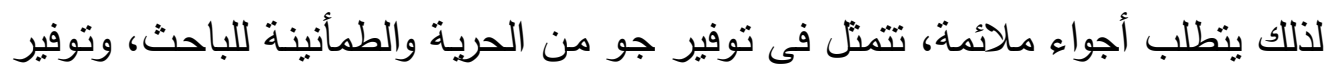

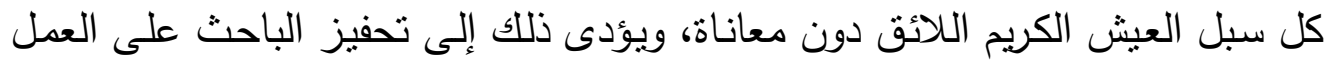

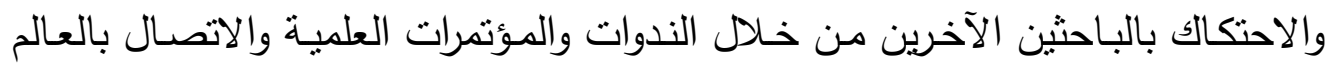

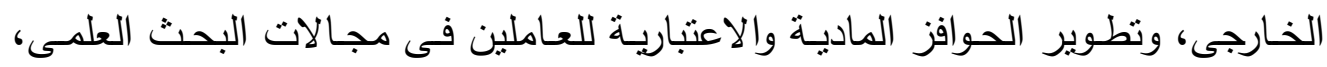
وتوفير الكانة والرعاية من قبل المجتمع ومؤسساته لعلمائه وباحثيه.

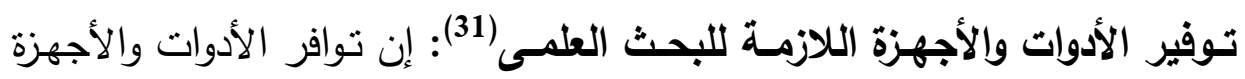
اللازمة للبحث العلمى تزيد من إدكانات الباحث، يضاف إلى ذلك الحاسبات والعقول الإكترونية، وتوفر النشر والتوثيق والمكتبات والدوريات.

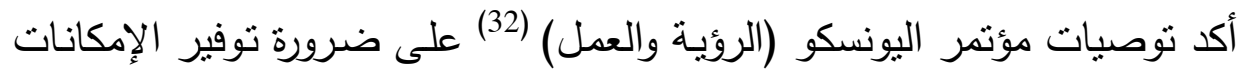

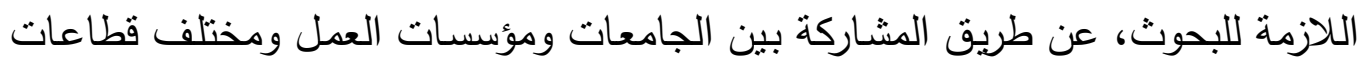

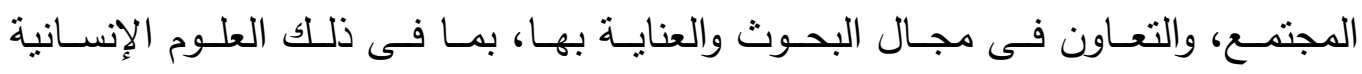

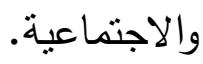

(30) عبد الل عبد الدائم: الآفاق المستقبلية للتربية فى البلاد العربية: التربية العربية- بنى ومراحل

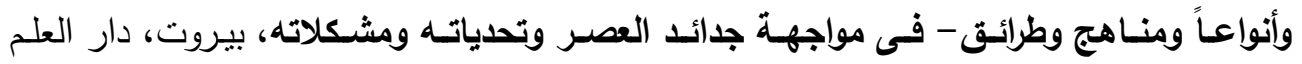

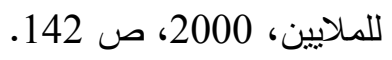

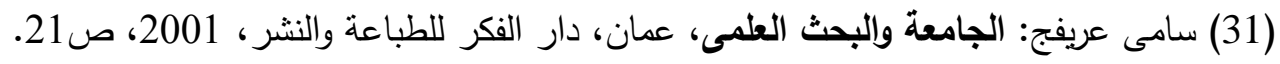

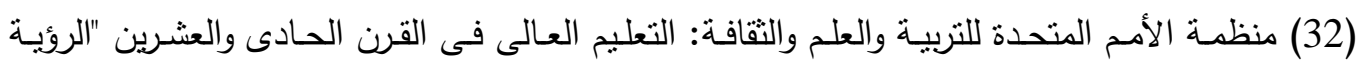

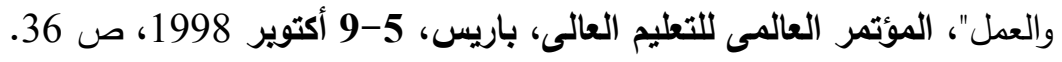
489 


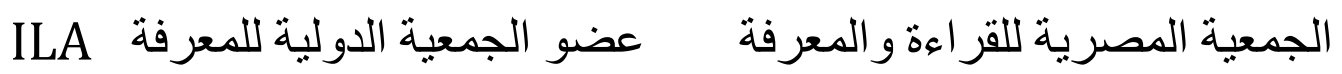

- وجود مؤسسات للبحث العلمى(33): تعد مراكز البحث من الروافد الرئيسة للنشاط

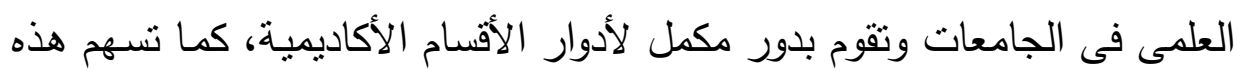

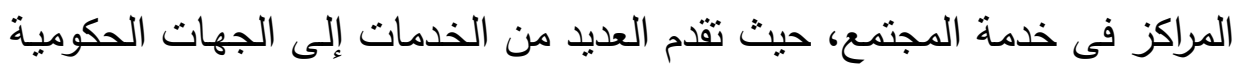

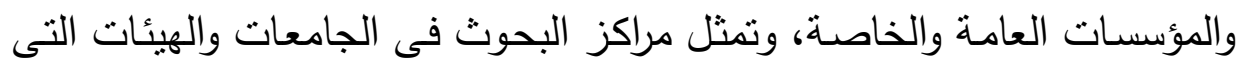
تقوم من خلال الإمكانات المتتوعة برسم برامج البحوث العلمية وتقديمها للباحثين، وتعزز العلاقة بين البحث العلمي الجامعة وقطاعات الصناعة، ونسويق خدمات الجامعة البحثية لاى هذين القطاعين بما يلبى احتباجاتهها.

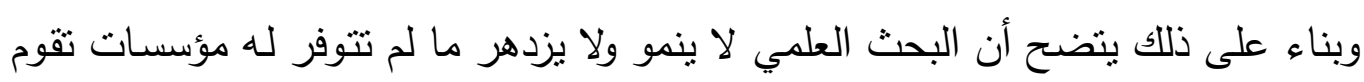

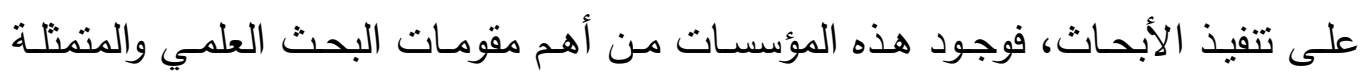

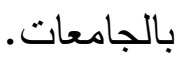

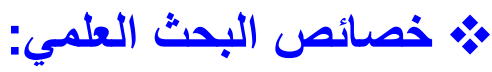

أولاً: الموضوعية: ويُقصد منها الباحثون جانبين مهمين هما : البحئ

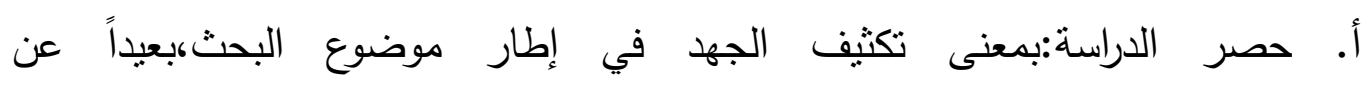
الاسنطراد،والخروج عن موضوع البحث إلى نقاط جانبية هامشية.

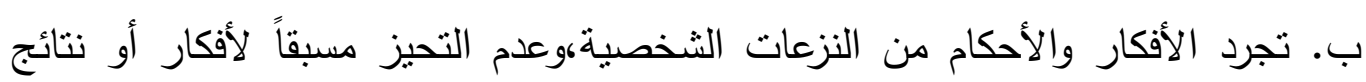

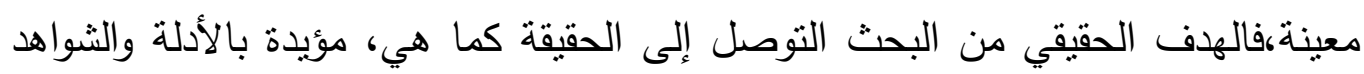

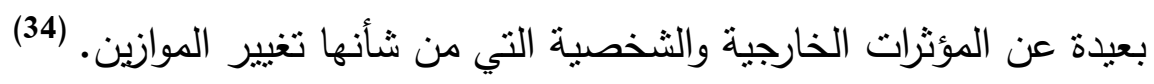

(33) رييع نجيل، عدنان الجوارين: معوقات البحث العلىى فى مراكز الدراسات والبحوث فى جامعة

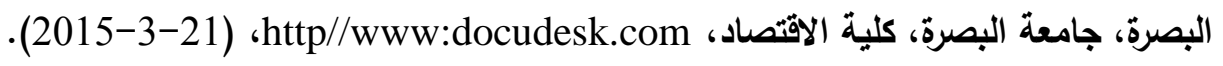
(34) أبو سليمان، عبد الوهاب إبراهيم (1996) كتابة البحث العلمي - صياغة جديدة،

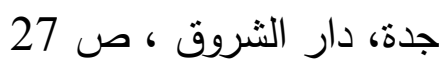


الجمعية المصرية للقراعة والمعرفة عضو الجمعية الدولية للمعرفة

وتتعدد الأسباب المؤدية إلى ضآلة حجم الإنفاق على البحث العلمي في الوطن العربي مقارنة بالواقع العالمي منها :

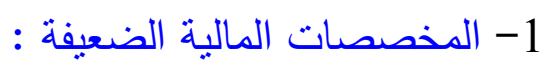

يعود قصور الجامعات في البحث العلمي إلى عدم تخصيص ميزانية مستقلة ومشجعة للبحوث العلمي ،إضافة إلى أن الحصول علي منحة بحثية بستغرق إجراءات طويلة إندات

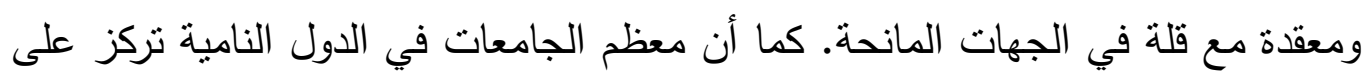

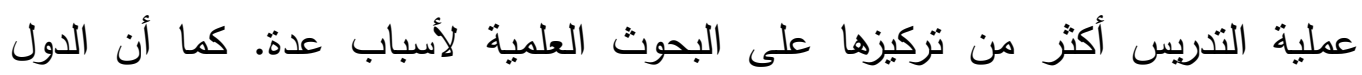

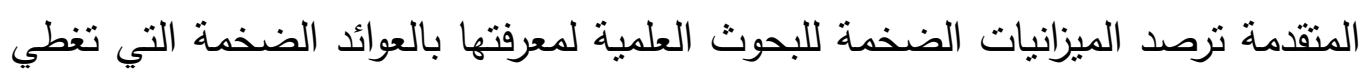

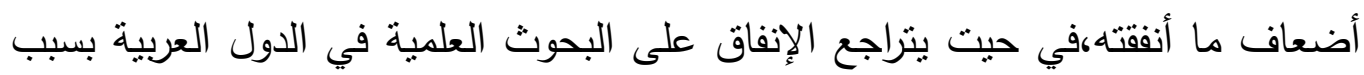

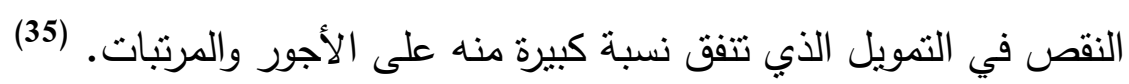
2- ضعف مساهمة القطاع الخاص: يعد القطاع الحكومي الممول الرئيس لنظم البحث العلمي في الدول العربية،حيث يبلغ

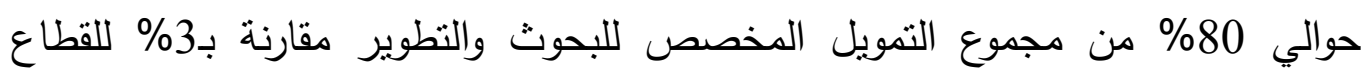
الخاص، و7\% من مصادر مختلفة. وذلك على عكس الدول المنقدمة و إسرائيل حيث

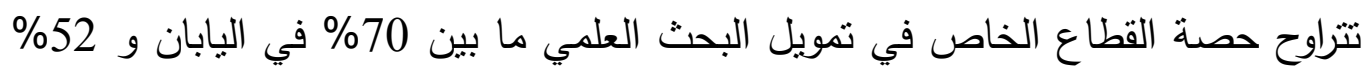

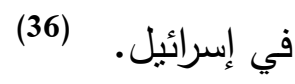
وهذا الإسهام الضعيف من قبل القطاع الخاص للمؤسسات البحثية يرجع إلى عدم تقدير

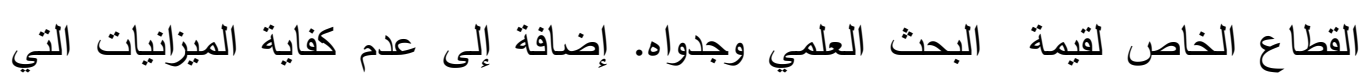

(35) ياقوت، محمد مسعد : البحوث العلمية في العالم العربي غير مجدية،الرياض ، وزارة

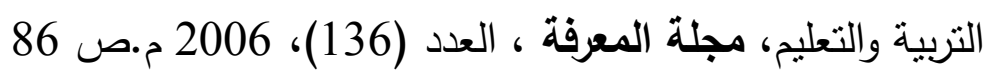

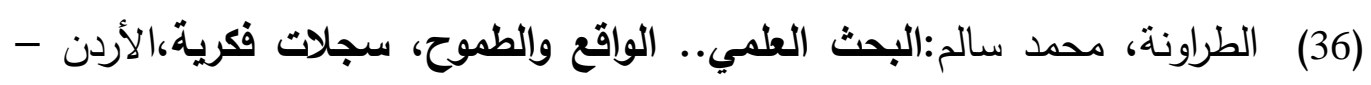

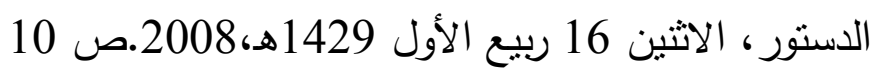
491 
الجمعية المصرية للقر اعة والمعرفة عضو الجمعية الدولية للمعرفة ال

ترصدها المراكز والجامعات ومؤسسات المجتمع للبحث العلمي، و إلى الفساد المالي والإداري الملحوظ في الجامعات ومراكز البحوث العربية.

3- عدم وجود إستراتيجية للنسويق:

من أسباب ضآلة حجم الإنفاق على البحث العلمي العبون افتقار أغلب المؤسسات العلمية

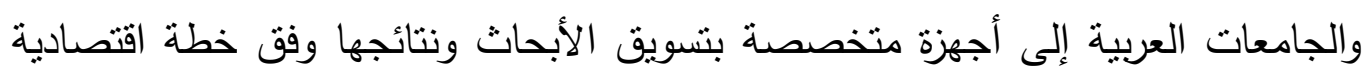

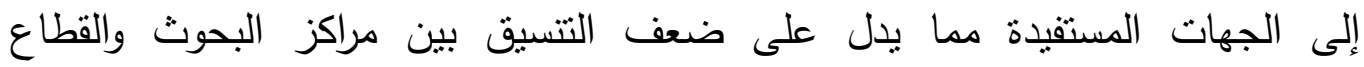
الخاص.كذلك غياب المؤسسات الاستشارية المختصة بتوظيف نتائج البحث العلمي

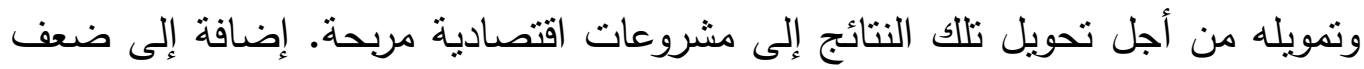
القطاعات الاقتصادية المنتجة واعتمادها على شراء المعرفة.

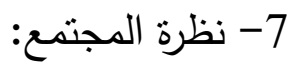

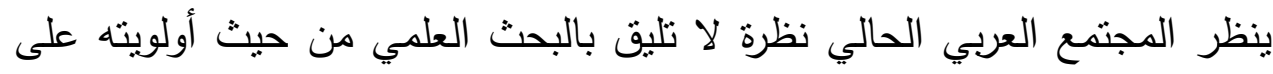
كثير من الأنشطة والمجالات،وربما يتعلق ذلك بالتشئئة الاجتماعية التي أكسبت الجماهير

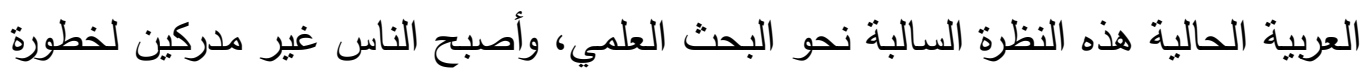
تدهور البحث العلمي العربي،وتأخره عن ركب الحضارة.

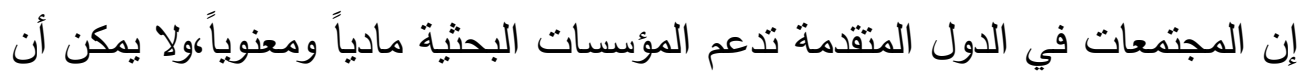
تبخل عليها بالمال أو بالإمكانات، أو حتى الدعم اللفظي،حتى إنه في كثير من الألهات الأحيان

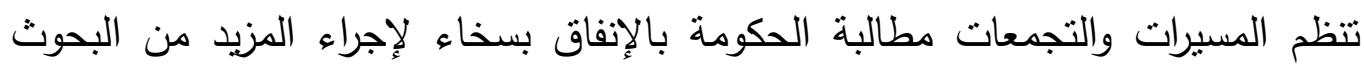

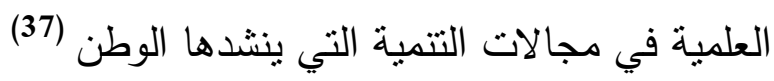
•. ملامح المعاهد والمراكز البحثية بجامعات المملكة العربية السعودية ومصادر تمويلها

(37) ياقوت، محمد مسعد: البحوث العلمية في العالم العربي غير مجدية،الرياض ، وزارة التربية والتعليم، مجلة المعرفة ، العدد (136)، 2006 م.ص الص 88 


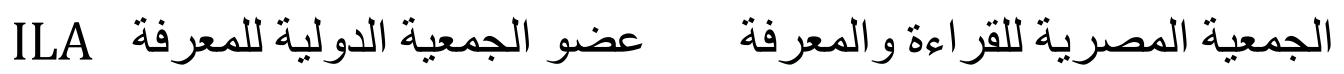

تتنوع المعاهد والمراكز البحثية بالجامعات السعودية ومنها على سبيل

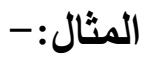

\section{المعاهد البحثية بجامعة أم القرى :}

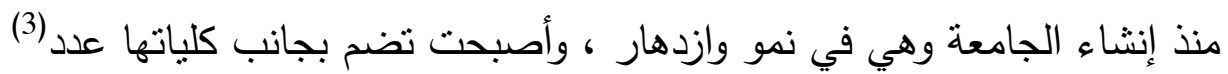

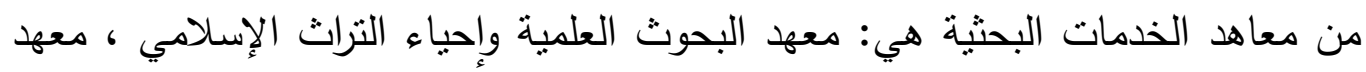

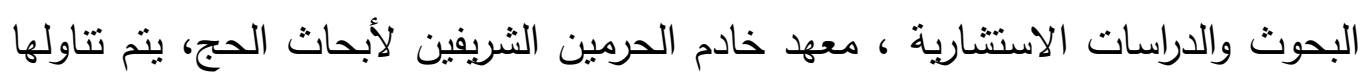

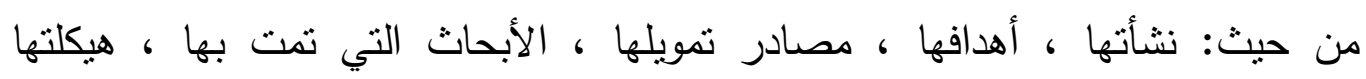

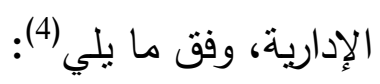

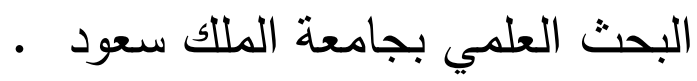
عمادة البحث العلمي :

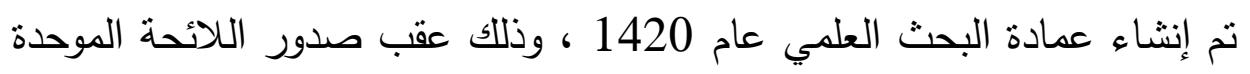

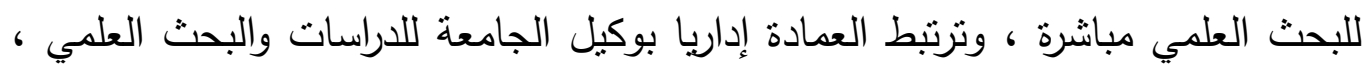
ويقتزح مجلس عمادة البحث العلمي اللوائح التفصيلية والقواعد الداخلية المنظمة لانجاز

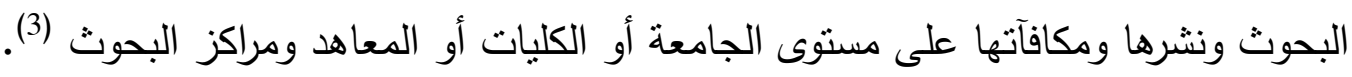
ب- معهد الأمير عبد الله للبحوث والدراسات الاستثارية.

(30-30) جامعة أم القرى: النثأة والتطور ، مكة المكرمة ، مطابع جامعة أم القرى ، 1406 ، ص ص . 30-20

(4)جامعة أم القرى : دليل معله البحوث العلمية وإحياء التراث الإسلامي ، مكة المكرمة ، 2007 ، 20 ،

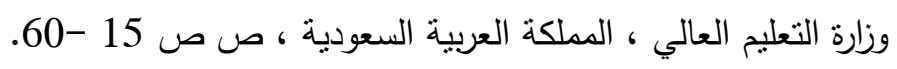

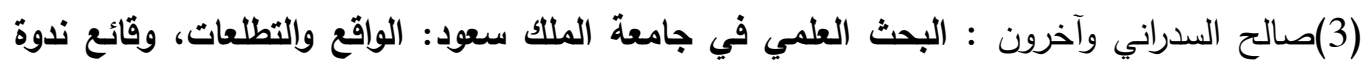

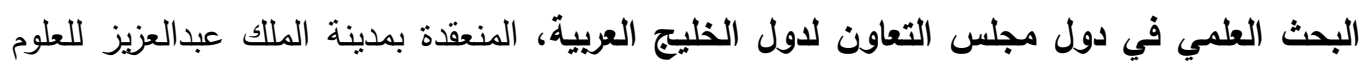

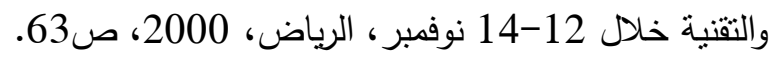
493 
الجمعية المصرية للقراعة والمعرفة عضو الجمعية الدولية للمعرفة ال

نظراً لتعدد مراكز البحوث وتوفر الإمكانات البثرية والمادية للجامعة بادرت

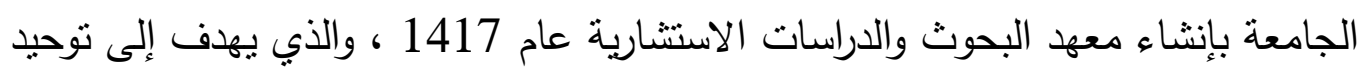

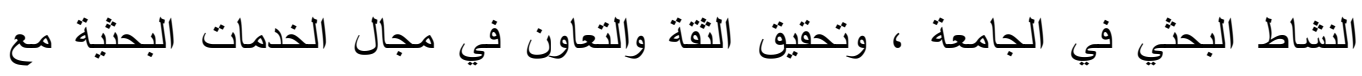
المؤسسات الحكومية والخاصة ، والعمل على إيجاد سبل وقنوات للتمويل والدعم المالي

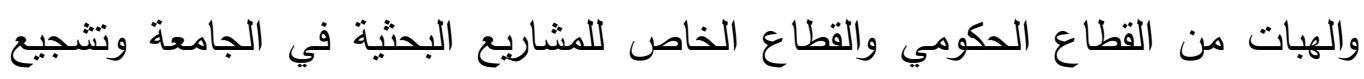
التبرعات من المؤسسات والأفراد لذلك. ونكي

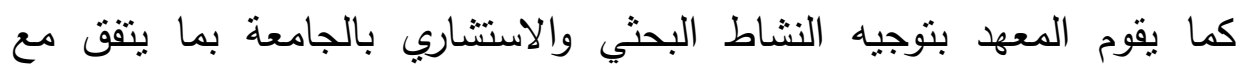
منطلبات التتمية في المجالات المختلفة ، إضافة إلى تثجيع تكوين لجان متخصصة

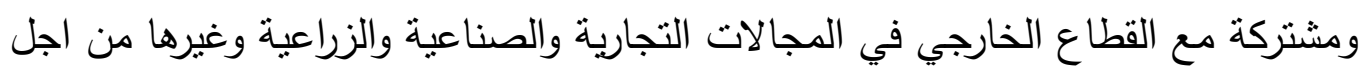
وضع التصورات العملية للعمل المشترك في مجالات البرامج الاستشارية والبحثية وإبرام

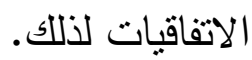

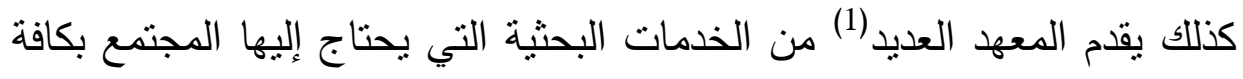

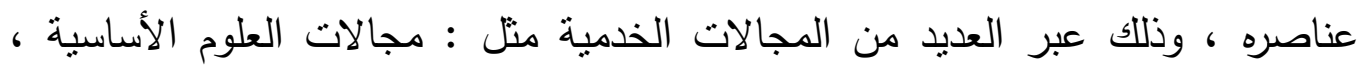

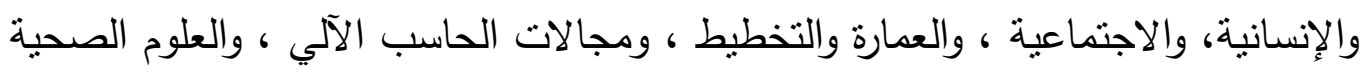

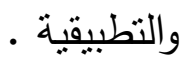

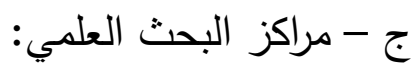
تهدف مراكز البحوث التابعة للجامعة إلى نتجيع حركة البحث العلمي وتتشيطها

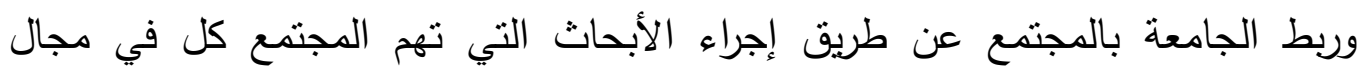
تخصصه ، ولكل مركز مجلس إدارة يضع الخطط البحثية ويعمل على تتفيذها بكفاءة .

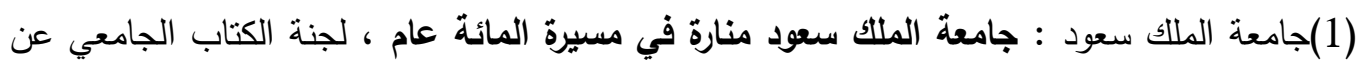
تاريخ الجامعة ، مطابع جامعة الملك سعود ، الرياض ، 1999 ، 1992 ، ص 512. 494 
ILA الجمعية المصرية للقز اءة والمعرفة عضو الجمعية الدولية للمعرففة

وقد أنشئت نلك المراكز البحثية في كلية الآداب ، والتربية ، والعلوم الإدارية ، والطب ، والعلوم التطبيقية ، والهندسة ، والعلوم ، والزراعة ، والعمارة والتخطيط ، وطب الاسنان وغيرها ، وقدمت هذه المراكز العديد من الخدمات البحثية بالتعاون مع جهات

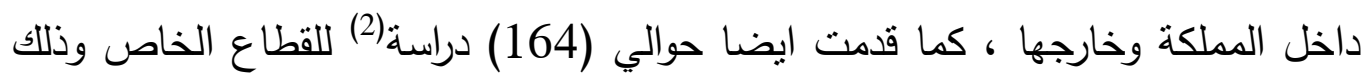
خلال ثلاثة اعوام ، من عام 1408 إلى عام 1411 ـ ويوجد في جامعة الملك سعود العديد من مراكز البحوث العلمية ومن أهمها(3): مركز البحوث بكلية العلوم، مركز البحوث بكلية الآداب، مركز البحوث بكلية التربية، مركز البحوث بكلية الصبدلة، مركز البحوث بكلية الهندسة، مركز البحوث بكلية علوم الحاسب والمعلومات، مركز البحوث بكلية الطب، مركز البحوث الزراعية بكلية الزراعة، مركز البحوث بكلية العلوم الإدارية، مركز البحوث بكلية العلوم الطبية التطبيقية، مركز البحوث بكلية طب الاسنان، مركز ابحاث الزلازل، مركز البحوث بكلية العمارة والتخطيط، مراكز البحوث في مركز الدراسات

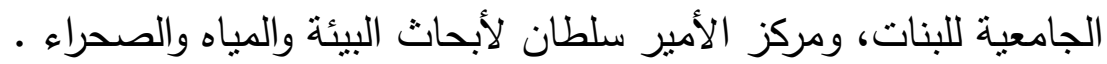
وعلى سبيل المثال في مجال تتشيط حركة الخدمات البحثية بكلية العمارة والتخطيط بالجامعة يتم الاتصال بين مركز البحوث بالكلية والجهات الراغبة فى إجراء

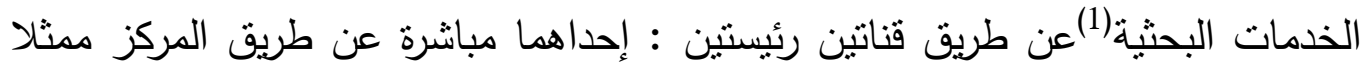
بعميد الكلية أو مدير المركز ، وذلك للاتصال مباشرة بالمؤسسات والمكاتب المستفيدة

(2)الغرفة التجارية الصناعية بالرياض ، نبذة مختصرة عن مراكز البحوث في الجامعات السعودية ،

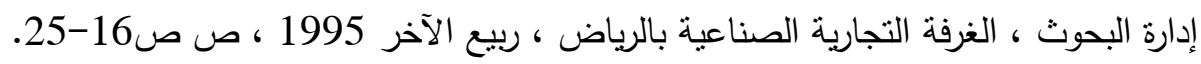

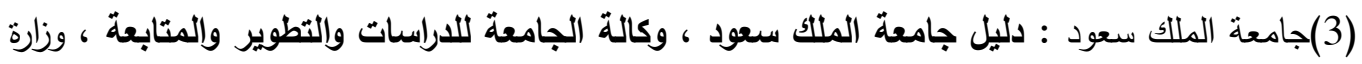

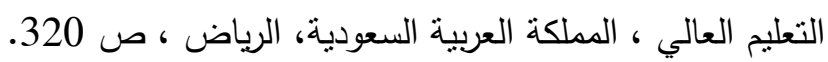

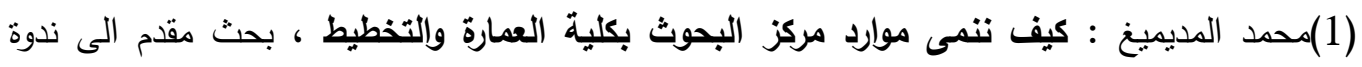

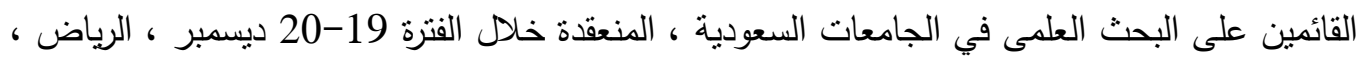

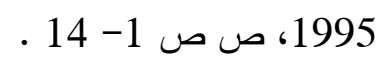


ILA الجمعية المصرية للقز اءة والمعرفة عضو الجمعية الدولية للمعرففة

للتعرف على البحوث التي يمكن أن يسهم المركز في دراستها ومدى إسهام تلك الجهات

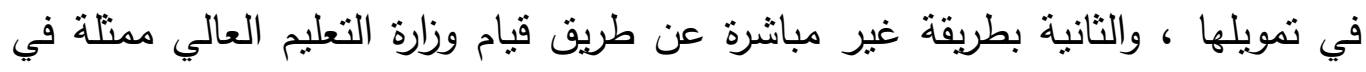
إدارة تتمية الأبحاث والترجمة بالاتصال بالوزارات والجهات الحكومية للتعرف على البحات البحوث والمشكلات التي ترغب في دراستها ، والتي بدورها تحيلها الوزارة إلى وكالة الجامعة

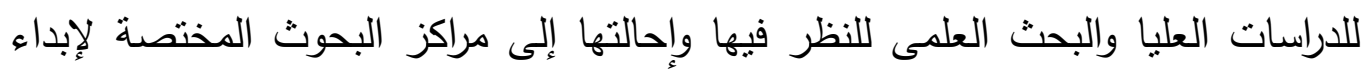

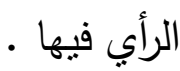

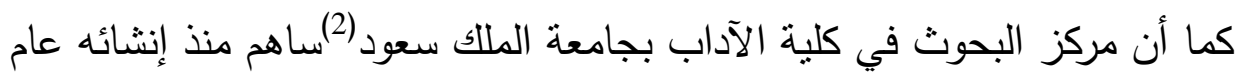

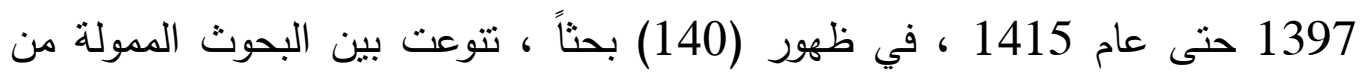

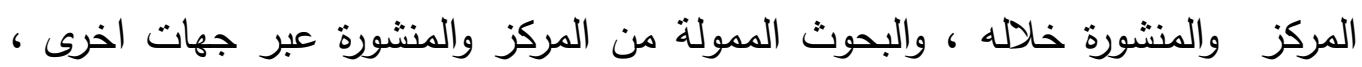
والبحوث الممولة من جهات أخرى والمنشورة فقط من المركز .

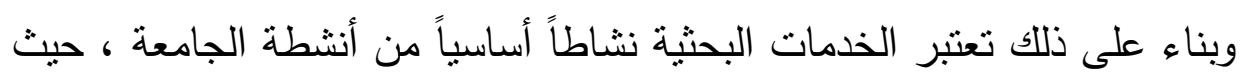

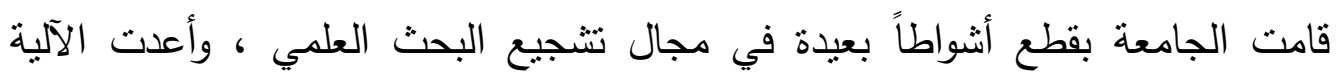

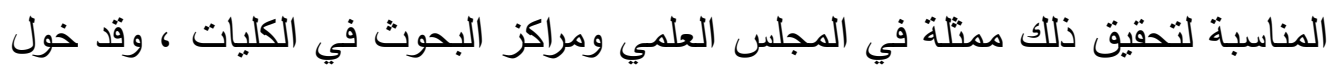

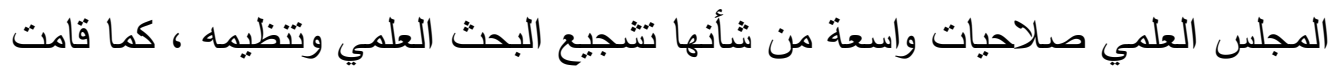

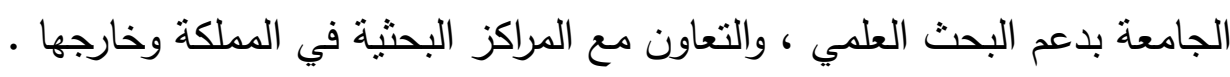

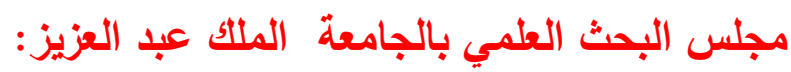

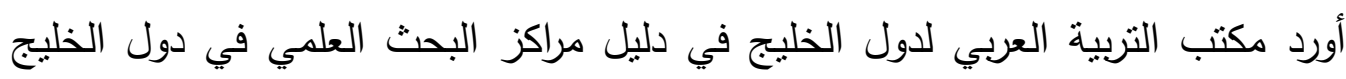

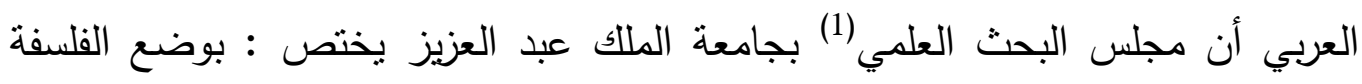

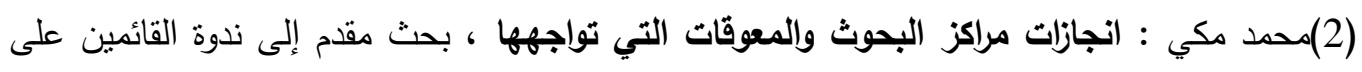

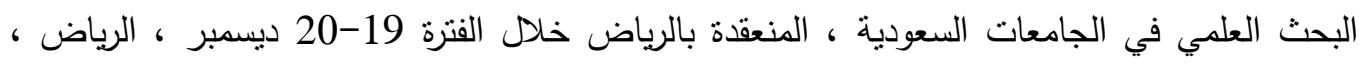

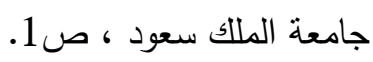

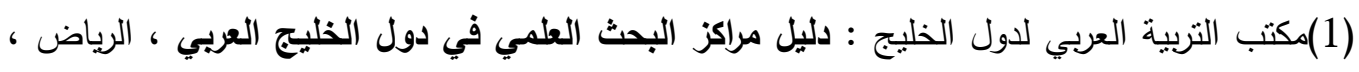
مكتب التربية العربي لدول الخليج ، 1989 ، ص 77. 496 
ILA الجمعية المصرية للقز اءة والمعرفة عضو الجمعية الدولية للمعرففة

والسياسة العامة للبحث العلمي بالجامعة ، اعتماد البرامج واتخاذ الإجراءات اللازمة لتنفيذ أهداف البحث العلمي بالجامعة ، الإشراف على تتفيذ الأهداف والسياسات المتعلقة بالأبحاث العلمية ، تحديد أولويات برامجها واعتماد مشاريعها الممولة من الجامعة ومن الإنرال خارجها ، إعداد كل ما يتطلب العرض على مجلس الجامعة من قضايا الأبحاث العلمية ، التوصية بمشروع ميزانية البحث العلمي بالجامعة ، متابعة نتائج الأبحاث العلمية داخل بنل وخارج الجامعة . مركز البحث العلمي جامعة الإمام. يتكون جهاز عمادة البحث العلمي بجامعة الإمام من عدد من الوحدات بحثية هي : وحدة بحوث القرآن والسنة ، وحدة البحوث الأدبية واللغوية ، وحدة بحوث العقبدة والمذاهب المعاصرة ، وحدة البحوث التاريخية ، وحدة البحوث الفقهية المعاصرة ، وحدة بحوث الجزيرة العربية والخليج ، وحدة بحوث الدعوة والإعلام ، وحدة البحوث الاجتماعية والإحصائية ، وحدة البحوث الاقتصادية ، وحدة البحوث التربوية والنفسية ، وحدة بحوث الدراسات الاستشرافية ، وحدة المعلومات والتوثيق والحاسب الآلي ، وحدة التأصيل الإسلامي للعلوم الاجتماعية ، وحدة البحوث الجغرافية .

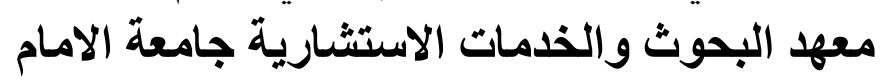

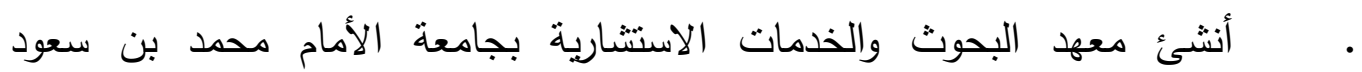
الإسلامية عام 2000 ، حيث(1) صدرت موافقة مجلس التعليم العالي على إنثائه في جلسته الثامنة عشرة من أجل تطوير البحث العلمي وتعزيز دور الجامعات في خدمة المجتمع ، وتمكينها من تسويق الخدمات البحثية والاستشارية لدى القطاعين العام والخاص

(1)جامعة الامام محمد بن سعود الاسلامية : الكتيب التعريفي للبرامج والدورات الدراسية ، وكالة

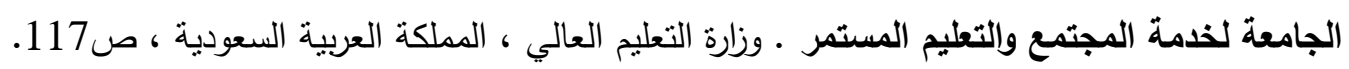
497 
الجمعية المصرية للقراعة والمعرفة عضو الجمعية الدولية للمعرفة

• مصادر البحث العلمي بالمملكة العربية السعودية .

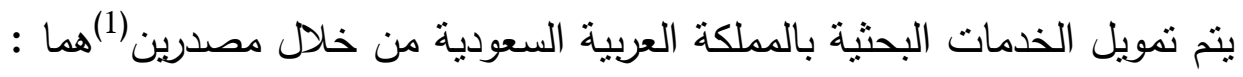

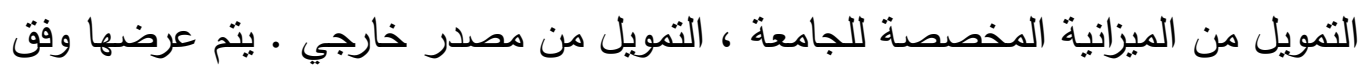
ما يلي : أ- التمويل من الميزانية المخصصة للجامعة:

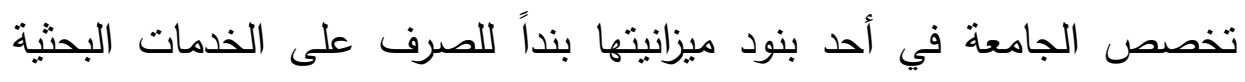

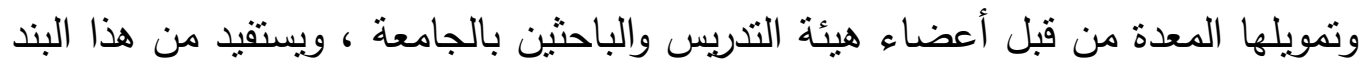

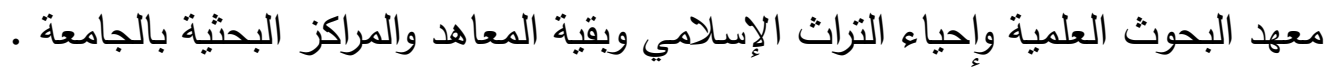

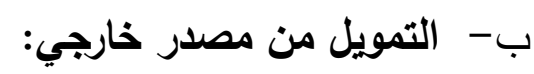
تعد مدينة الملاك عبدا لعزيز للعلوم والتقتية مؤسسة حكومية علمية لها شخصيتها:

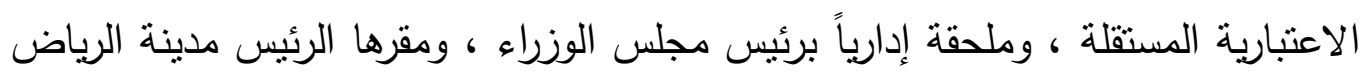

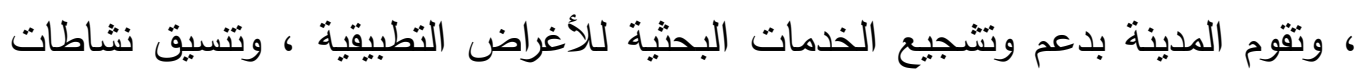

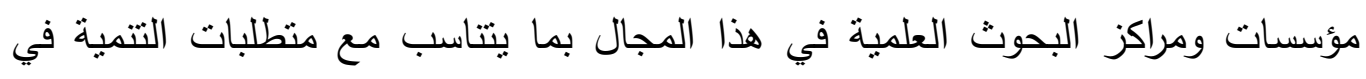
المملكة ، والعمل على تطوير الكفاءات العلمية الوطنية ، واستقطاب الكفاءات العالية

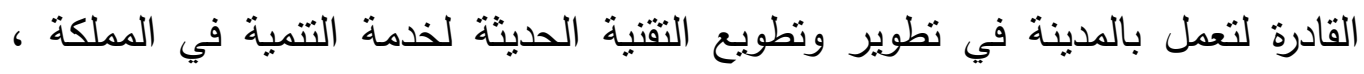

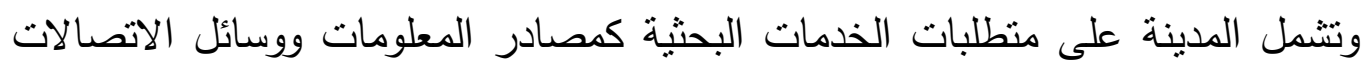

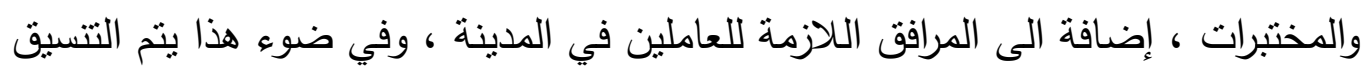

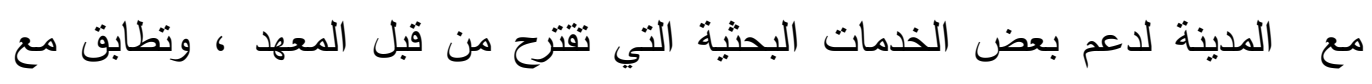

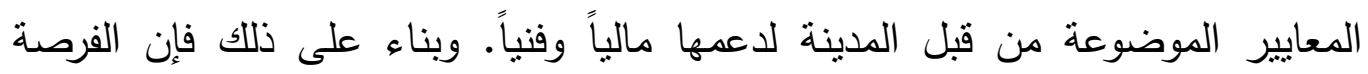

(1) جامعة أم القرى ، معهد البحوث العلمية وإحياء التراث الاسلاهي : مرجع سابق ، ص ص 75- 
الجمعية المصرية للقر اعة والمعرفة عضو الجمعية الدولية للمعرفة

سانحة لمعهد البحوث وإحياء التزاث الإسلامي لتفعيل التعاون لتحقيق أهداف المراكز البحثية بالمعهد .

يعتمد معهد البحوث والدراسات الاستشارية كمصدر رئيس في التمويل على ما يحققه المعهد من الانجازات العديدة للاستشارات العلمية وإدارة الكراسي العلمية ، حيث العادئ

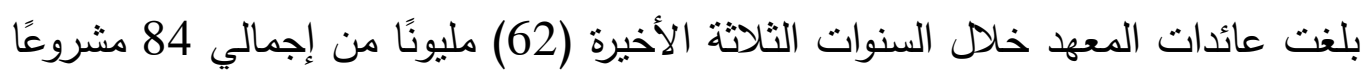

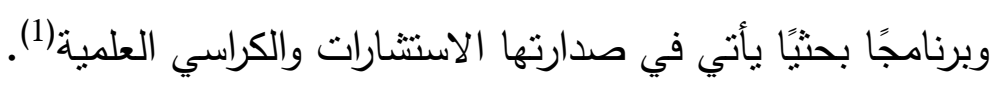

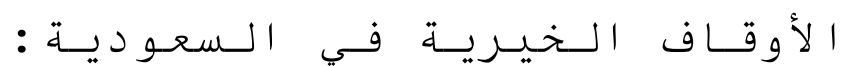

تتقسم الأوقاف فى الإخلار القانوني السعودي إلى نوعين: أوقاف خيرية خاصة، وأوقاف خيرية عامة، وتتمنل الأحكام المتعلقة بهما فيما يلى الإنى الفاني أ) الأوقاف الخيرية الخاصة: هذا النوع من الأوقاف يقوم بالنظارة عليه من يحدده الواقف، فإن لم يحدد الواقف ناظرا، تقوم الدحاكم الثرعية بنعيين ناظر للوقف.

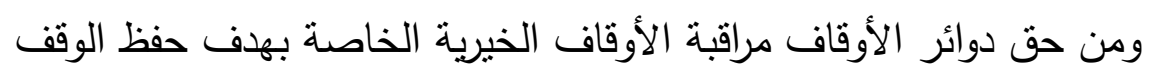

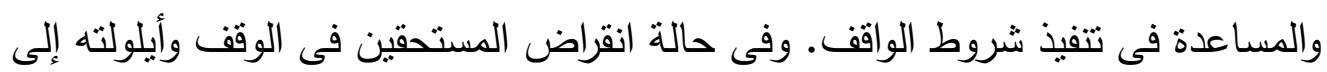

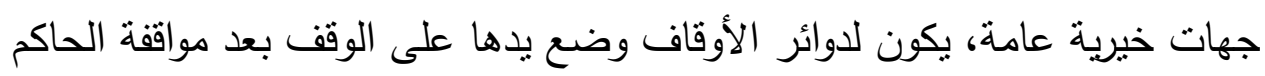
الثرعى (38)

ب) الأوقاف الخيرية العامة:

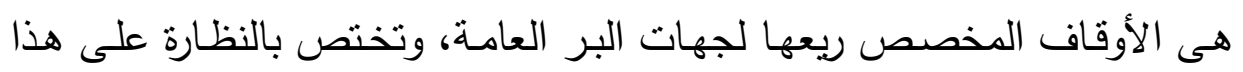
النوع من الأوقاف وزارة الثئون الإسلامية والأوقاف والدعوة والإرشاد.

(1) http://www.sauress.com/almadina/340948. 12-10-2016.

(38) الأمانـة العامـة لمجلس الأوقاف (). لائحة تنظيم الأوقاف الخيريـة. وزارة الثئون الإنسلامية

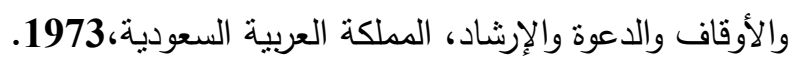


الجمعية المصرية للقراعة والمعرفة عضو الجمعية الدولية للمعرفة

وقد أنشأت الوزارة مجلسا أعلى للأوقاف يختص بالإثراف على جميع الأوقاف

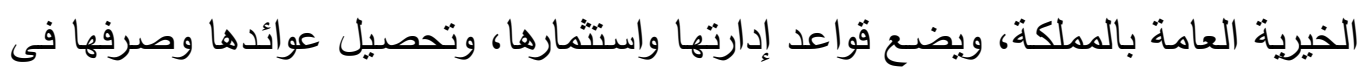

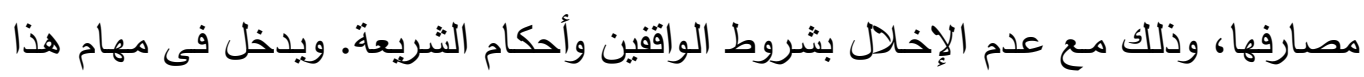

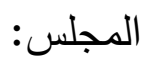

- - حصر وتسجيل الأوقاف الخيريـة العامـة داخل المملكة، وكذلك جميع الأوقاف الخيرية خارج الملكة التى تكون موقوفة على الحرمين الثريفين.

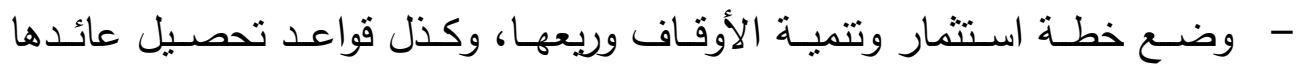
والصرف منه على جهات البر. - - وضع التقديرات المالية السنوية لإيرادات ومصروفات عوائد الأوقاف، والتصديق على حساباتها الختامية.

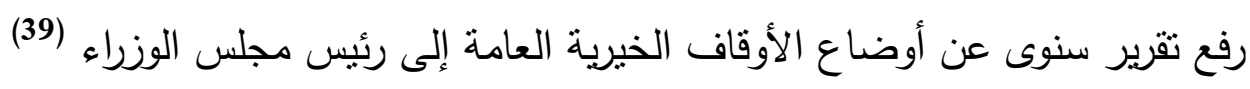

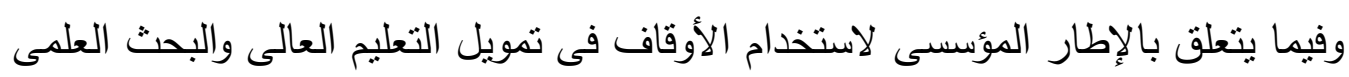

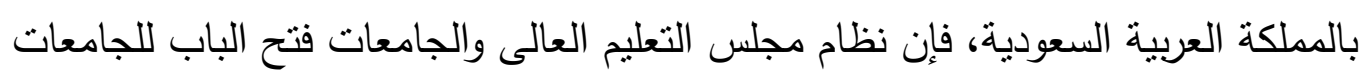

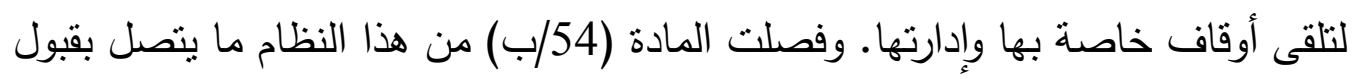

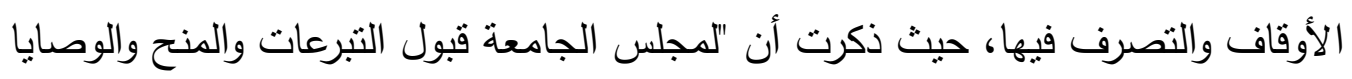

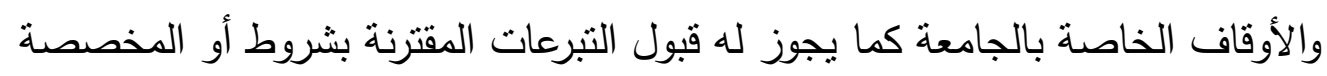

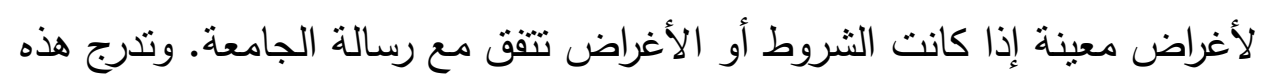

(39)(الأمانة العامة لمجلس الأوقاف(1966). نظام مجلس الأوقاف الأعلى، وزارة الشئون الإسلامية والأوقاف والدعوة والإرشاد، المملكة العربية السعودية. 
الجمعية المصرية للقراعة والمعرفة عضو الجمعية الدولية للمعرفة

التبرعات فى حساب مستقل يصرف منه للأغراض المخصصة لها وفقاً للقواعد التى يضعها مجلس التعليم العالى" (40)

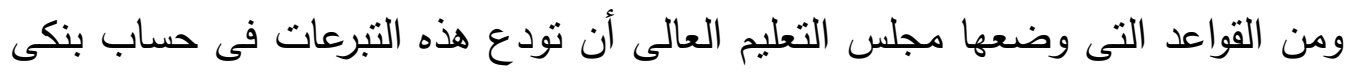
مستقل باسم الجامعة، ويتم الصرف منه بموجب مستتدات رسمية، ويراقب عليه المراقب المالى. كما يفحص المراقب المالى السجلات الخاصة بالتبرعات والمنح والوصايا

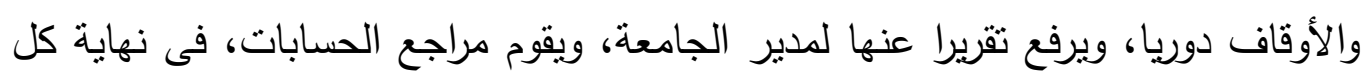

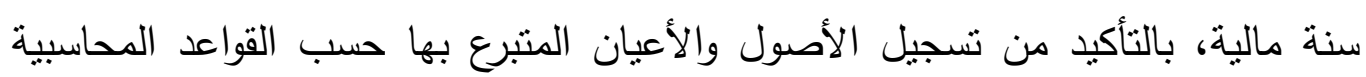

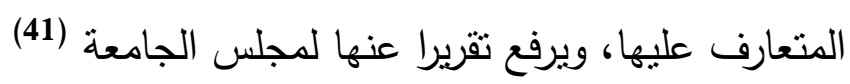

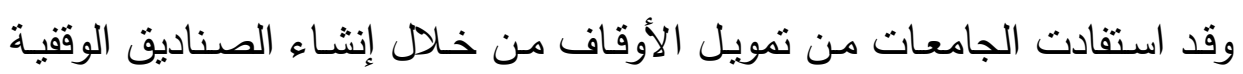

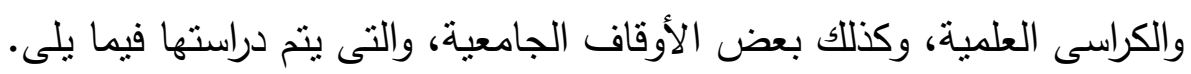
• ثانيا: الكراسى العلمية الوققية: تنتشر الكراسى العلمية (42) فى العديد من الجامعات العات بالمملكة العربية السعودية،

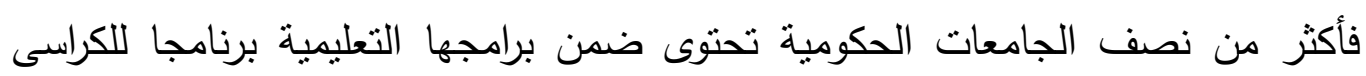

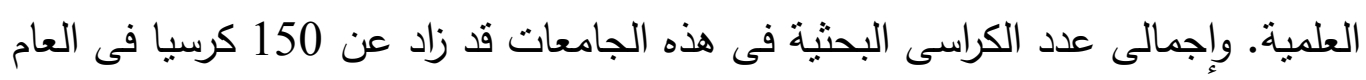

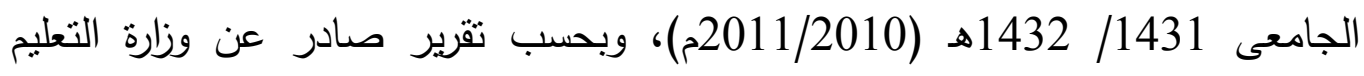
العالى السعودية(43)

(40) مجلس التعليم العالى السعودى (2007). نظام مجلس التطيم العالى والجامعات ولوائحسه. (الطبعة الثاثثة). الرياض، المملكة العربية السعودية.

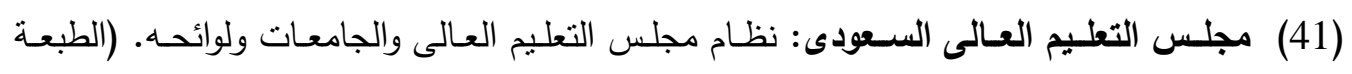
الثالثة). الرياض، المملكة العربية السعودية،2007. (42) وتسمى أحيانا بـ "الكراسى البحثية".

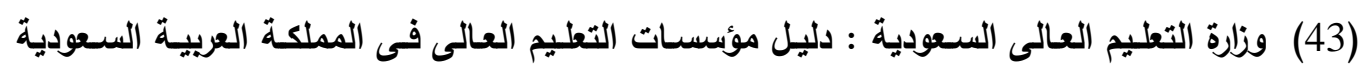
(الجامعات والكليات الحكومية والأهلية). إدارة المعلومات، الرياض، المملكة العربية السعودية،2012 
ILA الجمعية المصرية للقراعة والمعرفة عضو الجمعية الدولية للمعرفة

وتدور روية الجامعات السعودية فى إنثاء برامج الكراسى العلمية حول استكمال

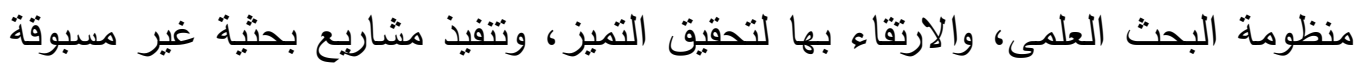

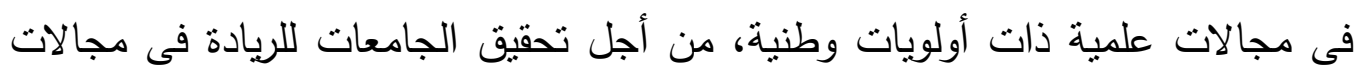

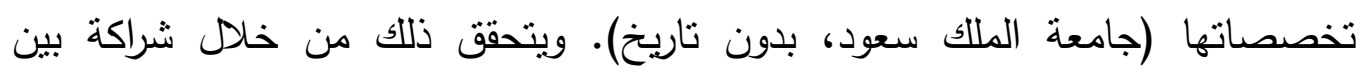
الجامعات ومختلف مؤسسات المجتمع نستهدف إثراء المعرفة النظرية والتطبيقية، وتوفير بيئة بحثية واستثارية وتدريبية ذات معايير علمية عالية (جامعة الإمام محمد بن سعود الجان الإسلامية، بدون تاريخ). أما عن مصادر إيرادات الكراسى البحثية، فقد تختلف من جامعة لأخرى، غير أنها تتلخص فى بعض المصادر الآثية، أو كلها: 1- التمويل السنوى الذى يقدمه داعمو الكراسى من المؤسسات والأفراد (44).

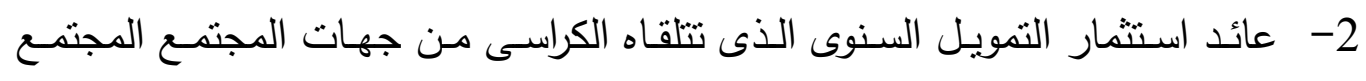

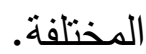

3- ما يتم رصده لتمويل الكراسي من ميزانية الجامعة، أو من أوقافها. 4- إيرادات الكراسى من الأنشطة العلمية التى تقوم بها.

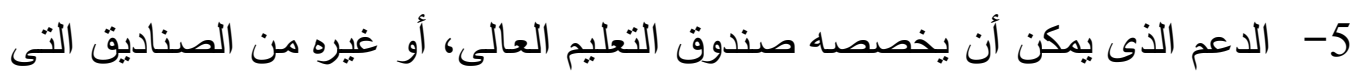
قد تنتأ لاعم كراسى البحث.

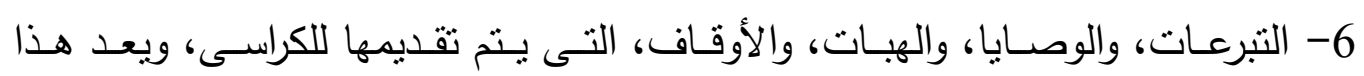
المصدر فى بعض الجامعات من أهم مصادر تمويل الكراسى العلمية (جامعة الإمام الامبان محمد بن سعود الإسلامية، بدون ناريخ).

(44) فليست كل الكراسى فى الجامعات السعودية تمول عن طريق إرصاد أوقاف لها، وإنما بعضها يمول عن طريق منح سنوية بلتزم بها المانحون. 
ILA الجمعية المصرية للقراعة والمعرفة عضو الجمعية الدولية للمعرفة

ويتحدد حجم تمويل الكراسى ومدته من قبل الجامعة، فبعض الكراسى تكون ممولة عن طريق منحة نقدية دائمة، والبعض الآخر قد تكون منحته مؤقتة ( بحد أدنى ثلاث سنوات، أو أربع سنوات، بحسب نظام الجامعة). ويختلف الحد الأدنى لتمويل الكرسى لفى دئه

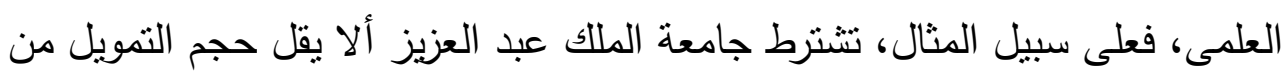

خمسمائة ألف ريال سنويا (45) فئل

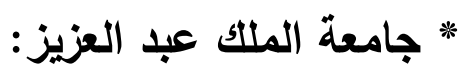

بحسب آخر تحديث للبوابة الإلكترونية للجامعة (فى أبريل 2014)، فإن الجامعة بها 21 كرسيا قائما حاليا، بالإضافة إلى كرسى علمى دولى بالتعاون مع جامعة باريس1 1

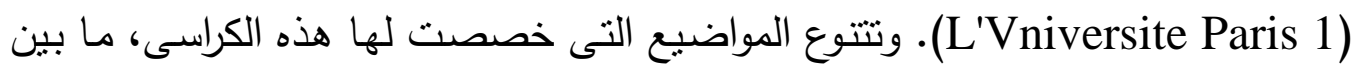

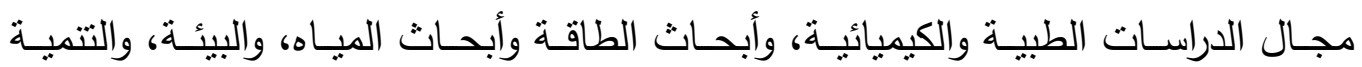
المستدامة. كما تشمل أيضا الدراسات الاقتصادية، والدراسات الصحفية، وأبحاث الثباب وله والقيم الأخلاقية، بالإضافة إلى الدراسة الدينية. وأحد نماذج النجاح التى تحتقى بها الجامعة: " كرسى سابك للحفازات الكيميائية". فقد نجح هذا الكرسى خلال الستة عشر شهرا الأولى من زمنه فى نشر 37 بحثا فى مجلات عالمية ومؤتمرات دولية، بالإضافة إلى تسجيل براءتى اختراع فى أوروبا. وساهم فريق الكرسى بستة مقترحات علمية داخل وخارج الجامعة، بالإضافة إلى ستة اسنتارات

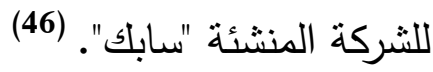

(45) جامعة الملك عبد العزيز .(بدون تاريخ). الكراسى العلمية. معهد البحوث والاستثـارات. متاح

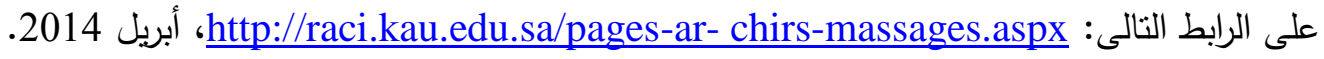

(46)جامعة الملك عبد العزيز (بدون تاريخ). الكراسى العلمية. معهد البحوث والاستشارات. متاح على

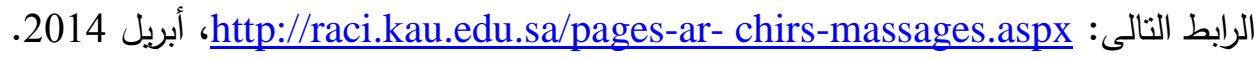


ILA الجمعية المصرية للقراعة والمعرفة عضو الجمعية الدولية للمعرفة

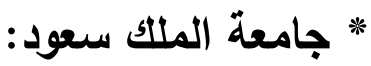

أطلقت الجامعة برنامج "كراسى البحث" عام 1428هـ - 2007م. ويذكر موقع فئان

الجامعة احتضانها لـ 111 كرسى بحثى فى مختلف المجالات. فهناك 42 كرسيا للأبحاث

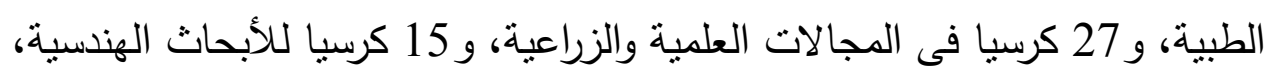

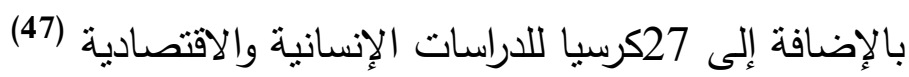

\section{" جامعة الإمام محمد بن سعود الإسلامية:}

بالجامعة عشرون كرسيا تغطى عددا من الموضوعات فى الدراسات الدينية،

والاقتصادية، والإعلامية، والاجتماعية، والقانونية، والطبية.

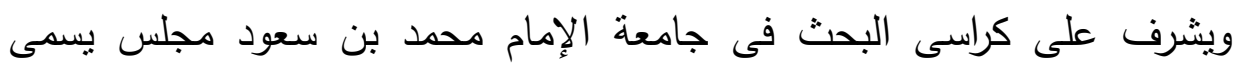

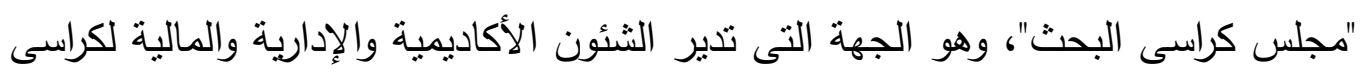

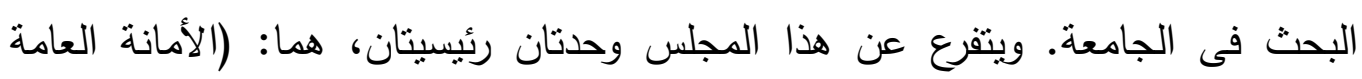
لمجلس كراسى البحث)، و(صندوق كراسى البحث) وهو صندوق مستقل ماليا وإداريا،

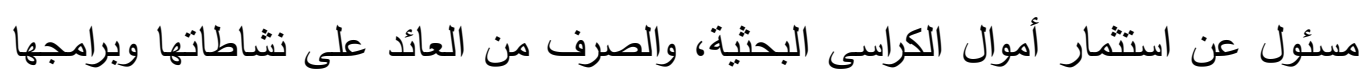

\section{* الجامعة الإسلامية بالمدينة المنورة:}

بها أثىى عشر كرسيا للاراسات الدينية، واللغوية، والتاريخية، والأسرية (49) الإندوة:

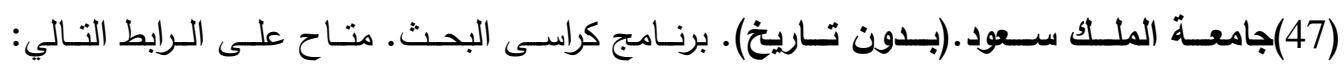

. 2014 .http://chairs.kus.edu.sa/

(48) جامعة الإمام محمد بن سعود الإسلامية.(بدون تاريخ). برنامج كراسى البحث. متاح على مائ http://www.imamu.edu.sa/RESEARCH

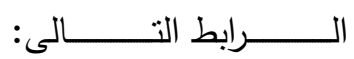

CHAIRS/Pages/default.aspx

(49) الجامعة الإسلامية بالمدينة المنورة: http:/www.iu.edu.sa، أبريل 2013. 
الجمعية المصرية للقراعة والمعرفة عضو الجمعية الدولية للمعرفة

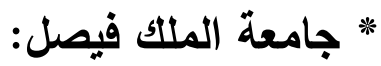

يذكر الموقع الإلكترونى للجامعة وجود أربعة كراس علمية قائمة بالجامعة، وكرسيا

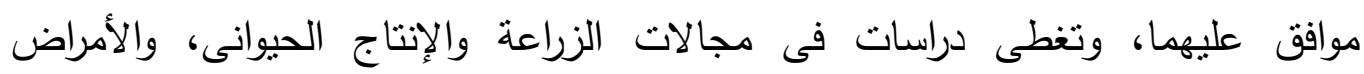

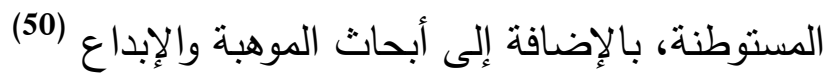

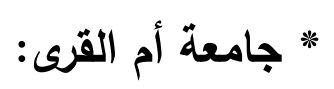
لديها ثمانية كراسى علمية، فى مجالات الدراسات الدينية، والتاريخية، والإنسانية، والطبية

\section{* جامعة الأمير محمد بن فهد:}

لديها خمسة كراسى وقفية، لدراسات الطاقة، والبيئة، والثباب، والتكنولوجيا، وإدارة المعلومات

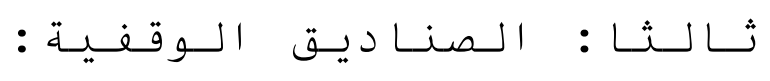

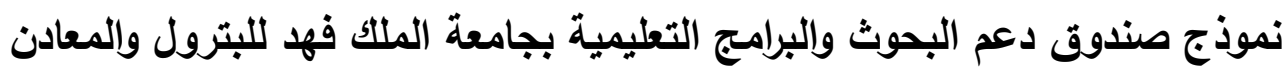

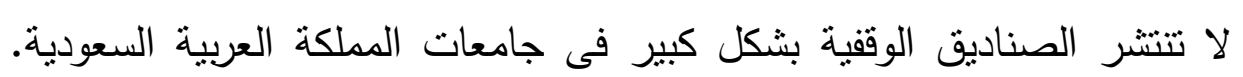

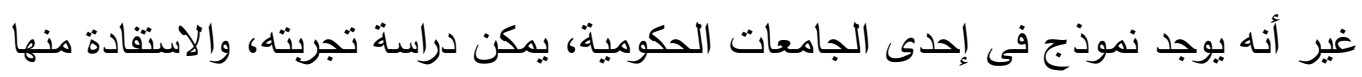

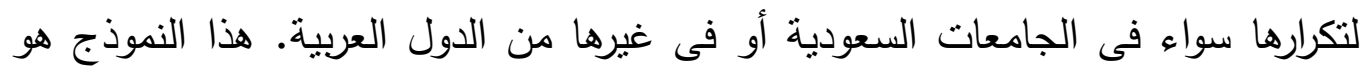

(50)جامعة الملك فيصل. (بدون تاريخ). الكراسى العلمية القائمة بالجامعة. مثاح على الرابط الثالى: http://www.kfu.edu.sa/ar/departments/knowledge ،22-10-2016 Exchange/pages/chairshtescientific1.aspx

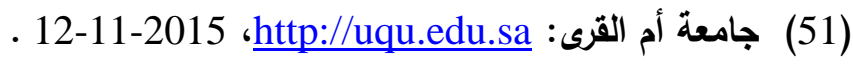
(52) جامعة الأمير محمد بن فها:http://www.pmu.edu.sa أبريل 2013. 


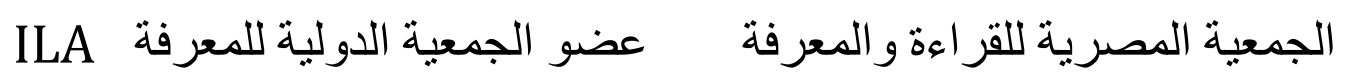

صندوق دعم البحوث والبرامج التعليمية بجامعة الملك فهز للبترول والمعادن "وقف

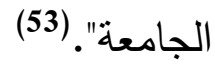

- تمويل الجامعة والكلية الأهلية: حددت لائحة الكليات الأهلية إيرادات الكلية لتتكون من الرسوم الدراسية، وإيرادات

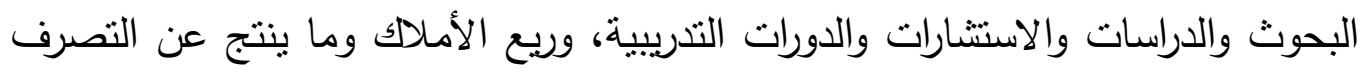

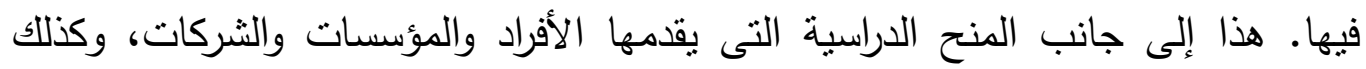

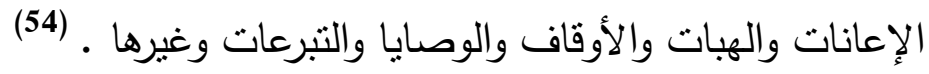

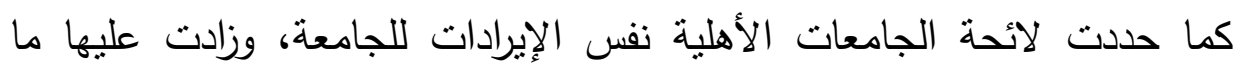

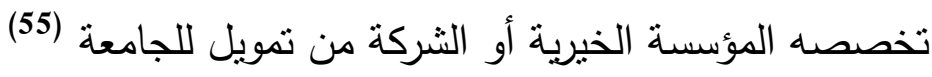

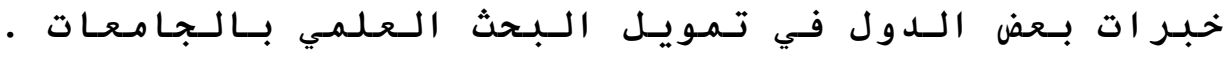
تركيا من أهم دول المركز في العالم الإسلامي نظراً لموقعها المتميز وما تمر به به بـاه

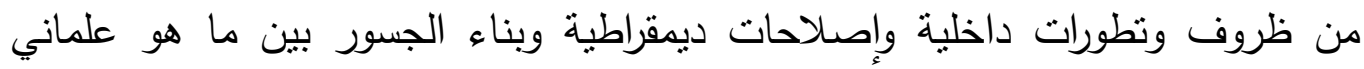
وإسلامي وأثر ذللك على عملية إصلاح التعليم في تركيا لتستقيد من هذه التجربة دولاًا أخرى (56).

إستراتيجية الحكومة نحو الإصلاح في مجال التمويل الجامعي:

(53) كوثر، عصام بن حسن ويعد الله بن محمد العمرانى (2011). دور الوقف فى دعم التعليم

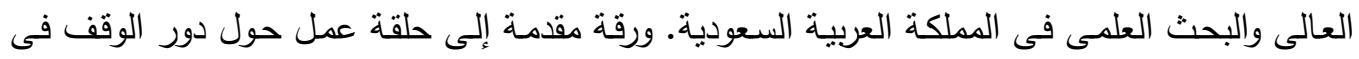

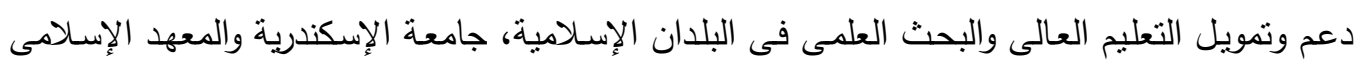
اللبحوث والنتريب، الإنكندرية.

(54)ونارة التعليم العالى السعودية (2000). لائحة الكليات الأهلية. (55) وزارة التعليم العالى السعودية (2003). لأيحة الجامعات الأهلية. (1) نبيل السمالوطي: الجامعات ونهضة الأمة- تجربة التعليم الجامعي في تركيا- نموذجاً. 506 
ILA الجمعية المصرية للقر اعة والمعرفة عضو الجمعية الدولية للمعرفة

\section{السمات المميزة للتعليم الجامعي في تركيا(57):}

يصل عدد الجامعات في تركيا إلى 132 جامعة، وهناك خطة طموحة لأن يصل عدادها إلى 500 جامعة عام 2020 وتم استفتاء الثعب للوقوف على لـألى رأيه في دعم وتزايد

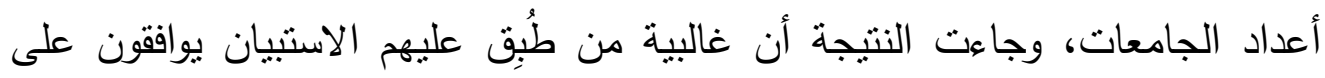

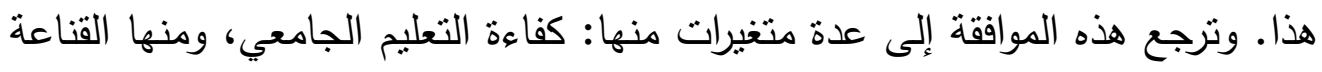

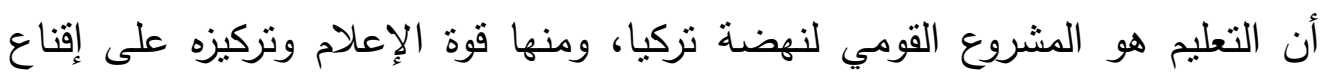

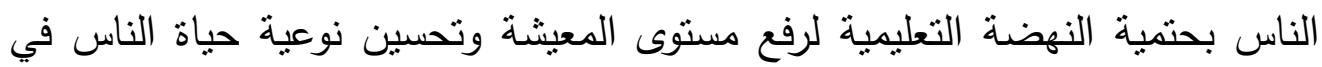
تركيا.

- ي أوروبا والولايات المتحدة يتم من خلالها تبادل مشترك للطلاب المنفوقين لمدة عام

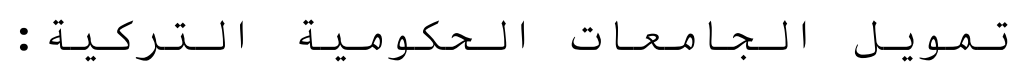

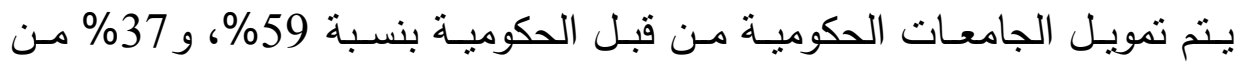

صندوق المال المتحول و4\% من رسوم الطلاب والمصدر الأساسي للمال المتحول هو إيرادات الجامعة من العقود والاسنتشارات، والبحوث العلمية، والخدمات الصحية والمشاريع

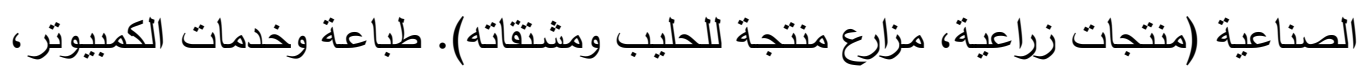
تضاف الأموال التي يتم صرفها إلى السنة المالية التالية لتغذية صندوق المال المتحول.

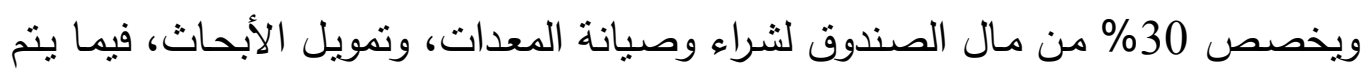

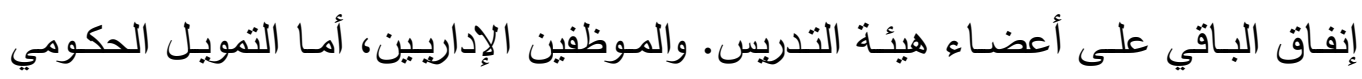

( ) نبيل السمالوطي: الجامعات ونهضة الأمة. تجربة التعليم الجامعي في تركيا، نموذجا: http://islamirabta.com/index.php?pageshow=shawarticle\&ids9615/7/2011. 


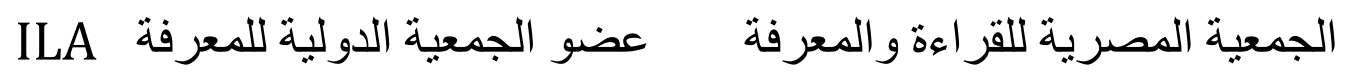

59\% فيتم إنفاقه على البنية التحنية وتغطية المصاريف الجارية للجامعة وقد بلغت نسبته \% 3.7 من الناتج المحلي (58). علماً بأن الوقف الخيري الممول للجامعات غالباً ما يكون غير الوقف الذي أنشئت من خلاله الجامعة.

معايير التمويل الحكومي للجامعات الأهلية: - عدد الأبحاث العلمية التي قامت بها الجامعة نسبة اللى أعضية: العضاء هيئة التدريس. - عدد المدرسين بالنسبة لعدد الطلاب. - مدى استخدام اللغات الأجنبية في التدريس بالجامعات الأهلية. - عدد المنح التي استفاد منها الطلاب. - القيام بأنشطة نقافية. - الإنفاق على الكتب والمجلات العلمية.

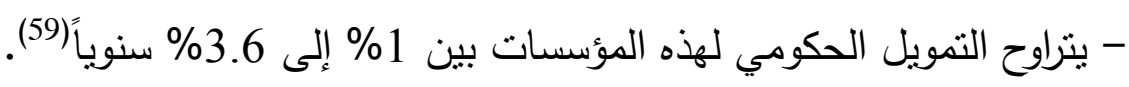

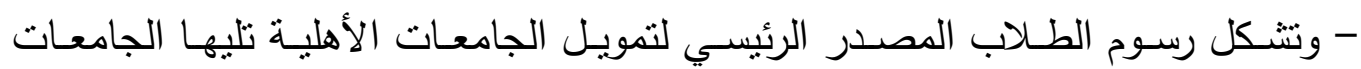
الوقفية(60).

وهناك مثال لتوزيع مصادر التمويل ينطبق على "جامعة بيلكنت" عام 2007 فقد

بلغت إيرادات هذه الجامعة في عام 2007 حوالي 202 مليون دولار أمريكي، 47\% منهم من الرسوم الطلابيـة، 18\% من البحوث والمساعدات الحكومية 4.5\% من تأجير سكن الطلاب ومن التبرعات والهبات الصغيرة، و30\% من أموال وقف الجامعة. أما عن نفقات

$\left({ }^{58}\right)$ Council of Higher Education Report on Foundation universities. 2007, p. 101.

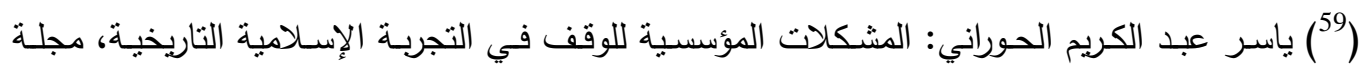

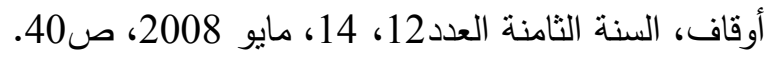

$\left({ }^{60}\right)$ Mukesh Chawla, How much does Turkey Spend on Education? 2005, World Bank. 


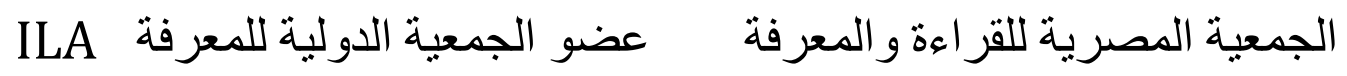

الجامعة فالجامعة أنفقت 25\% من مجموع مصاريفها على المنح الدراسية في عام 2007

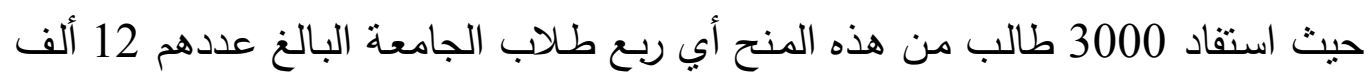

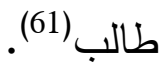

الإدارة المالية وتمويل الجامعات (62) :

وتحدد مصادر دخل مجالس التعليم العالي والوحدات المرتبطة بها من :

1- مخصصات الميزانية السنوية للاولة والموجهة للتعليم العالي.

2- المساعدات من المؤسسات الخاصة والحكومية.

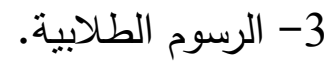

4- إيرادات المبيعات وتسويق الخدمات التعليمية.

5- الدخل من الممتلكات المنقولة وغير المنقولة (الوقف).

6- - - - الهبات والوصايا.

7- الأرباح الناتجة من صندوق الثركايات النشات التعليمية.

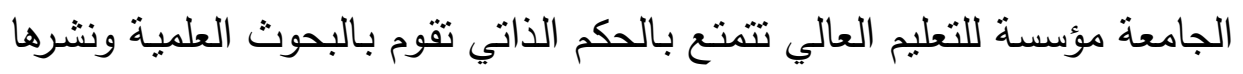

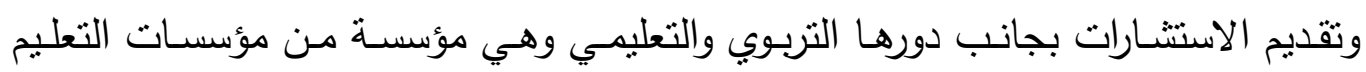

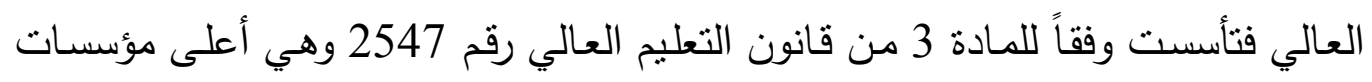

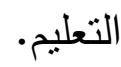

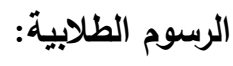

$\left({ }^{61}\right)$ Ali Doĝramaci (2008): Private university initiatives in Turkey: The Bilkent Experience International conference in Higher Education. Technion, Turkey, p.

(22) منى محمد أبو الفتوح: نظام إعداد معلم المرحلة الأولى في مصر وتركيا وإنجلترا، كلية البنات-

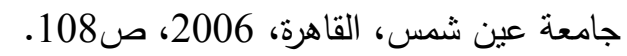


ILA الجمعية المصرية للقز اءة والمعرفة عضو الجمعية الدولية للمعرففة

الرسوم التي يتم دفعها سنوياً ثابتة مع الأخذ في الاعتبار طبيعة ومدة الدراسة في

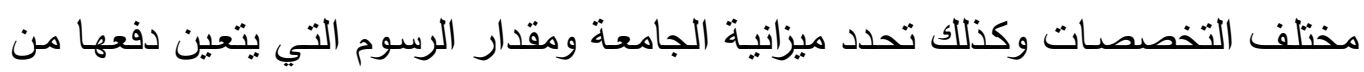
قِبل الدولة ويحدد ذلك من خـال المجلس الأعلى للجامعات. وقد حدد مجلس الوزراء الميزانية ونصيب كل طالب فيها على حدة والجزء المتبقي من الرسوم يدفعها الطلاب

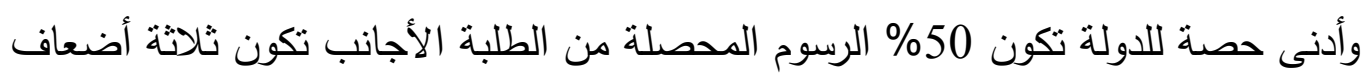

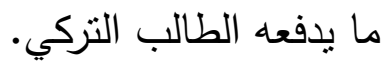
ويختلف مقدار هذه الرسوم من جامعة إلى أخرى وبين كلية وأخرى حتى الجامعة نفسها

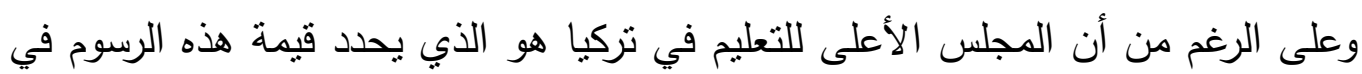

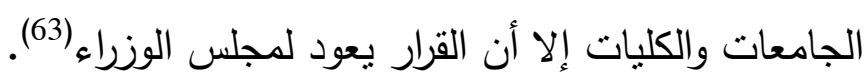

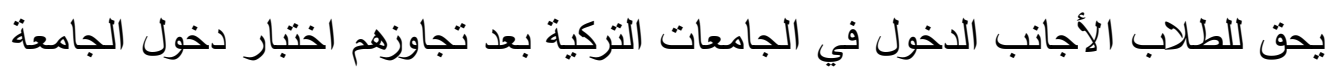
التي تجريه مراكز الامتحانات (OSYM) ويكون الاختبار باللغة الإنجليزية والتركية لذللك لكي يدخل الطالب الأجنبي هذا الاختبار ليس بالثرط أن يتكلم بالتركية.

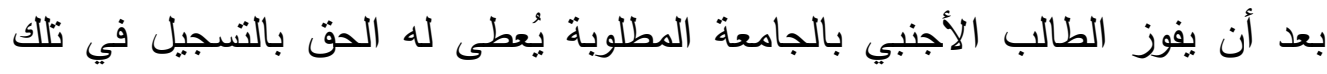

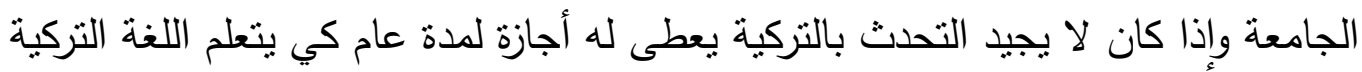

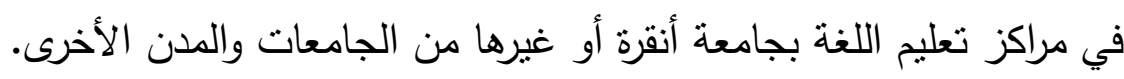

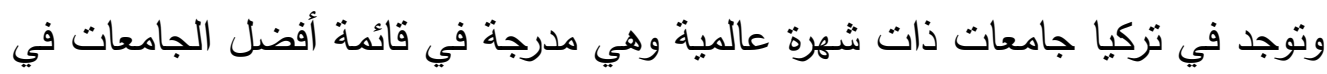

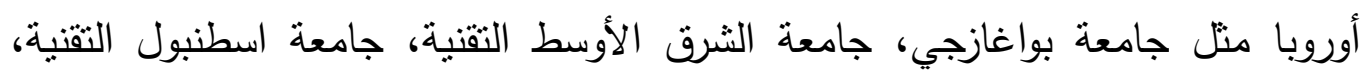

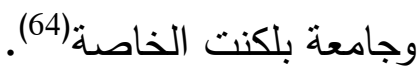
الـوقف كمصدر من مصادر الـتمويـل الــذاتـي لـلجهامعـات الـتـركيـة: (1) يحيى أكيوز : تاريخ التعليم التزكي من البداية حتى النهاية، "ألفا" للطباعة والنشر ، اسطنبول، 2001، ص50. (2) أحمد أبو زيد: نظام الوقف الإسلامي: تطوير العمل وتحليل نتائج بعض الدراسات الحديثة، المنظمة

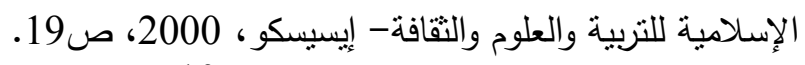


الجمعية المصرية للقراعة والمعرفة عضو الجمعية الدولية للمعرفة ILA

\section{الوقف كمصدر لتمويل الجامعات التركية}

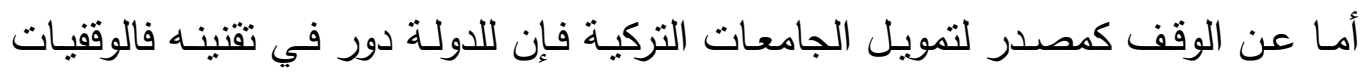

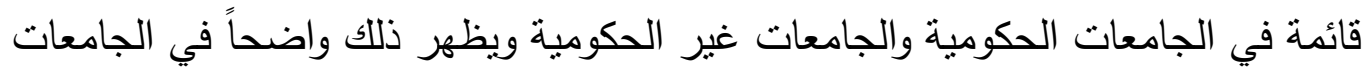
التركية حيث يقتصر على الجامعات غير الحكومية كبديل عن الجامعات الربحية، وهي

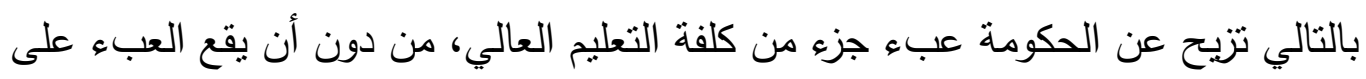

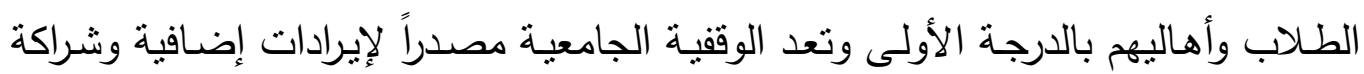
اجتماعية في توفير هذه الإيرادات وتحمل جزء من شئون إدارة التعليم الجامعي والتمويل

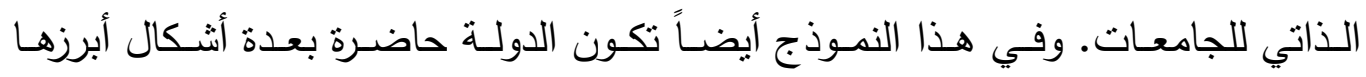
المشاركة الجزئية المشروطة في تمويل الجامعات غير الحكومية وهو دور تحفيزي( (65). ويمكن الاستفادة من التجربة التركية في تمويل الجامعات عن طريق الوقف في في التئ

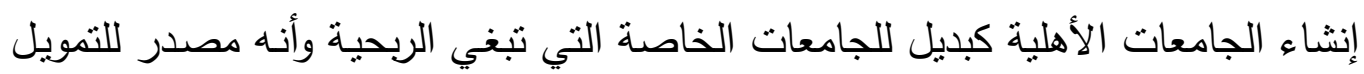

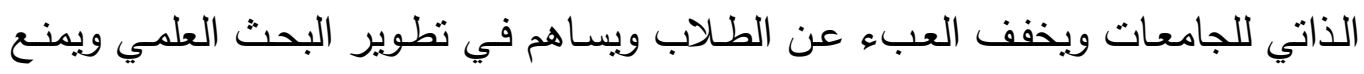

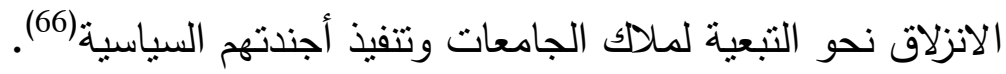

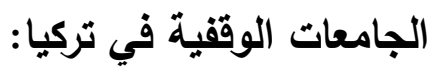

يوظف الوقف في هذه الجامعات كمصدر تمويل قوي وثابت يضمن ديمومة

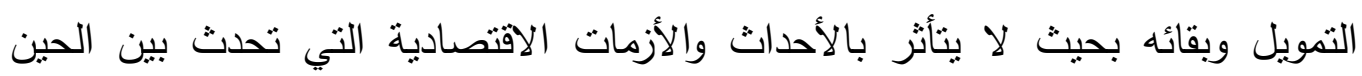
والآخر تمويل نظيف يرتبط بالعقيدة الإسلامية ويرتكز على سمو الهذف، والغاية، تمويل يقوم على فكرة الأوقاف الإسلادية.

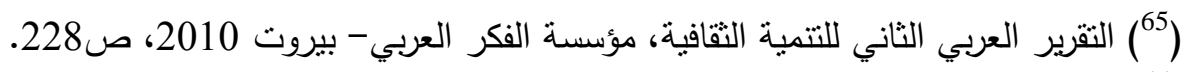
(66) النقرير العربي الثاني للتنمية الثنافية، مؤسسة الفكر العربي- بيروت، ص235. 
الجمعية المصرية للقر اعة والمعرفة عضو الجمعية الدولية للمعرفة

وهذا ما حدث في التجربة التعليمية التركية من خلال الأوقاف والتي أسهمت في

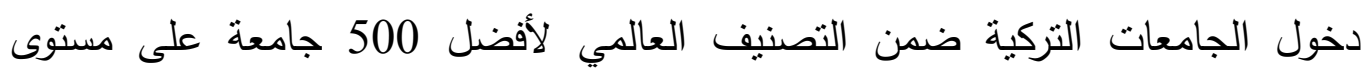

$$
\text { 2- أعدافهها: }
$$

تتمنل أهداف الجامعات الوقفية وفقاً لرابطة الجامعات الوقفية بتركيا، فيما يلي:

- التعليم باللغات الأجنبية الحية.

- إقامـة روابط بين الجامعات والمؤسسـات البحثية العالميـة لتحقيق الاستفادات العلميـة

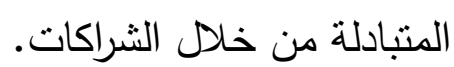

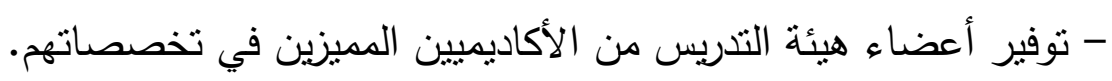
- عمل شراكات علمية للحصول على الثهادات المزدوجة.

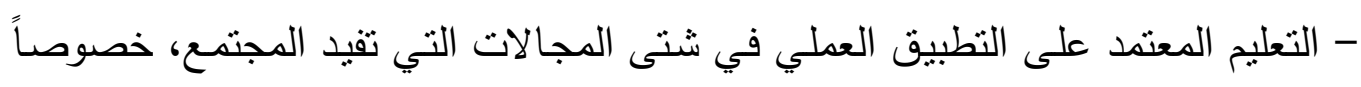
المجالات التكنولوجية الحساسة. - إمكانات لإيجاد فرص عمل بعد النخرج. - الزيادة المستمرة في الجودة. - العمل على إعادة الأكاديميين الأتراك من بلاد المهجر، بزيادة المزايا التي تقدمها لهم.

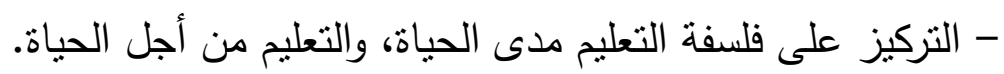
- تكوين أجيال قادرة على خدمة المجتمع، ويتميزون بالحساسية في المسئولية الاجتماعية. 3- تمويلها:

للجامعات الوقفية ثلاثة مصادر أساسية للتمويل، وهي:

$$
\text { - }- \text { - الوقف المؤسس للجامعة. }
$$




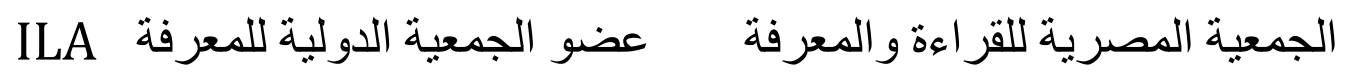

$$
\text { التعليم الجامعي في ماليزيا: }
$$

يوجد نوعين رئيسيين من مؤسسات التعليم العالي في ماليزيا هما مؤسسات التعليم العالي العام

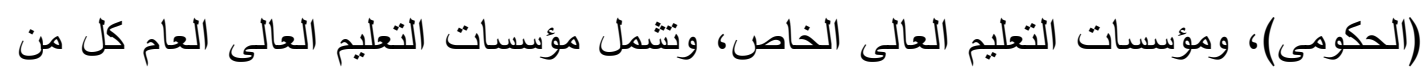
الجامعات وكليات المجتمع والمعاهد الفنية ومؤسسات تدريب المعلمين ${ }^{68}$ ،بينما تتكون مؤسسات التعليم العالى الخاص من الجامعات والكليات الجامعية وفروع الجامعات والكليات الجامعية الأجنبية ، وقد بلغ عدد الجامعات العامة (21) جامعة 69 ب، بينما بلغ عدد وفيم الجامعات

(1) ياسر عبد الكريم الحوراني: المشكلات المؤسسية للوقف في التجربة الإسلامية التاريخية مجلة أوقاف،

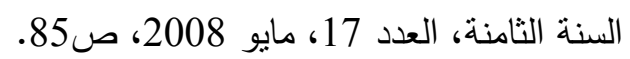
Hoquel Kazi Enamul and et.al : Service delivery in Higher Education 68 (HE): A comparative study Between Public and Private Universities, Life Science Journal. 10(3),2013.p109-110.

Lee Molly N.N. and et.al: Case Study: the Effectiveness of Research and 69 Innovation Management at Police and Institutional Levels Combodia, Malaysia. Thailand and Vietnam, In Asa Olsson Lunn Meek, OECD,( W.d).p108. 
الجمعية المصرية للقر اعة والمعرفة عضو الجمعية الدولية للمعرفة

الخاصة (53) جامعة خاصة ، و (6) فروع للجامعات الأجنبية 70 ، و (403) كلية جامعية

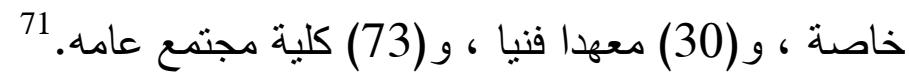

التمويل

يتم تمويل التعليم الجامعي فى ماليزيا من خلال عدة مصادر هى التمويل الحكومى والرسوم

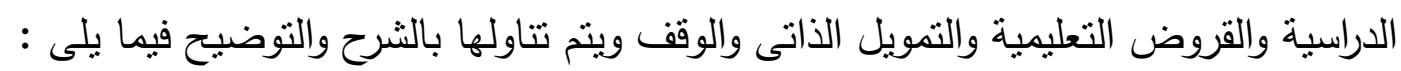

1- التمويل الحكومى Public Funding

ينلقى قطاع التعليم الماليزى بشقية العام والجامعى الدعم المالى من الحكومة وذلك لنوفير

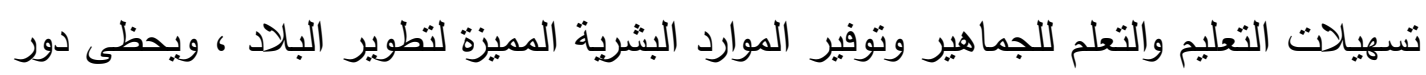

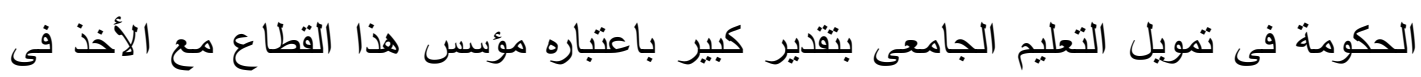

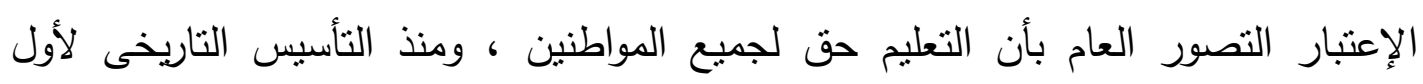

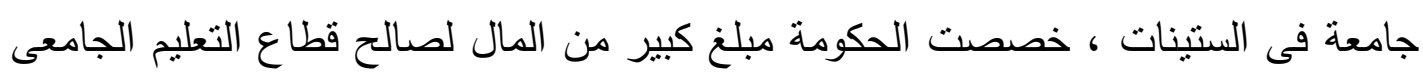

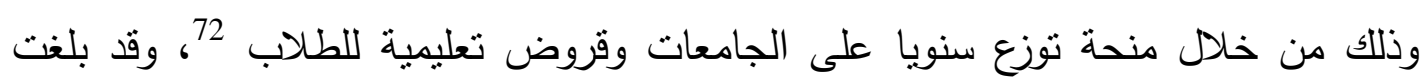

Yuen- Onn and et.al: Organizational Commitment: An Empirical Choong ${ }^{70}$ Investigation on the Academician of Malaysia private universities. Business and Economics Research journal, Vol(3), No(2), 2012.p51.

${ }^{71}$ Ahmed Zamri bin, Abd Razak Nordin bin: Assessing Factors Influencing Students Choice Of Malaysian Public University: A Reach model Analysis, International Journal of Applied psychology, 3(1), 2013.p.19.

\footnotetext{
${ }^{72}$ Ramii Asharf Mohd, Mohamed Mostafa Omar: An Over View Of Public Funding For Higher Learning Education In Malaysia And The Prospect Of Waqf Funding, This Study Is Apart Of Research in "Pembentukan Model Baru Wakaf Korprat Di Malaysia, Ministry Of Higher Education (mohe), (w.d).p.5.
} 


\section{ILA الجمعية المصرية للقر اءة والمعرفة عضو الجمعية الدولية للمعرففة}

نسبة الإنفاق على التعليم الجامعى الماليزى حوالى 1.69\% من إجمالى الناتج المحلى الأجمالى.

ومنذ عام 1980م والتعليم الجامعى يتم تمويله بالكامل من القطاع العام والحكومة ، حيث قامت بتوفير التمويل الكامل لجميع مؤسسات التعليم الجامعى العامة وذللك من خلال مخصصات الميزانية لتمويل التعليم العالى ، وقد أبقت الحكومة الرسوم الدراسية منخفضة بشكل كبير ، كما قامت الحكومة بتوفير القروض والمنح للطلاب من ذوى الدخول المنخفضة

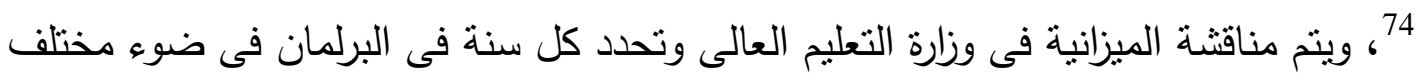
الأنشطة والمشاريع المقترحة .

كما اتجهت الحكومة الماليزية لعمليات الخصخصة للتعليم العالى وبدأت بجامعة مالايا عام 1998 م ، وتبع ذللك أربع جامعات أخرى فى مارس من العام نفسه ، ويقصد بالخصخصة هنا أن تدار الجامعات كثركات الاعمال ويصبح من حقها الدخول فى الثى المشروعات التجارية ، وانثاء شركات تابعة لها وحيازة الاملالك والاسهر ، بالاضافة الى تلى

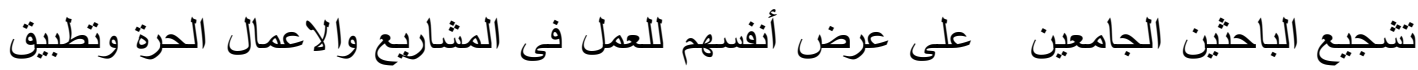
نتائج أبحاثهم التى من الممكن ان نولد الربح لهم ولجامعاتهم ،ويصبح من حقها تخطيط

World Bank: Putting Higher Education to Work Skills and Research The ${ }^{73}$ for Growth in East Asia,'World Bank East Asia and Pacific Regional Report, The World Bank,Washington DC 20433,2012.p.113.

${ }^{74}$ Associacao Brasilerira De Educacao Adistancia : Distance Education Public Policy And Practice In Higher Education; The Case Study of Malaysia,(part 11), Revista Brasilerira De Aprendizagem Abertae Adistance, Saopaulo, Setember, 2003.p.1.

Ahmed Abd Rahman and et.al: Funding Reform In Malaysian Public Universities: 75 Transitions Towards Competitive Funding, Australian Journal Of padc And Applied Sciences.7( 1 0),20 13.p.556. 


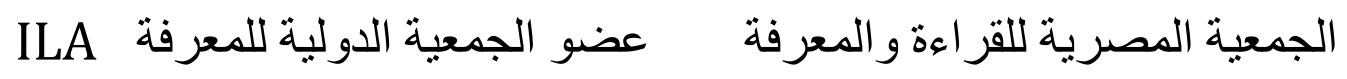

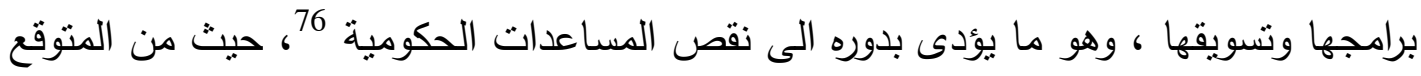
ان يقل الدعم الحكومى من 90\%الى 70\% بحلول عام 2020 م وفقا للخطة الاستراتيجية الوطنية للتعليم العالى الماليزى والذى يؤدى بدوره الى زيادة درجة استقلالية الجامعات الماليزية ، وقد دعم هذا الاتجاه وخاصة فى خطة ماليزيا العاشرة وذلك من خلال استتاد عمليات التمويل على نظم تقييم جديدة لمؤسسات التعليم الجامعى.

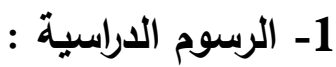

تمثل الرسوم الدراسية نسبة 10\% من تمويل التعليم الجامعى الماليزى وهى نسبة منخفضة الى

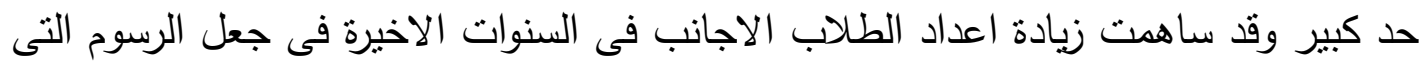

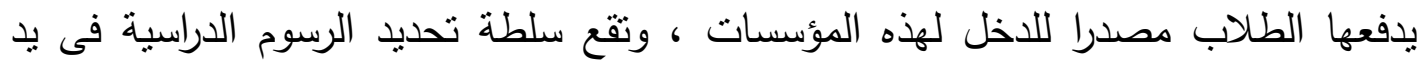

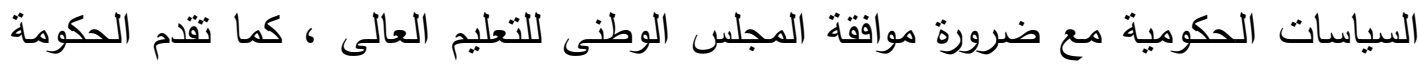

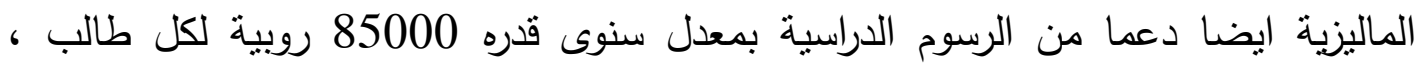

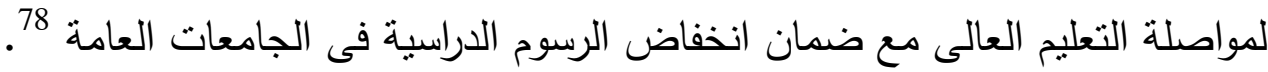

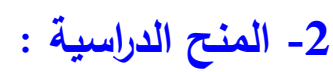

N. V.: Incentives and Institutional changes In Higher Education, Varghese ${ }^{76}$ Higher Education Management and Policy,Vol.16, No. 1, OECD, 2004p.37.

${ }^{77}$ Asharf Mohdramili, Mohamed Mostafa Omar: An Over View Of Public Funding For Higher Learning Education In Malaysia And The Prospect Of Waqf Funding, This Study Is Apart Of Research in "Pembentukan Model Baru Wakaf Korprat Di Malaysia, Ministry Of Higher Education (mohe), (w.d).pp7-8.

Ahmed Abd Rahman and et.al: Funding Reform In Malaysian Public Universities: Transitions Towards Competitive Funding, Australian Journal Of padc And Applied Sciences.7( 1 0),20 13.p.558. 


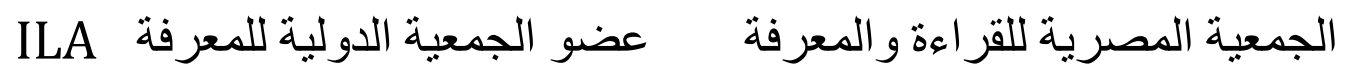

الدنح الدراسية تعد احد مصادر تمويل التعليم الجامعى الماليزى حيث تقدم لطلاب التعليم الجامعى من قبل العديد من المؤسسات ومنها وزارة التعليم العالى وذلك من خلال ادادارة الخدمات العامة بالوزارة حيث تقام منحا دراسية للطلبة المتفوقين من اجل دفعهم لمواصلة دراساتهم فى مؤسسات التعليم الجامعى المحلية او فى الخارج وذلك للطلاب فى مستويات البكالوريوس والدبلوم والماجستير والدكتوراه ، وعادة ما يتم تقديم المنح الدراسية للطلاب الذين الذابن برغبون فى متابعة الدورات التى تصنف على انها ذات اهية للمصلحة الوطنية وفى عام 2007 كان هناك 8000 منحة دراسية للطلبة المتفوقين فى كل من الجامعات الحكومية العاتية

$$
\text { القروض التطليمية : }
$$

تقام الحكومة الاتحادية الماليزية وتحت اثنراف وزارة التعليم العالى انواعا مختلفة من القروض التعليمية للطلاب حيث توجد العديد من الهيئات التى تقدم منل هذه القروض مثل مجلس امانة مجلس النواب ، ووزارة الخدمة المدنية وبعض الثركات المساهمة والثركات المرتبطة بالحكومة متل (بتروناس ، تليكوم ، ماليزيا ، المؤسسات المصرفية ، مؤسسة الثنة صندوق التعليم العالى الوطنية ، وبعض الهيئات الوطنية المستقلة ). 79

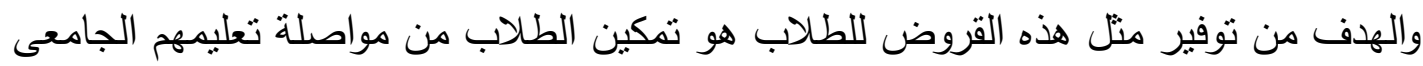
فى مؤسسات التعليم العالى المحلية والاجنبية ، وذلك من اجل تحقيق الهدف الوطنى لماليزيا

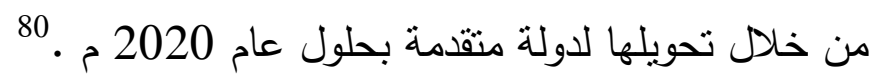

Students' Attitude to Education Loan Repayments: Astructural Modelling 79 Approach, Dissertation of Philosophy, Brunei University, West London, 2011.,p.87.

Ismail Shafmar: Antoaneta Serguieva: Investigating Possible Benefits Of ${ }^{80}$ Student Loan Backed Securitization In The Context Of The Malaysian

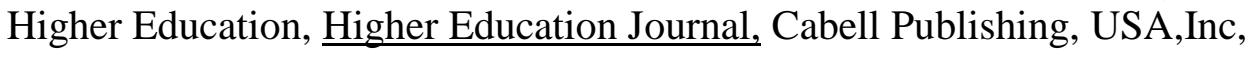
2009.p.4. 


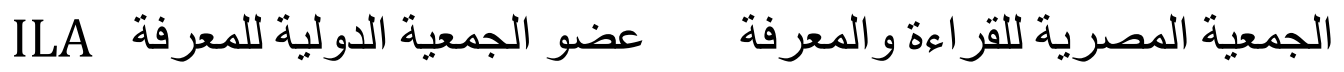

3- 3 - 3 - 3ق:

من الناحية التاريخية فان وجود الوقف فى ماليزيا يرجع الى بدايات دخول الإسلام اليها ، وتتقسم بداية وتطور الوقف فى ماليزيا الى ثلاث فترات هم : فترة ما قبل الاستعمار ، وفترة الاستعمار ، وفترة ما بعد الاستقلال ، ففى فترة الاستعمار ومع قيام المستعمر البريطانى بتتفيذ سياسته العلمانية أجبر المسلمين فى ماليزيا الى العمل على حماية شعائرهم الدينية وذلك عن الكن طريق قيامهم بالتبرع بالاراضى لبناء المساجد والمدارس الدينية ، وبالتالي فان قطاع التعليم فى

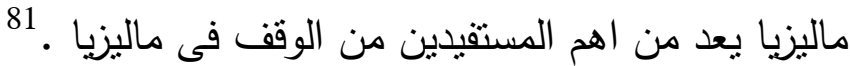
وينقسم الوقف فى ماليزيا الى نوعين اوقاف عقارية منل الاراضى والمباى والعقارات الوقفية والاوقاف النقدية 82، حيث تهدف الاوقاف العقارية الى توليد مزيد من الدخل للمؤسسات الوقفية لصالح المستقيدين ، كما تتجه ماليزيا نحو تزويد مواردها الوقفية من خلد الثراكة بين المؤسسات الوقفية والهيئات الاعتبارية كل هذا بهدف تطوير الاصول وخلق مصادر جديدة لصندوق الوقف.

Ramii Asharf Mohd, Mohamed Mostafa Omar: An Over View Of Public ${ }^{81}$ Funding For Higher Learning Education In Malaysia And The Prospect Of Waqf Funding, This Study Is Apart Of Research in "Pembentukan Model Baru Wakaf Korprat Di Malaysia, Ministry Of Higher Education (mohe), (w.d).p115.

Mohamed Zuraigah and et.al: Acomparative Study Of Waqf Management ${ }^{82}$ in Malaysia, 2011 International Conference on Sociality and Economics Development, IpEDer, vol.10, IACSIT Press, Singapore, 2011.p.562.

Ibrahim and et.al: Waqf Fund Management in Kuwait and Egypt: 'Ahmed ${ }^{83}$ Can ${ }^{\wedge}$ Malaysia leams From Their Experience, The International Conference on Masjld. Zakat and Waqf, 1-2 December, Kuala Lumpur, Malaysia, 2014.p.80. 
الجمعية المصرية للقر اعة والمعرفة عضو الجمعية الدولية للمعرفة

ومن أنثهر الجامعات التى قامت فى اسسها كوقف جامعة ماليزيا الاسلامية (uim)

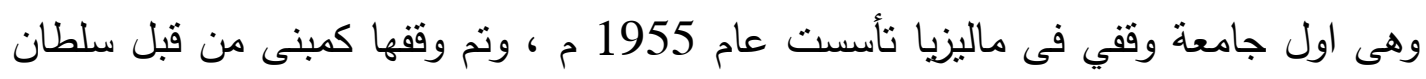

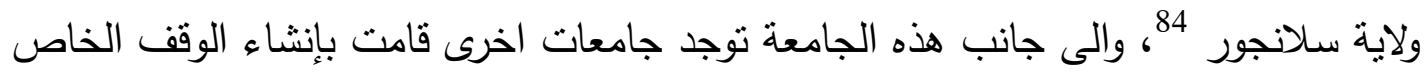

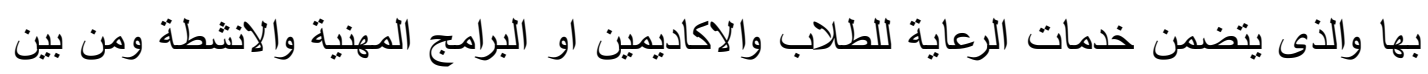

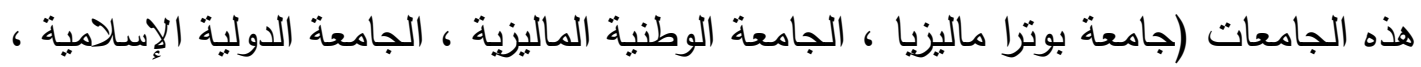

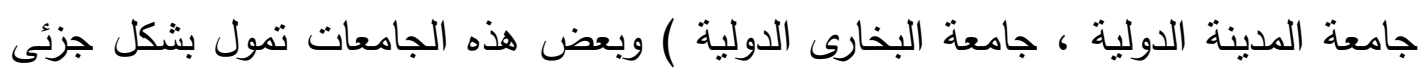
من خلال الوقف ، وبعضها بشكل كامل

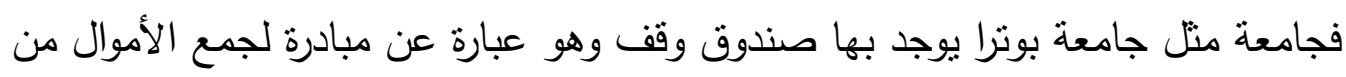

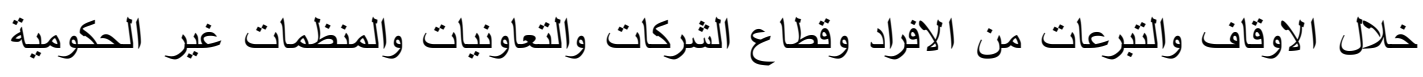

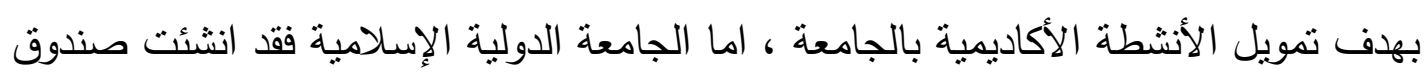

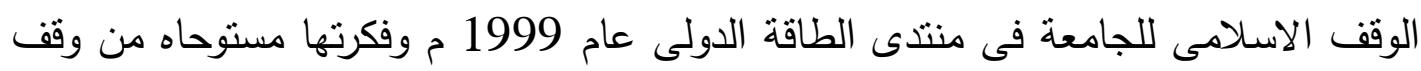

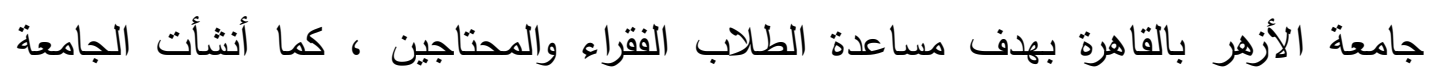

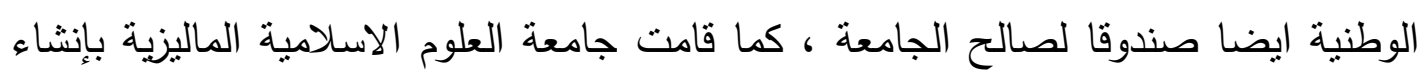

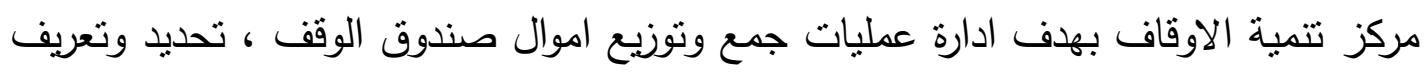

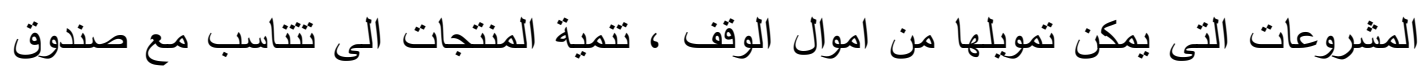

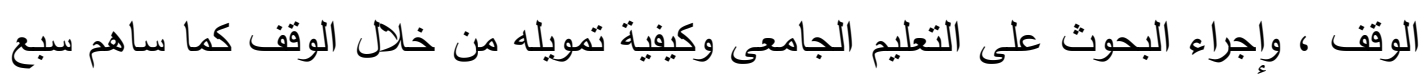

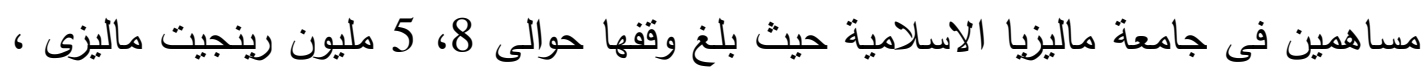

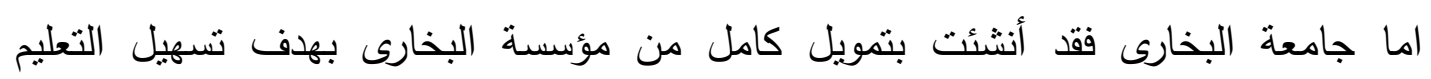

Yaakub Noor Inayah: The Transformation Of The Role Of Waqf in The ${ }^{84}$ Higher Learning Education In Malaysia: A New paradigm For Islamic Financial Institutions, $11^{\text {th }}$ Kuala lumper Islamic Finance Forum 2014, Hotel Istana kualalumper city Center, Malaysia, 11-12 November 2014.p.3. 
الجمعية المصرية للقر اعة والمعرفة عضو الجمعية الدولية للمعرفة

الجامعى عالى الجودة وتمكين الطلاب سواء المحليين او الدوليين من ذوى الدخول المخفضة

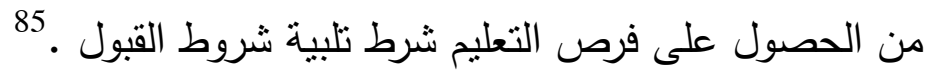

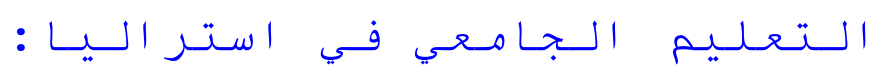

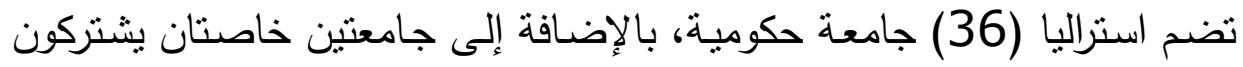

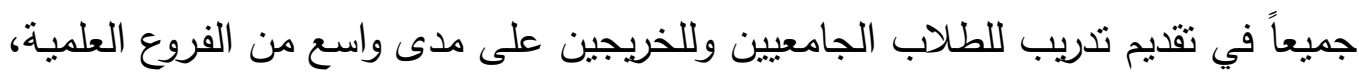

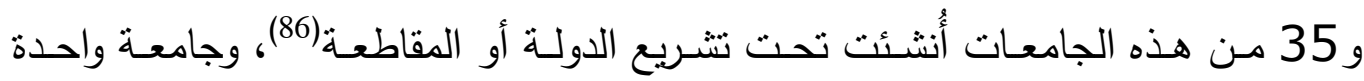

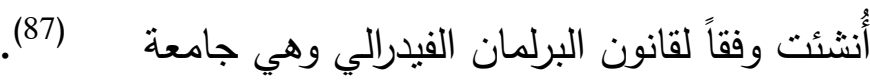

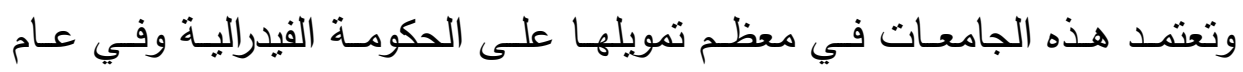
1999 كان عدد الطلاب المسجلين في برامج التعليم العالي في جميع أنحاء استراليا

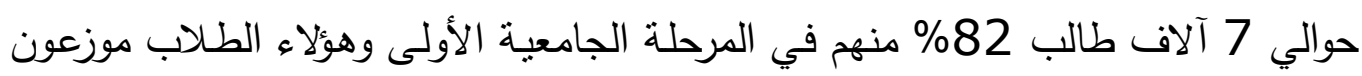

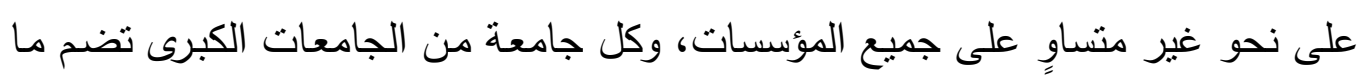

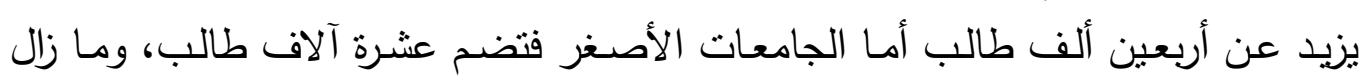

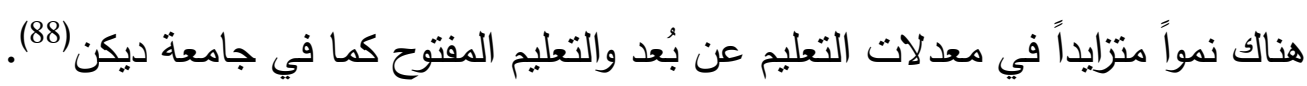

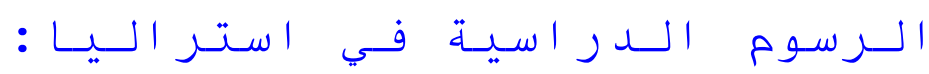

${ }^{85}$ Fuadah Johari , Mohammed Haji Alias: Potential Of Waqf and Instruments in Contemporary Economic System, available at: www.nuradli.comliecons 2013/ B.4Pdf 17/5/2015. 2:30 pm.

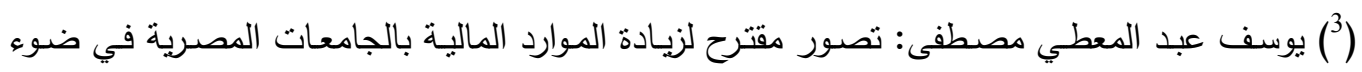
خبرات بعض الجامعات الأجنبية، مجلة التربية- الجمعية المصرية للتربية المقارنة والإدارة التعليمية،

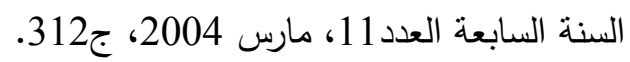

${ }^{87}$ ) Steering committee for the review of commonwealth state service provision Report on government services 2007, Australia, conberra: productivey commissiony, 2003, p. 7.

$\left({ }^{88}\right)$ Diedra young (1998): Teacher Moral and Efficacy in Rural Western Australia A paper presented At the Annual conference of Australian Association for Research in Education, South Australia, No. 29, De3, p.15. 
الجمعية المصرية للقراعة والمعرفة عضو الجمعية الدولية للمعرفة

بعد فرض مؤسسات التعليم الجامعي رسوماً دراسية عنصراً أساسياً في أي استراتيجية

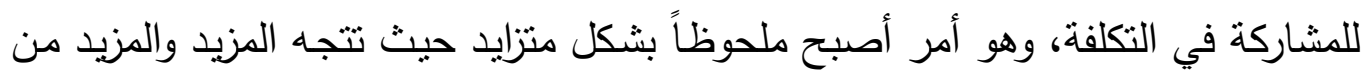

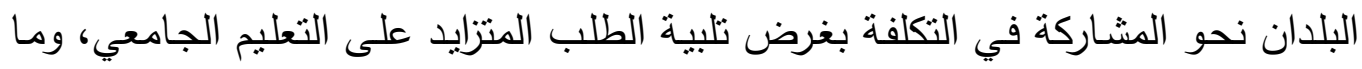
يقابله من نتاقص في الاستثمار الحكومي (89). فإن سلطة وضع رسوم دراسية للتعليم الجامعي راسخة بالنسبة للكيانات الدختلفة

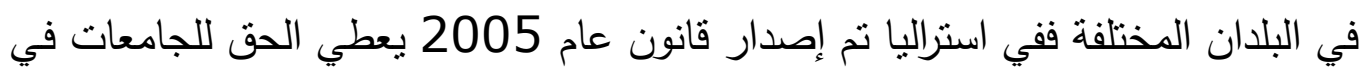

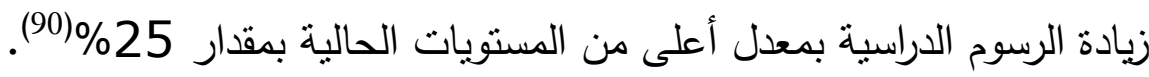
القروض المؤجلة للطلاب باستراليا:

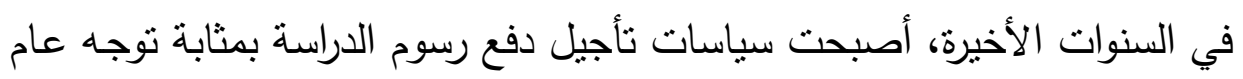
يهذف إلى التوافق بين الرغبة في مطالب الطلاب بالمساهمة في تكاليف التعليم الجامعي

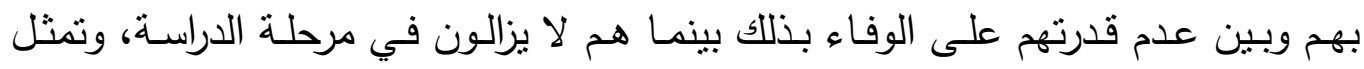

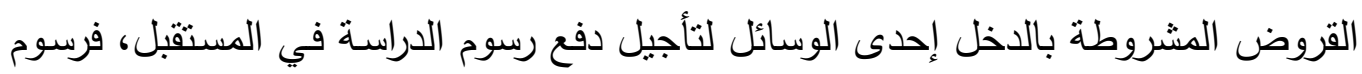

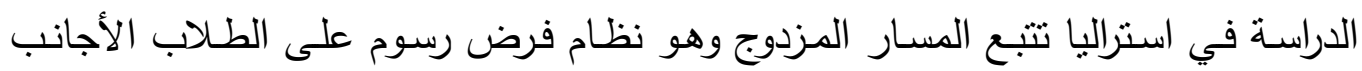

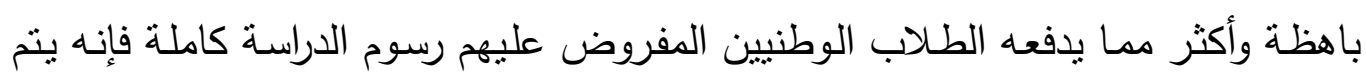

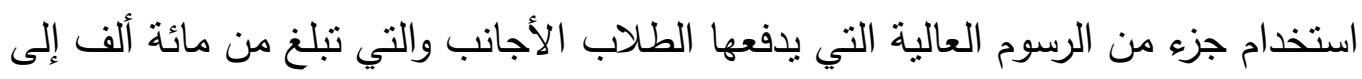

$\left.{ }^{89}\right)$ Bain, Olga. (2001)The costs of Higher Education to students and parents in Russia: Tuition policy Issues.Peabody Journal of Education, P. 76, 57- 80.

$\left({ }^{90}\right)$ Champan, Bruce and chris Ryan (2003). The Access Implications of Income contingent charges for Higher Education: Lessons from Australia Discussion paper No. 463 Center for Economic Policy Research, Australian National university, p. 14. 
ILA الجمعية المصرية للقز اءة والمعرفة عضو الجمعية الدولية للمعرففة

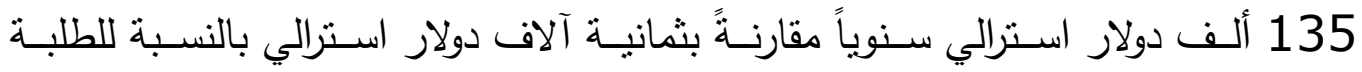
الوطنيين في النفقات الرأسمالية وفي دعم اللغة الإنجليزية ومهارات الطلاب (91). وهناك نوعان من المنح الدراسية.

1- منحة على أساس الجدارة وتمنح للطلاب المتفوقين ويحصل الطالب على أكثر من لـن 2000 دولار سنوياً.

2- منحة للمساعدة على الإقامة وتغطية تكاليف السكن والمعيثة تصل إلى أربعة آلاف دلإ دولار في السنة(92.).

واتجهت الحكومة الاسترالية إلى زيادة الدعم لقطاع التعليم العام والجامعي ليصل

$$
\text { إلى } 11 \text { مليار دولار عام الإنفاق على التعليم الجامعي في استراليا: }
$$

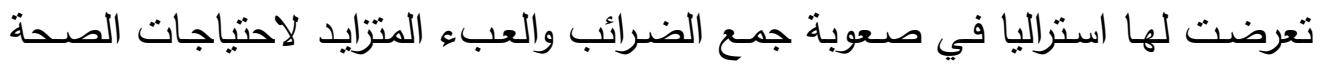

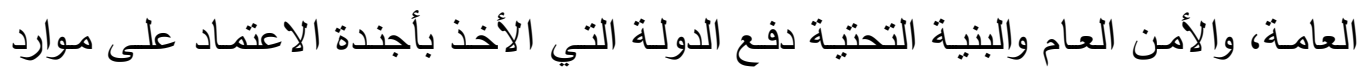

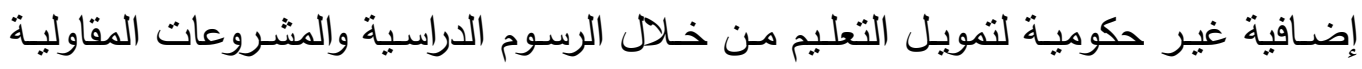

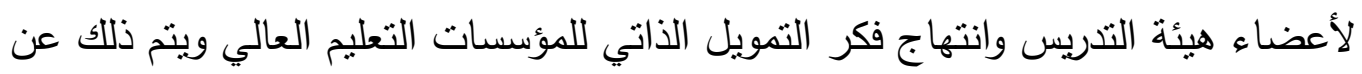
طريق إنشاء مؤسسات تمويلية وبرامج مختلفة تتبناها الجامعات لزيادة التمويل ومن هذه

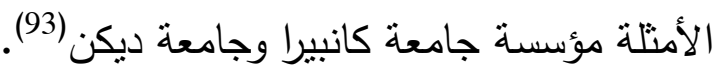

$\left.{ }^{91}\right)$ Larocque Norman. (2003) Who should pay? Tuition fees and tertiary education financing in New Zealand, (Wellington, Education Farom. P.3).

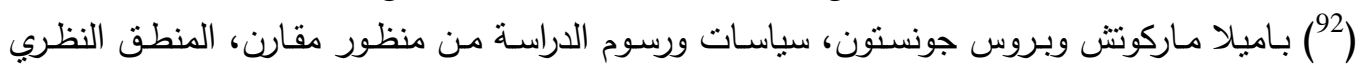

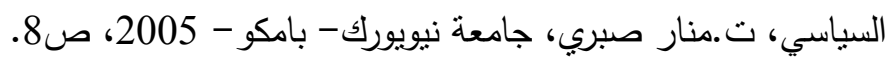

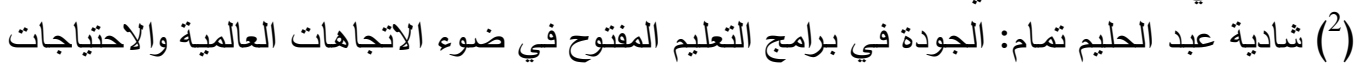

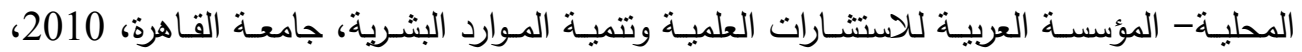

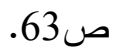


الجمعية المصرية للقراعة والمعرفة عضو الجمعية الدولية للمعرفة ال

تضاعفت ميزانية برامج البحث العلمي في استراليا من 200 مليون دولار استرالي

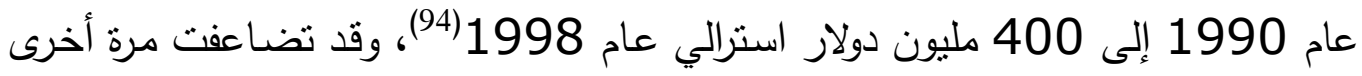

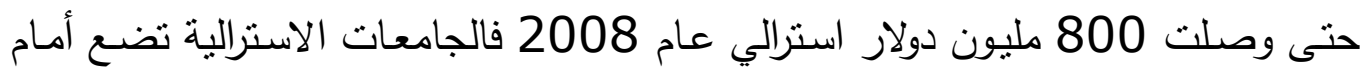

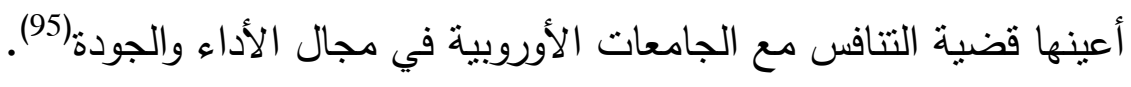
تسويق الخدمات التعليمية الجامعية: النموذج التسويقي لجامعة أستراليا القومية:

\section{The Australian National university (ANU):}

تُعد جامعة أستراليا القومية جامعة بحثية تقع في كانبرا Canberra بأستراليا،

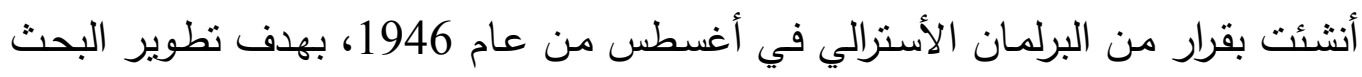
العلمي في أستراليا، وتصنف الجامعة أفضل جامعة على مستوى أستراليا، وهي الجامعة الإنة

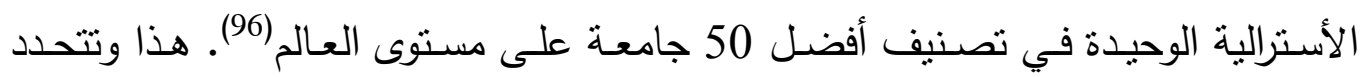

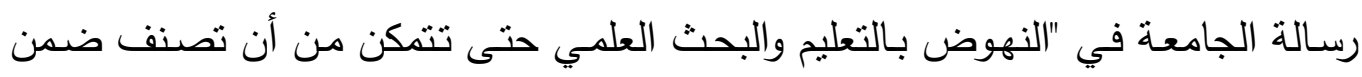
أفضل وأعظم الجامعات في العالم"، وبالفعل استطاعت الجامعة خلال العامين الماضيين

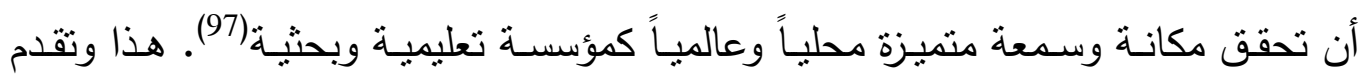

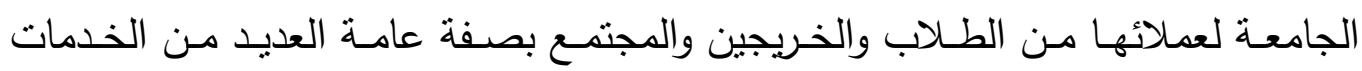
المتميزة والتي يمكن إيجاز بعضها فئها فيما يلي:

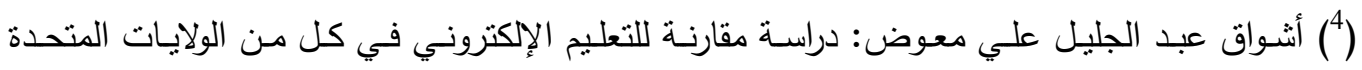

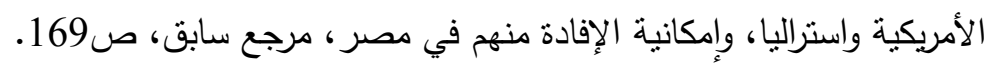

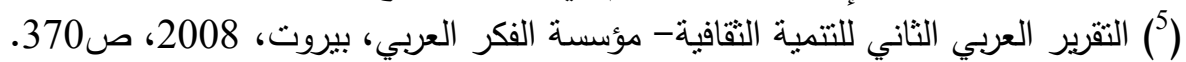
$\left.{ }^{96}\right)$ The Australian National university, discover ANU, university mission, available at http: // www. Anu. Edu. Au/ discoveranu, 2009.

$\left.{ }^{97}\right)$ The Australian National university, office of commercialization, about us, available at http: // www. Anu. Edu. Au/ commercialisation / about- us. Php, 2009. 


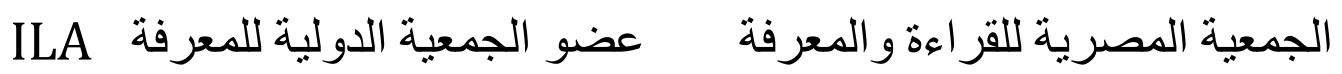

\section{1- تسـويق البــوث العلميـة:}

research

وذلك من خلا مكتب تسويق البحوث العلمية حيث تدور الأنشطة الرئيسية لهذا

المكتب حول مساعدة الباحثين، وأعضـاء هيئة التدريس بالجامعة على نقل التكنولوجيا والمعرفة، وفي تسويق نتائج البحوث العلمية. ويقوم المكتب بتقديم خدمات متخصصـة

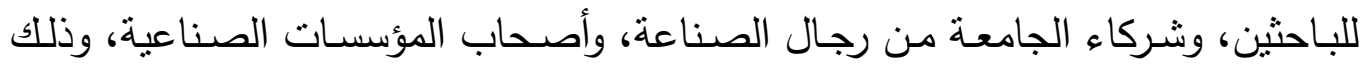

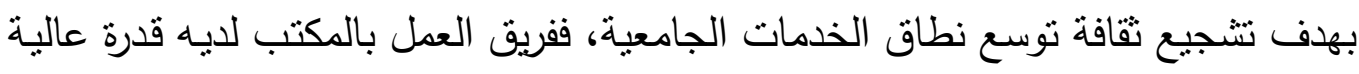

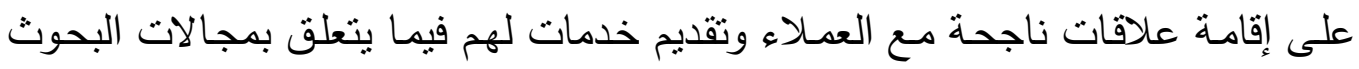
التعاقدية، وحقوق حماية الملكية الفكرية والترخيص وإقامة الثركات.

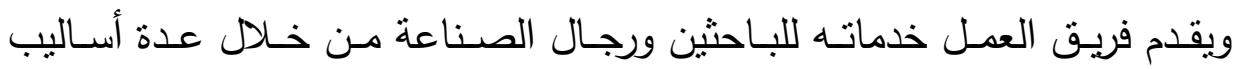
:

أ- المساعدة في تكوين وتحسين العلاقات بين كل من الباحثين في الكليات المختلفة بالجامعة وأقرانهم في الجامعات الأخرى، وكذا بين الباحثين ورجال الصناعة. ب- إدارة هذه العلاقات على نحو جيد لتحقيق المنافع لجميع الأطراف. ج- حماية إإدارة حقوق الملكية الفكرية. د- خدمات التفاوض بشأن الاتفاقات المختلفة لتسويق ننائج البحوث العلمية.

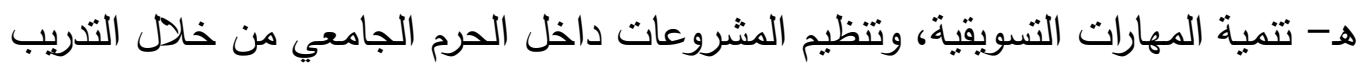
والتعليم.

\section{2- وحـدة الاتصـالات والتسـويق Marketing of communication \\ division}

$\left.{ }^{98}\right)$ The Australian National university, Marketing \& Communications at ANU, available at http: // www. Anu. Edu. Au / mac/ content/ about, 2009. 
هذه الوحدة مسئولة عن كافـة أنشطة التسويق بالجامعـة، مثنل تصميم وتنسويق العلامهة التجاريـة للجامعة University's brand image وتقديم العون لأعضاء هيئة

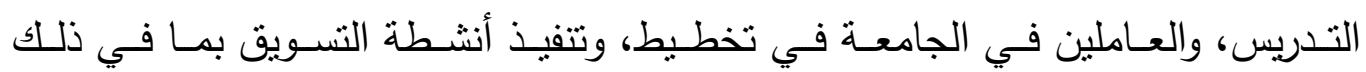
الإعلانـات، والمطبوعات والنشـر والإعـلان الإلكترونـي عبـر شبكة الإنترنـت (99)، وتقوم

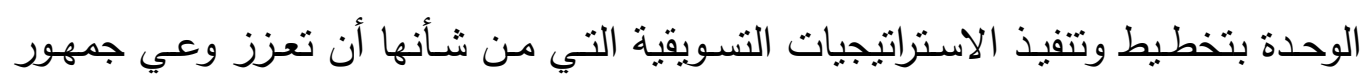

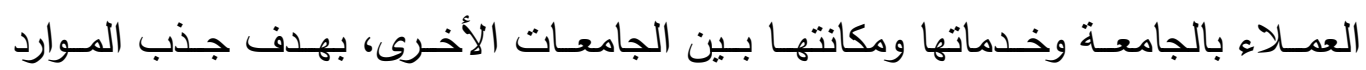
والتبرعات والطلاب إليها(100) .

كما تقدم الوحدة عدة محاضرات تلعب دوراً فعالاً في برنامج الجامعة لتوسيع نطاق The ANU Community outreach الاستفادة من خدمات ومنتجات الجامعة مهات program ولقاء نخبـة مـن أفضـل العلمـاء، والخبراء، والأكاديميين، كمـا أن هذه المحاضـرات تتيح الفرصـة للكليات، والمراكز التابعة للجامعة لتكوين اتجاهات إيجابيـة نحوها من قبل أفراد المجتمع، وذلك من خلال عرض مواطن القوة لدى أعضـاء هيئة التدريس بها، ففي عام 2007 عقد للقسم 93 محاضرة حضرها أكثر من 14 ألف من أفراد المجتمع(101). 3- تسويق الطلاب والخريجين:

تقوم الجامعـة بتسـويق طلابهـا وخريجيهـا مـن خـلال مركز التوظيف بالجامعـة ANU career centre

$\left.{ }^{99}\right)$ The Australian National university, marketing \& Communications at ANU, marketing office, available at http: // www. Anu. Edu. Au/ mac/ content/ about/ area/ marketing office/, 2009.

$\left({ }^{100}\right)$ The Australian National university, Marketing \& Communications at ANU, Alumni Relations, available at http: // www. Anu. Edu. Au/ mac/ content/ about/ area/ alumni_relations/, 2009.

$\left({ }^{101}\right)$ The Australian National University, The ANU Careers Centre, available at http: // www. Anu. Edu. Au/ careers/ index. Php? Page=2., 2009. 
الجمعية المصرية للقراعة والمعرفة عضو الجمعية الدولية للمعرفة ال

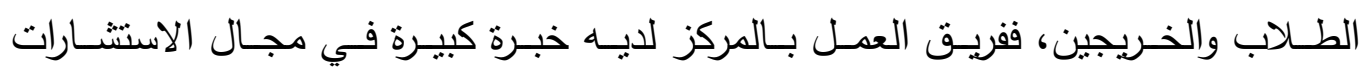

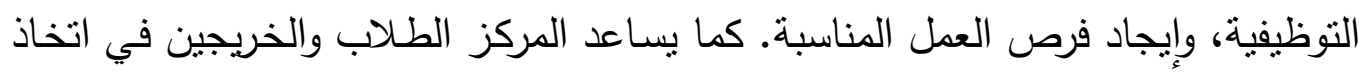

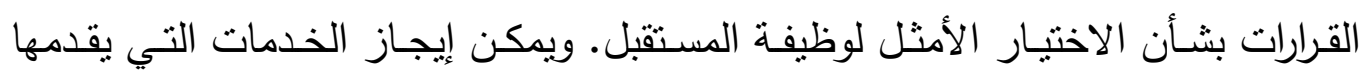

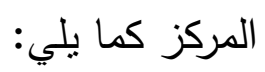
أ- توفير قائمة بفرص العمل والوظائف الثناغرة. ب- تقديم المشـورة للطـلاب والخريجين عن الأسس التي يجن التبل اتباعها في المقابلات الثخصية career interviews.

ج- عقد ورش عمـل وسـيمنارات حــول تتميـة المهــارات الوظيفيـة والمهنيـة للطــلاب والخريجين، والتي تعظم من فرص اختيارهم في المقابلات الثخصية للتقدم للوظائف.

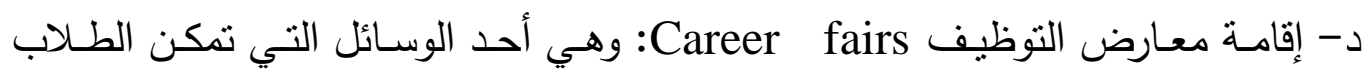
والخريجين من لقاء ممنلي الثركات، والمؤسسات المختلفة بشكل مباشر . هـ - خدمات الاستشارات الفردية Individual careers counseling. الوقف كمصدر من مصادر التمويل الذاتي بالجامعات الاسترالية: * الوققيات كمصدر لتمويل الجامعات الاسترالية:

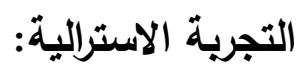

قدرت وققيات جامعة استراليا الوطنية بحسب التقرير المالي لعام 2007 بـ850

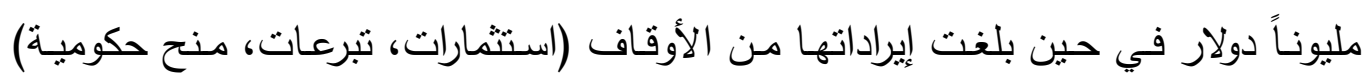

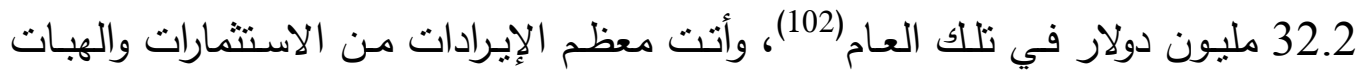
المقدمة من جمعيات غير حكومية (87.3\%) نوزعت كالتالي 73.7\% من من الاستثمارات،

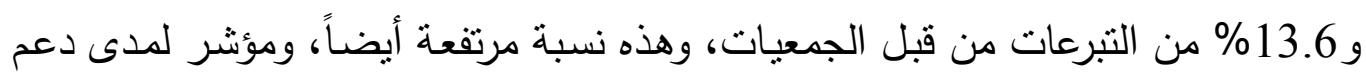

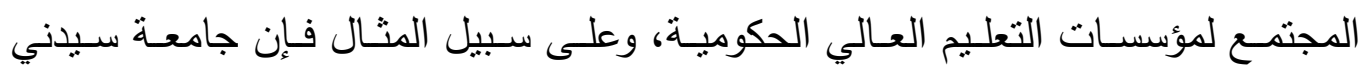
${ }^{102}$ http://www.anu.edu.au/mac/images/uploadsannual.report.2007.forweb.pdf. 526 
ILA الجمعية المصرية للقز اءة والمعرفة عضو الجمعية الدولية للمعرففة

الحكومية تختلف عن حاجة استراليا الوطنية بأن معظم وققياتها تتخذى من الدعم الحكومي أما جامعة ملبورن الخاصة. فقد بلغ حجم الوققيات في السنة المالية 2007 أكثر من مليار

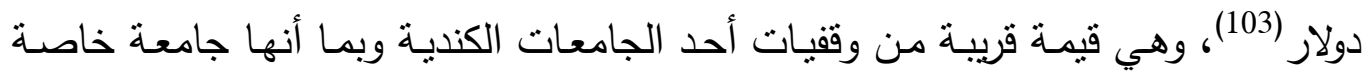
فهي تعتمد على رسوم الطلاب بنسبة وصلت في السنة المالية 2008 إلى حوالي 80\% مقابل 4\% حصلت عليها من تبرعات قدمتها جمعيات وهيئات غير حكومية(104). الروئة المستقبلية لتمويل البحث العلمي لتمويل البحث العلمي بالتعليم الجامعي بالمملكة العربية السعودية في ضوء خبرات بعض الدول منطلقات الروئية المستقبلية 1. أن هناك اهتماماً عالمياً بتمويل البحث العلمى، ويرجع ذلك لقصور مصادر تمويلة بالجامعات، والتغيرات المجتمعية المتزايدة.

2. أن التمويل الذاتي يعطي الحرية للجامعات في التصرف في شئونها المالية والإدارية.

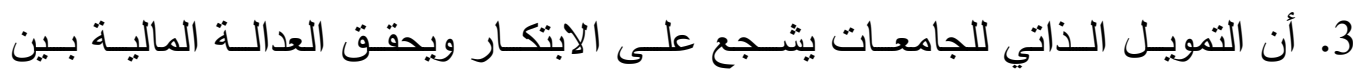

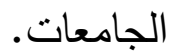

4. الاستفادة من دول المقارنة في مجال التمويل البحث العلمي بالمملكة العربية السعودية من خلال اختبار الصيغ التي تتاسب البحث العلمي ومراكزه ومعاهده بالمملكة. 5. أن نجاح التمويل للبحث العلمي بالمملكة العربية السعودية رهن بكفاءة أعضاء هيئة التدريس ومن ثم لابد من التنمية المهنية المستمرة لهذه الهيئة.

( ) عبد الوهاب السعدون: هل ينم نوظيف "الوقف" للارتقاء بأداء الجامعة الوطنية، المجلة الإكترونية

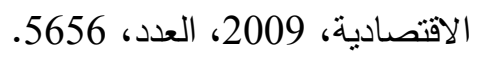

(4) التقرير العربي الثاني للتتمية الثقافية (نماذج عالمية في الوققيات الجامعية) مؤسسة الفكر العربي،

$$
\text { بيروت، 2010، ص216. }
$$


الجمعية المصرية للقراعة والمعرفة عضو الجمعية الدولية للمعرفة

6. التخطيط العلمي السليم لاستثمار الموارد المتاحة للجامعات بكفاءة فالتخطيط والبحث

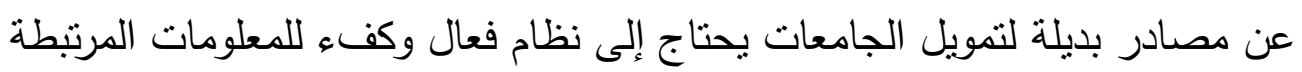

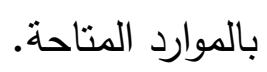

7. أن الاستخدام الكفء والفعال للموارد المتاحة في مؤسسات التعليم الجامعي في ظل التل قلة مواردها المالية، والتحديات التي تواجه التمويل الجامعي.

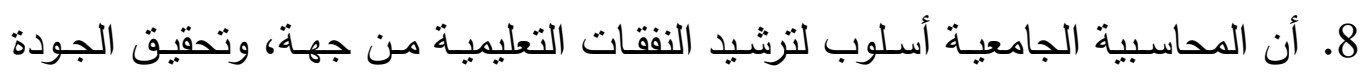
الثناملة من جهة أخرى وتحسين مخرجات التعليم الجامعي من جهة ثالثة الثة.

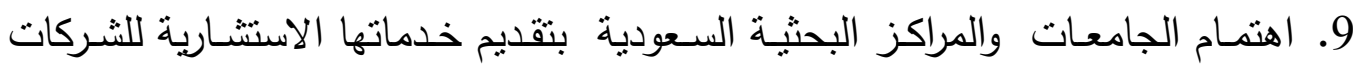
والمصانع والمؤسسات المختلفة. 10. اهتمام الجامعات بالبحوث التطبيقية وإجراء العقود البحثية مع المؤسسات الأخرى مقابل عائد مادي. 11. التخطيط السليم لبرنامج توعية إعلامية بالوقف ومنافعه ومجالاته وأهدافه.

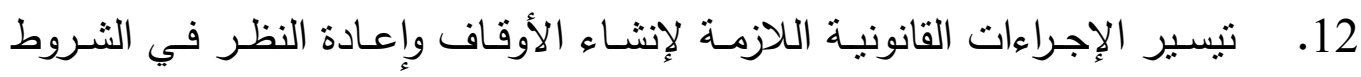
والقيود الثكلية القائمة في هذا الخصوص. محاور الروئية أولاً: التخطيط والبحث عن مصادر بديلة لتمويل الجامعات:

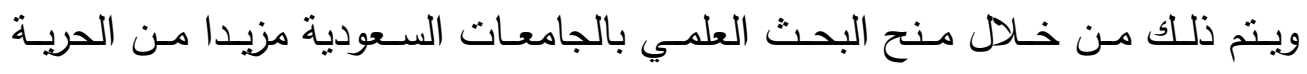
والاستقلالية للتخطيط والبحث عن مصسادر بديلة لتمويلها وتوليد الدخل من الإمكانيات المتاحة لهذه الجامعات والاهتمام بتحديد الأهداف الخاصة بتحقيق التمويل الذاتي بدقة التحة

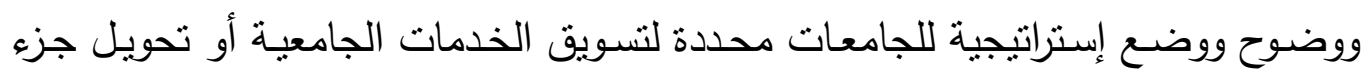
منها إلى جامعات منتجة ومولدة للاخل.. ويتم ذلك من خلال ما يلي: 


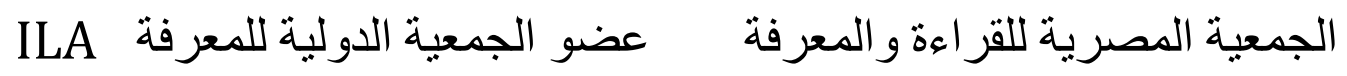

- تحديد الأهداف التي ينت من خلالها تحقيق التمويل الذاتي للجامعات بدقة ووضوح بحيث تكون إجرائية وقابلة للقياس.

- وضع خطة إستراتيجية للمساهمة في تحقيق التمويل الذاتي للبحث العلمى بالجامعات

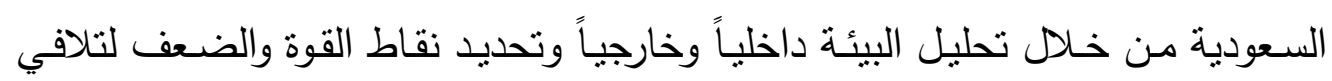

نقاط الضعف وتعزيز نقاط القوة.

- التركيز على الجودة في تحقيق التمويل للبحث العلمى بالجامعات المختلفة بالمملكة

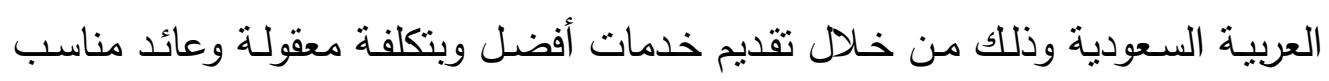
يُُسهم في تمويل الجامعات ويحقق تخفيف العبء عن المملكة العربية السعودية ويكون

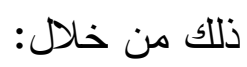

* أن تقوم كل جامعـة بتحديد الأهداف الإجرائيـة الخاصـة بها، وفقاً لظروفها

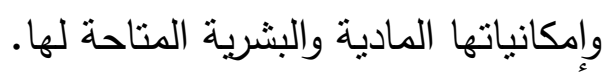

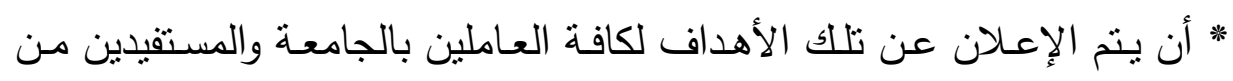

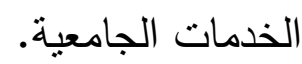

* أن تثتق أهداف الأنشطة النسويقية للجامعات من الأهداف العامة لها.

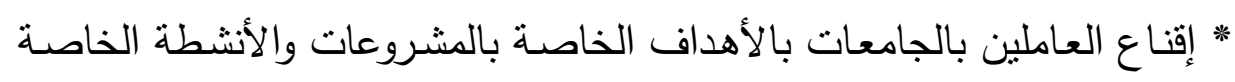
بنوليد الدخل وتسويق الخدمات الجامعية من خلال عقد دورات تدريبية لهم ونثر الوعي والثقافة التسويقية من خلال نشرات نوضيحية.

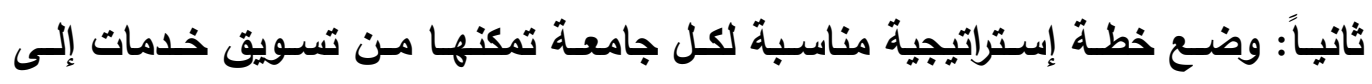
مؤسسات المجتمع المختلفة داخلياً وخارجياً:

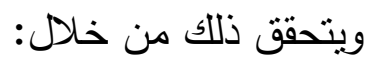

- تسعير الخدمات التي تقدمها الجامعات مـع الوضع في الاعتبار التكلفة الفعلية

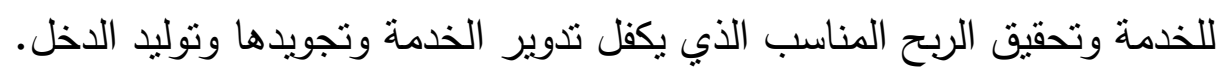


ILA الجمعية المصرية للقراعة والمعرفة عضو الجمعية الدولية للمعرفة

- - الترويج والإعلان عن الخدمات التي تقدمها الجامعات وذلك من خلال وسائل

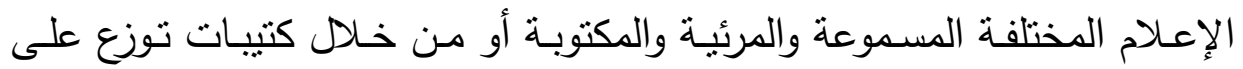

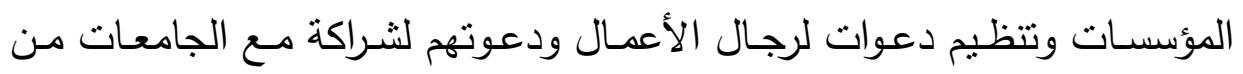
خلال الوحدات والمراكز ذات الطابع الخاص.

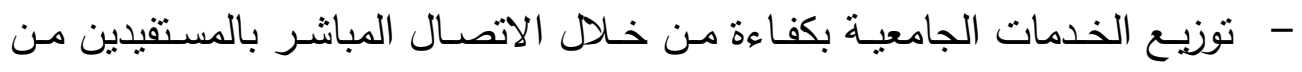

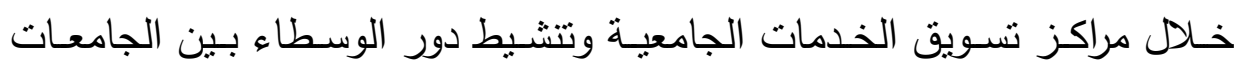
والمستقيدين. زيادة مخصصات البحث العلمي للمراكز والمعاهد البحثية بالجامعات المختلفة بالمملكة:

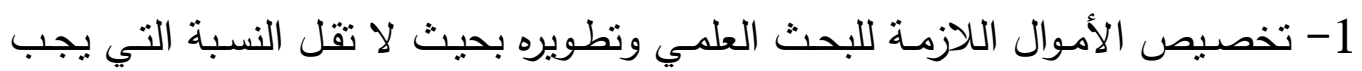
تخصيصها لهذا الغرض عن 5\% من الناتج القومي وفق تتسيق علمي عربي.

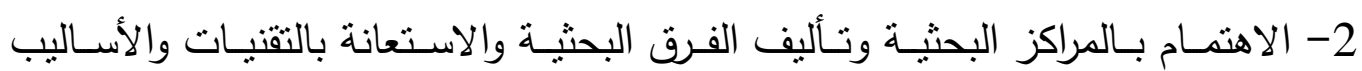

$$
\text { المستخدمة في كل مركز بحثي. }
$$

3- تكوين قاعدة معلوماتية عن جميع البحوث العلمية العربية وفقاً للتخصصات والنتائج لجعلها قاعدة تساعد على الانطلاق في التوجيهات البحثية المستقبلية.

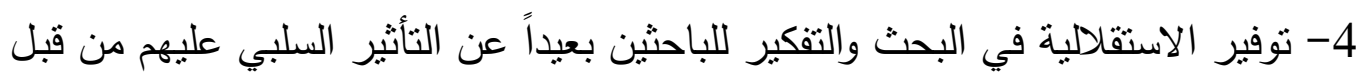

$$
\text { دوائر صنع القرار. }
$$

5- الاهتمام بالبحوث الاجتماعية والإنسانية وتوفير مستلزمات البحث فيها.

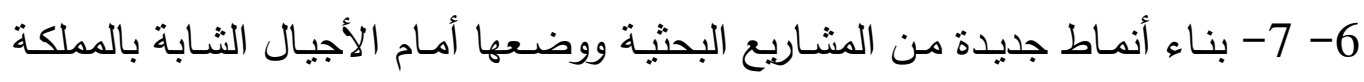

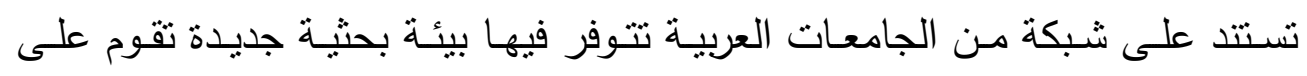
الاستقلالية.

الاهتمام بعمل قاعدة بيانات توفر نظام مطلومـات فعال وكفء للموارد المتاحة للجامعة

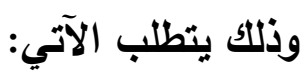


الجمعية المصرية للقراعة والمعرفة عضو الجمعية الدولية للمعرفة ال

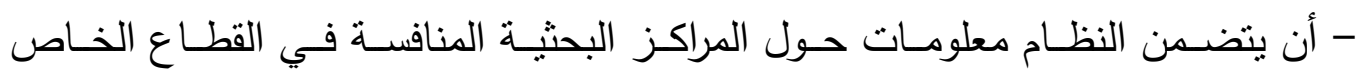

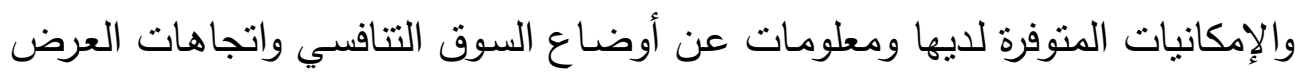
والطلب والأسعار السائدة للخدمات البحثية المختلفة.

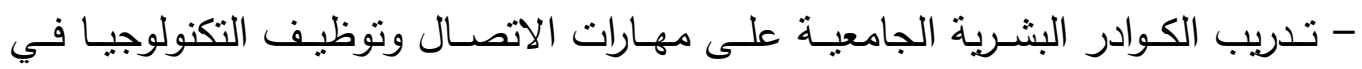
الحصول على المعلومات الخاصة بالعملاء وتذليل العقبات والمشكلات التي تواجههم.

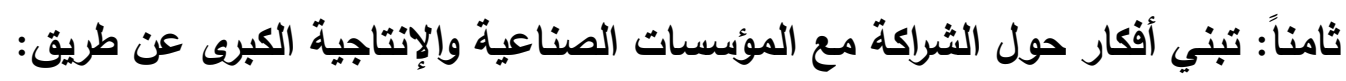

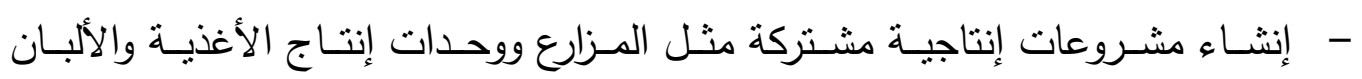
والمنتجات الصناعية يخصص عائدها لزيادة الموارد المالية للجامعة.

- - مياغة قوانين وآليات وسياسات للثراكة بين الجامعة والمجتمع المحيط.

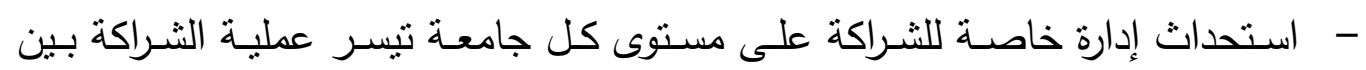

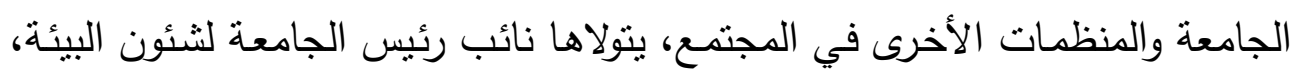

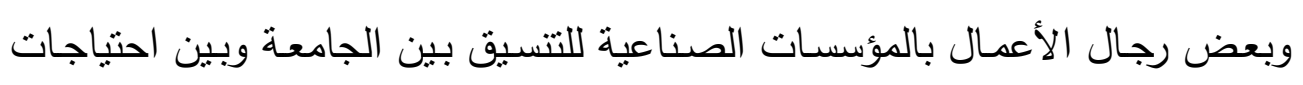
المؤسسات الصناعية. الاهتمام باستثمار مهارات أعضاء هيئة التدريس وخبراتهم في تقيم الاستثـارات ويكون

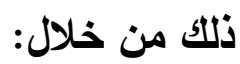

- - إنثاء مكاتب استشارية في الكليات المختلفة وفي كل أفرع التخصصات واختيار

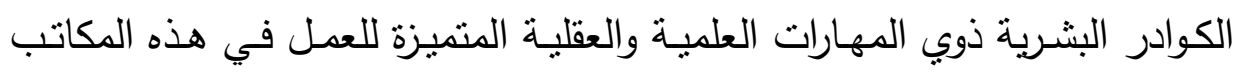

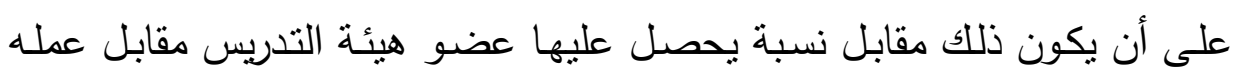
الاستشاري.

- تحديد الخدمات الاستشارية التي تقدمها المكاتب للمستفيدين وتعريفها.

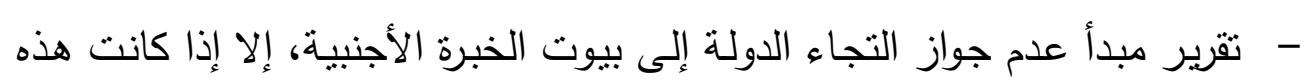

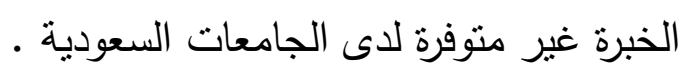




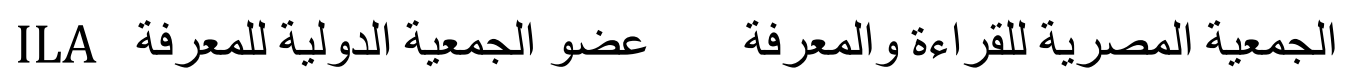

تسويق الخدمات التي تقدها الوحدات ذات الطابع الخاص ويكون ذلك من خلال: - مراكز التدريب المتخصصة والمراكز الصناعية والتجارية.

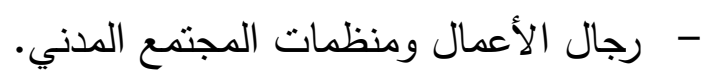

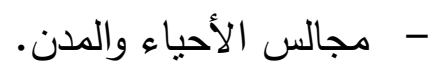

- - الوزارات والهيئات والنقابات المختلفة.

- - الجامعة التابعة لها الوحدة.

- مؤسسات القطاع الخاص من خلال قنوات اتصال بين الوحدات والقطاع الخاص.

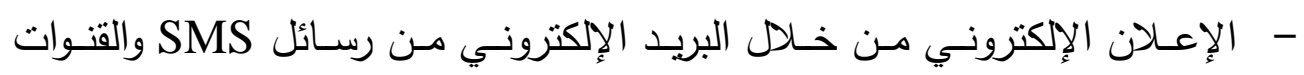

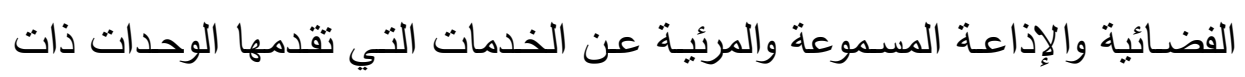

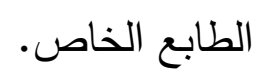

هـ- البحث عن مصادر تمويل إضافية للوحدات لاستمرار عملها وتحقيق أهدافها ويكون

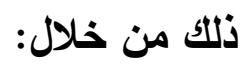

- - توليد الدخل من عوائد الأنشطة التي تقوم بها الوحدات نفسها.

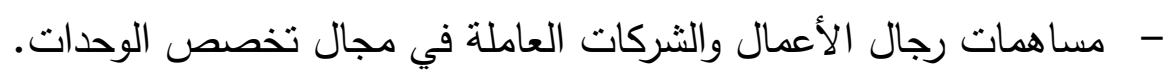
- - الوقف والهيات والتبرعات للهيئات المحلية والإقليمية. - - - - هيئات المعونة الدولية والقطاع الخاص.

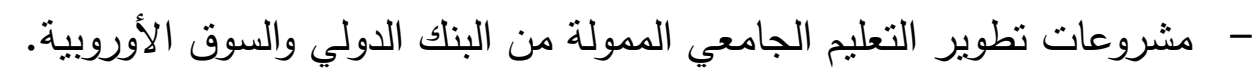

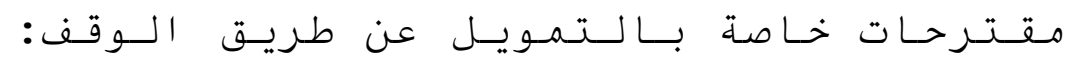

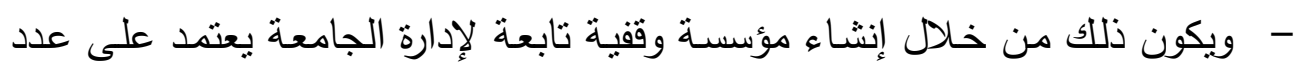
من المصادر لتمويلها أهمها:

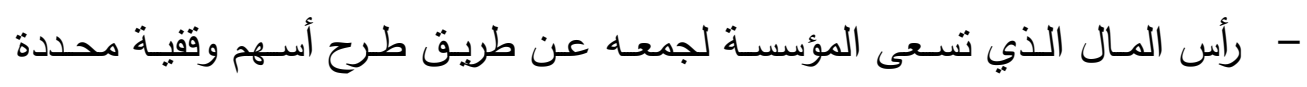
القيمة، وذلك بشهادات أسهم تحتوي على اسم الواقف والغرض من وقفة لجنه وشروطه. 


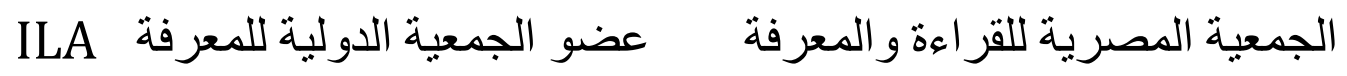

- قبول المؤسسة ما يوقف عليها من عقارات سكنية أو تجارية على أن يكون لها الحق في الإثراف عليها وتحصيل رياعها واستثماره.

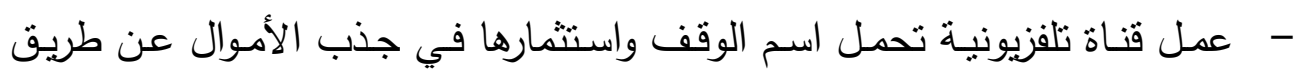
الإعلانات الني تبثها القناة للأفراد والهيئات. - استثمار الوقف النقدي من خـال المؤسسـة الوقفية التابعة للجامعة ليدر عائداً بيتخدم في تمويل الجامعة. إدارة المراكز والمعاهد البحثية بالجامعات السعودية ودورها فى دعم وتسويق البحوث

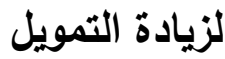

تحديث فنوات الاتصال بمعاهد البحوث في الجامعة ، والبعد عن المركزية في

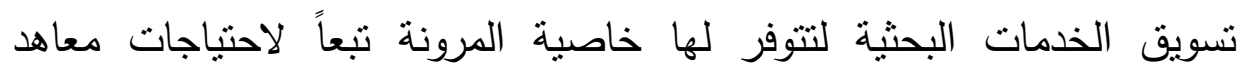

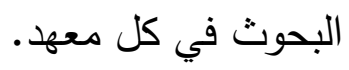
اتاحة الفرصة لإنثاء إدارة مستقلة تتبع " لوكيل الجامعة للتسويق" ، تهتم بتسويق

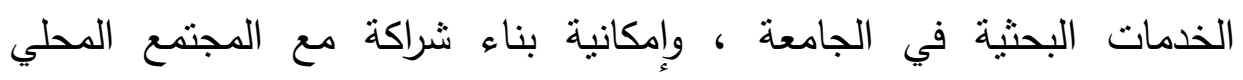
ومؤسساته. تقوم معاهد البحوث بالجامعة بدراسة السوق لمعرفة الفرص التسويقية المتاحة.

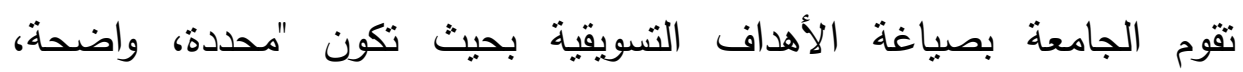

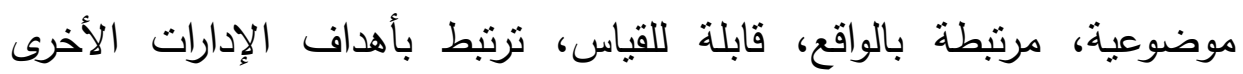
بالمؤسسة ، نابعة من الهدف العام للمؤسسة. ت تهتم الجامعة بتقوية الثراكات مع المجتمع ومؤسساته.

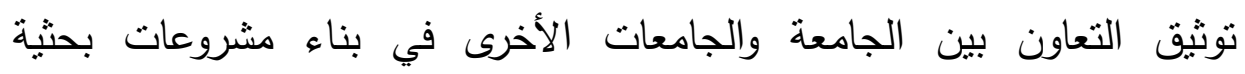
وتسويقها. 


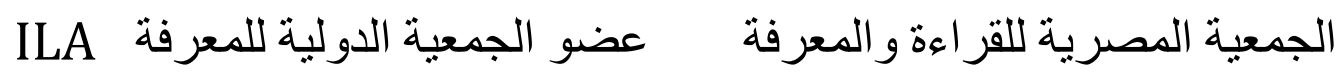

تدعم الجامعة نشاط تسويق الخدمات البحثية من خلال تخصيص جزء من

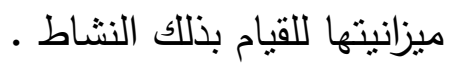
تقوم الجامعة باستضافة المختصين في التسويق لإقامة دورات تدربيية بمعاهد البحوث لتتمية مهاراتهم التسويقية. من الضروري أن تقدم الجامعة الاسنتارات العلمية من خله مراكزها المتخصصة. انثاء روابط ارشادية عبر البوابة الالكترونية الجامعية تتضمن حلقات نقاش حول تسويق الخدمات البحثية في ضوء الاتجاهات العالمية. نشر ثقافة تسويق الخدمات البحثية بما يتوافق والمتغيرات الحضارية المعاصرة ، والمستجدات التقنية الحديثة. تقدر الجامعة قيمة مناسبة للخدمات البحثية بالجامعة، لأن ذللك له تأثثر مباشر على حجم الطلب على الخدمات البحثية مثل " التسعير على أساس التكلفة، التسعير على أساس الطلب، التسعير على أساس المنافسة ".

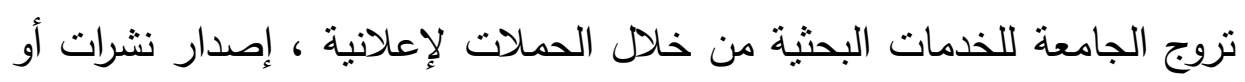
إعداد دليل عن الخدمات البحثية، المحادثات الثفوية كالمحاضرات، المواقع الإلكترونية بالجامعة، وسائل الاعلام المختلفة، الندوات والاجتماعات. ولضمان تميز المراكز البحثية لابد من مراعاة ما يلي :

توفير تمويل مالي مستقر ينزايد مع نتزايد الأنشطة البحثية ومتطلباتها.

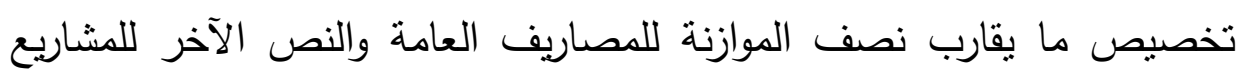
البحثية التعاقدية التي يمكن تمويلها من مصادر محلية ودولية. تحديث البنية التحتية بشكل دوري بواقع مرة كل عشرة سنوات على الأقل. توفير كوادر علمية متوازنة من الباحثين والفنيين والإداريين. 
الجمعية المصرية للقر اعة والمعرفة عضو الجمعية الدولية للمعرفة

العمل في إطار إستراتيجية علمية واضحة المعالم وثابتة على مدى (30-40) عاماً، تخضع لثروط صارمة للرقابة العلمية والإدارية.

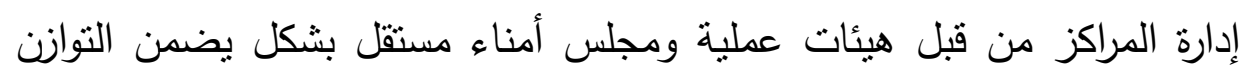
الدقيق بين الإدارة وصنع القرار العلمي. العمل في مشاريع البحث والتطوير التقني،وليس في الخدمات العلمية.

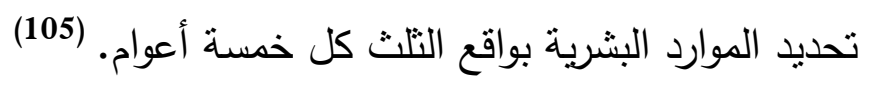

(105) محمود،سامي (2008 م) البحث العلمي وضرورات التحسين من خلال

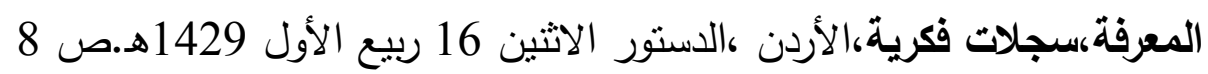
535 
الجمعية المصرية للقراعة والمعرفة عضو الجمعية الدولية للمعرفة ILA

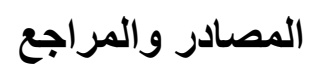

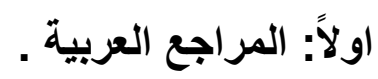

1. أبو سليمان، عبد الوهاب إبراهيم (1996) كتابة البحث العلمي - صياغة جديدة،

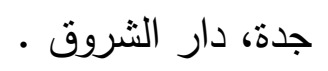

2. أحمد أبو زيد: نظام الوقف الإسلامي: نطوير العمل وتحليل نتائج بعض الدراسات

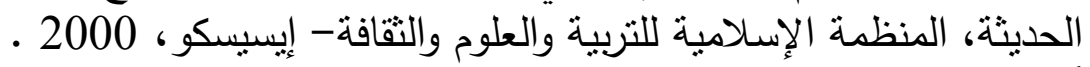

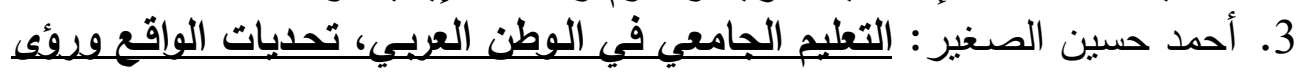

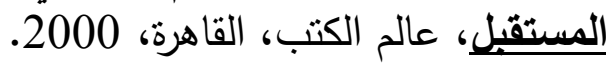

4. أكرم ناصر / صفوان الأخرس / وبشير بريز : البحث والتطوير التقني والابتكار

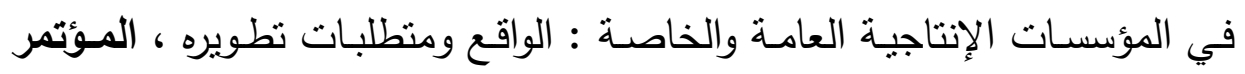

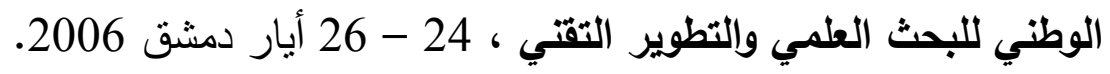

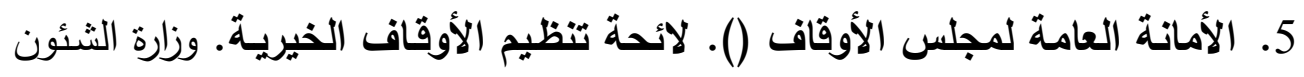

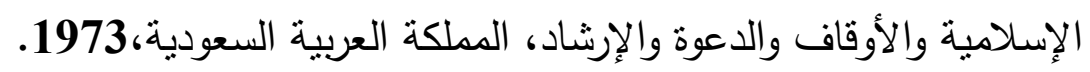

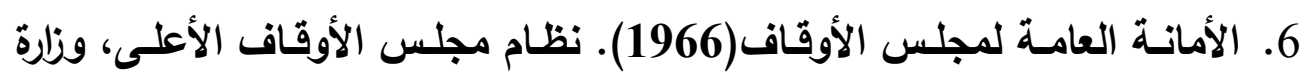

الثئون الإسلامية والأوقاف والدعوة والإرشاد، المملكة العربية السعودية.

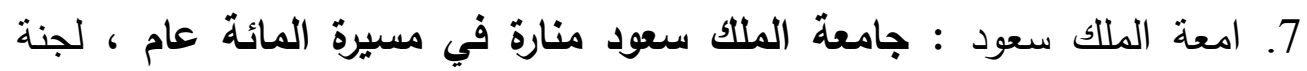

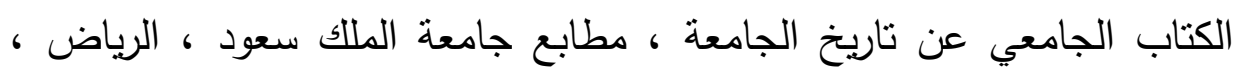

.1999

8. الأمم المتحدة : برنامج الأمم المتحدة الإنمائي ، تقرير التنمية البشرية ،

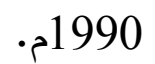

9. باميلا ماركونت وبروس جونستون، سياسات ورسوم الدراسة من منظور مقارن،

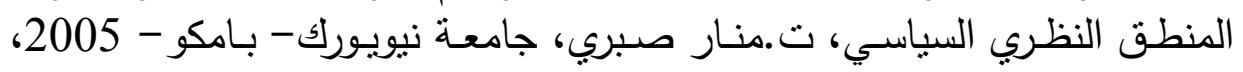

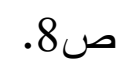

10. برنـامج الأمم المتحدة الإنمائي: تقريـر المعرفـة العريـي، نحو نواصل

معرفي منتج، الأداء العربي في مجال البحث والإبداع ، 2009 ـ 
الجمعية المصرية للقر اعة والمعرفة عضو الجمعية الدولية للمعرفة ILA

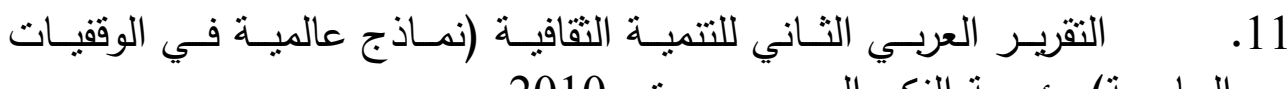
12. النقرير العربي الثاني للتنمية الثقافيـة- مؤسسـة الفكر العربي، بيروت، . 2008 13. التقرير العربي الثاني للتتميـة الثقافيـة، مؤسسـة الفكر العربيـ بيـروت .2010

14. التنقرير العربي الثاني للتنمية الثقافية، مؤسسة الفكر العربي- بيروت .

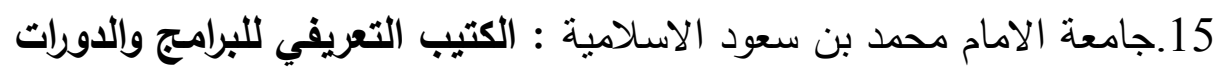

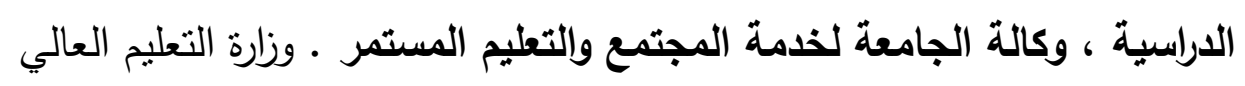
، المملكة العربية السعودية ، ص117. 16.جامعة الملك سعود : دليل جامعة الملك سعود ، وكالة الجامعة للاراسات

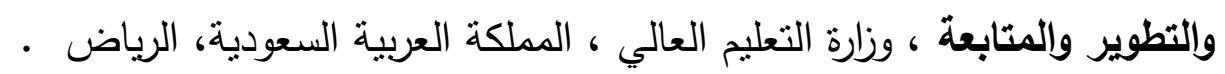

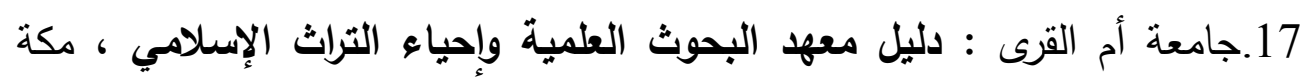

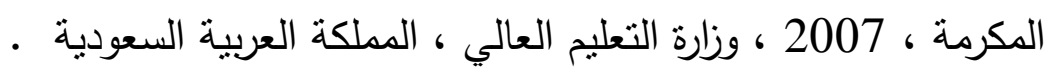
18.جامعة أم القرى: النثأة والتطور ، مكارة التطرئ ، المكرمة ، مطابع جامعة أم القرى ، 1406

جمـال الدهثـان: العلاقــة الإسـتراتيجية بـين البحـث العملـي الجـامعي

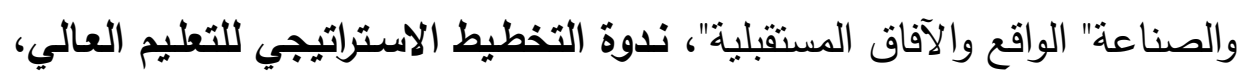

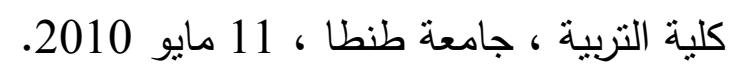

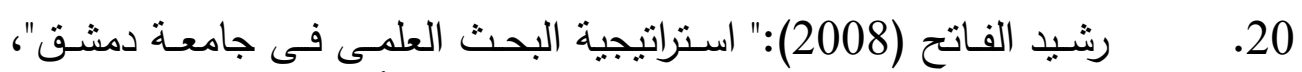

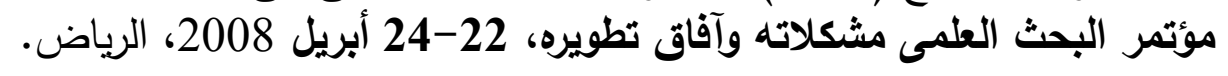

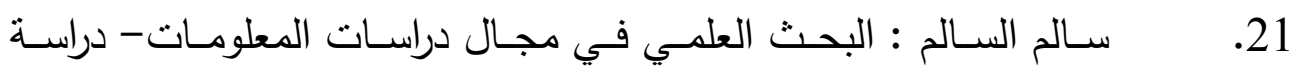

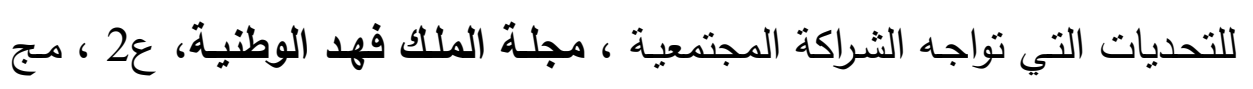
17، المملكة العربية السعودية ، 2011 . 
الجمعية المصرية للقراعة والمعرفة عضو الجمعية الدولية للمعرفة ILA

22. سامى عريفج: الجامعة والبحث العلى، عمان، دار الفكر للطباعة

$$
\text { والنشر، } 2001 .
$$

سعاد الحارثي: استراتيجيه مقترحة لدعم البحث العلدي في الجامعات

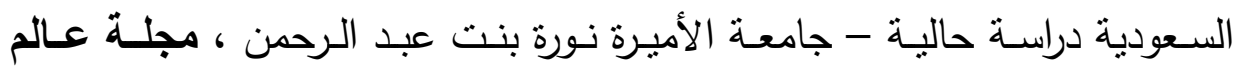

التربية، المؤسسة العربية للاستثارات وتتمية الموارد البشرية ، عدد ابريل 2012.

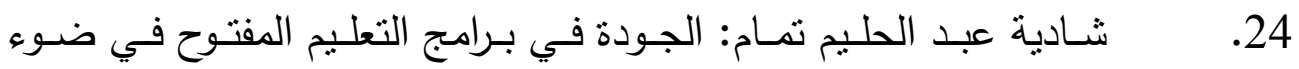

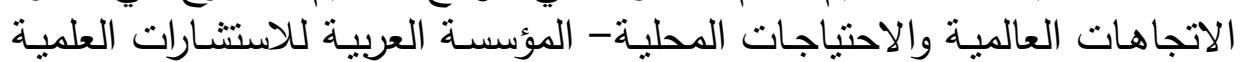

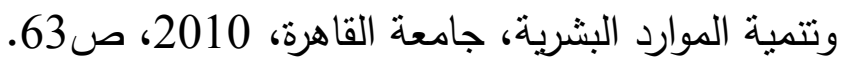

25.صالح السدراني وآخرون : البحث العلمي في جامعة المثلك سعود: الواقع

والتطلعات، وقائع ندوة البحث العلمي في دول مجلس التعاون لدول الخليج

العربية، المنعقدة بمدينة الملك عبدالعزيز للعلوم والتقنية خلال 12-14 نوفمبر ، التهل

$$
\text { الرياض، } 2000 .
$$

26. ملاح سالم زرنوقة: البحث العلمي والتتمية فى مصر، قضايا التنمية،

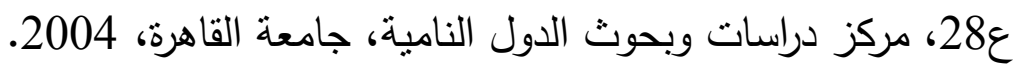

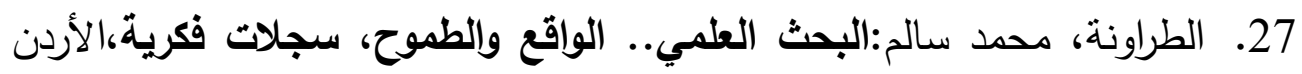

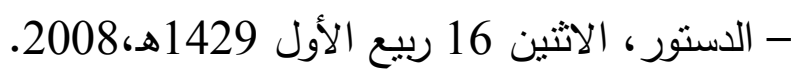

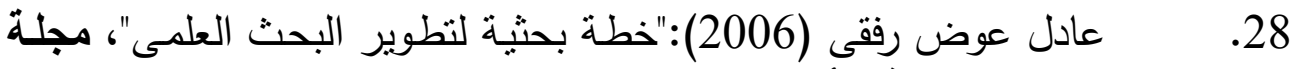

اتحاد الجامعات العربية،الأردن، عدد 54 . 5 .

عبد اله المجيدل وسالم شماس: معوقات البحث العلمي في كليات التربية

من وجهه نظر أعضاء الهيئة التصريسية ( دراسـة ميدانية كلية التربية بصلالة

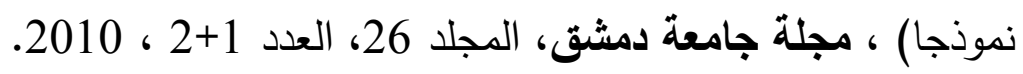

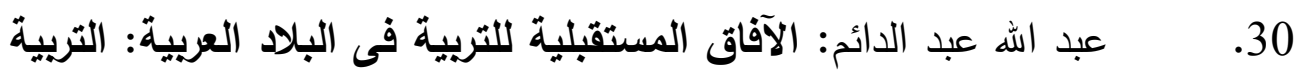

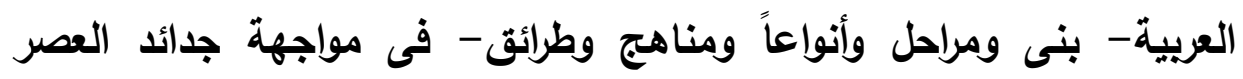
وتحدياته ومشكلاته، بيروت، دار العلم للملايين، 2000، ص 142. 


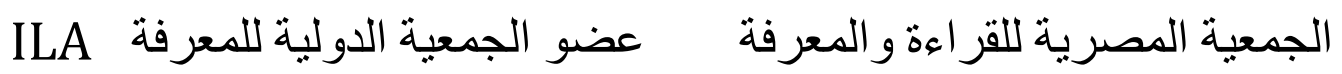

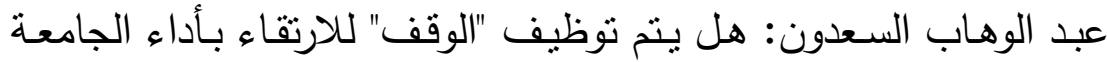

الوطنية، المجلة الإلكترونية الاقتصادية، 2009، العدد، 5656.

عمار عمارى، ليلى قطاف: الجامعـة الجزائريـة "الواقع والآفاق"، الملتقى لإنى

الأول حول إثـالية التكوين والتعليم فى أفريقيا والعالم العربى، سلسلة إصدارات

مخبر إدارة وتتميـة المـوارد البشـرية، جامعـة فرحـات عبـاس، سطيف (الجزائر )،

.2004

33.الغرفة التجارية الصناعية بالرياض ، نبذة مختصرة عن مراكز البحوث في الجامعات السعودية ، إدارة البحوث ، الغرفة التجارية الصناعية بالرياض ، ربيع

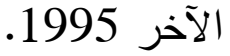

فليسـت كل الكراسى فى الجامعـات السـودية تمـول عن طريـق إرصـاد

أوقاف لها، وإنما بعضها يمول عن طريق منح سنوية يلتزم بها المانحون.

فؤاد العاجز ، حسن حماد : رؤية جديدة لدور البحث العلمي في تحقيق

الثراكة الفاعلة مع قطاعات الإنتاج من منظور تكاملي ، مؤتمر البحث العلمي وأخلاقياته وتوظيفه ، الجامعة الإسلامية ، غزة ، 2011.

كوثر، عصسام بـن حسن ويعـ الله بـن محمـد العمرانسى (2011). دور

الوقف فى دعم التعليم العالى والبحث العلمى فى المملكة العربية السعودية. ورقة

مقدمة إلى حلقة عمل حول دور الوقف فى دعم وتمويل التعليم العالى والبحث العلمى فهى البلـدان الإسـلامية، جامعـة الإسـكندرية والمعهد الإســامى للبحـوث

$$
\text { والتدريب، الإسكندرية. }
$$

37. مجلس التعليم العالى السعودى (2007). نظام مجلس التعليم العالى

والجامعات ولوائحه. (الطبعة الثالثة). الرياض، المملكة العربية السعودية.

38. مجس التعليم العالى السـودى: نظام مجلس التعليم العالى والجامعات ولوائحه. (الطبعة الثالثة). الرياض، المملكة العربية السعودية،2007. 
الجمعية المصرية للقراعة والمعرفة عضو الجمعية الدولية للمعرفة ILA

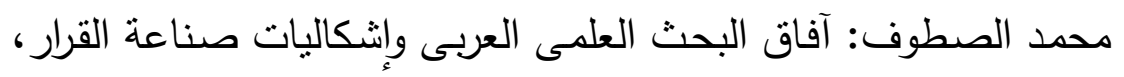

مؤتمر إدارة وتمويل التعليم العالى، الجامعة اللبنانية، بيروت، 2000.

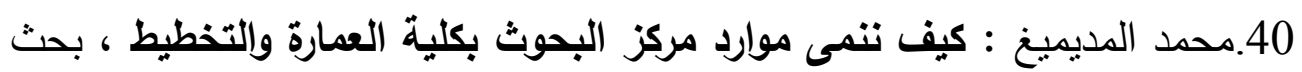
مقدم الى ندوة القائمين على البحث العلمى في الجامعات السعودية ، المنعقدة

خلال الفترة 19-20 ديسمبر ، الرياض ، 1995 ـ 199

محمد عثمان حميد : أساسيات التمويل الإداري واتخاذ قرارات الاستثمار

، القاهرة ، دار النهضة العربية ، 1998م.

محمد مسعد ياقوت : البحوث العلمية في العالم العربي غير

مجدية،الرياض ، وزارة التزبية والتعليم، مجلة المعرفة ، العدد (136)، 2006 م.

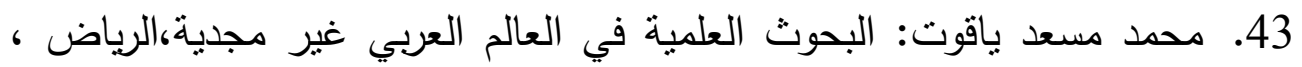

وزارة التربية والتعليم، مجلة المعرفة ، العدد (136)، 2006 م.

44.محد مكي : انجازات مراكز البحوث والمعوقات التي تواجهها ، بحث مقدم إلى الى

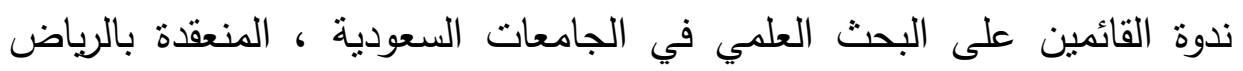
خلال الفترة 19-20 ديسمبر ، الرياض ، جامعة الملك سعود.

45. محمود،سامي (2008 م) البحث العلمي وضرورات التحسين من خلال

المعرفة،سجلات فكرية،الأردن ،الدستور الاثثين 16 ربيع الأول 1429هـ العهدي

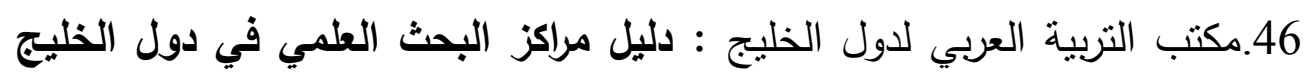

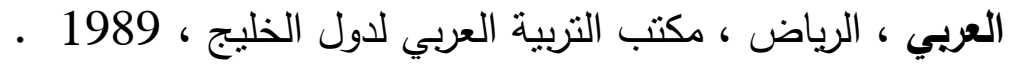

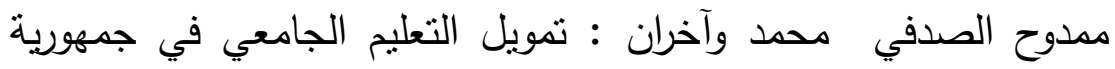

مصر العربية بدائل مقترحة في ضوء الاتجاهات العالمبة المعاصرة ، مجلة كلية

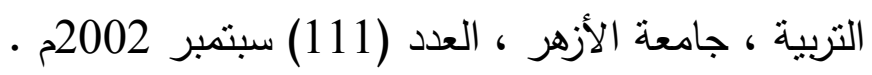




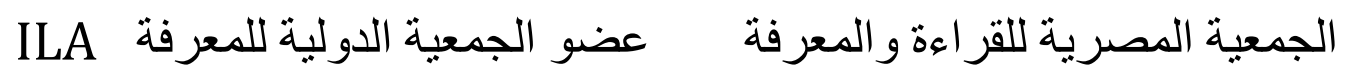

48. منذر واصف المصري : التمويل الحكومي والخاص للتعليم العالي دراسة مقدمة للمؤتمر الثامن للوزراء المسؤولين عن التعليم العالي والبحث العلمي في الوطن العربي ، المنظمة العربية للتربية والثقافة والعلوم بالاثتراك مع وزارة التعليم العالي ج.م.ع ، محور التعليم العالي ، القاهرة ، المنعقد في الفترة من 24-27 ديسمبر ولع 2001م .

منظمة الأمم المتحدة للتربية والعلم والثقافة: التعليم العالى فى القرن

الحادى والعشرين "الرؤية والعمل"، المؤتمر العالمى للتعليم العالى، باريس، 5-9 أكتوير 1998.

50. منى محمد أبو الفتوح: نظام إعداد معلم المرحلة الأولى في مصر وتركيا

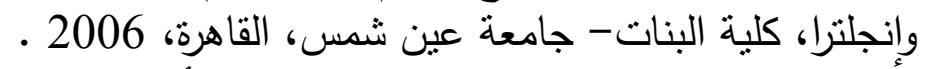
51. تركيا- نموذجاً.

52. وزارة التعليم العالى السعودية (2000). لائحة الكليات الأهلية. 53. وزارة التعليم العالى السعودية (2003). لائحة الجامعات الأهلية.

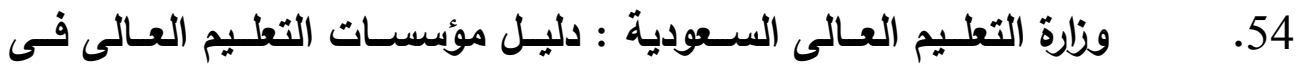
المملكـة العربيـة السـعودية (الجامعـات والكليـات الحكوميـة والأهليـة). إدارة المعلومات، الرياض، المملكة العربية السعودية، 2012

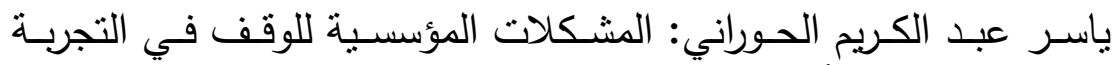

الإسلامية التاريخية، مجلة أوقاف، السنة التامنة العدد12، 14، 14، مايو 2008 ـ

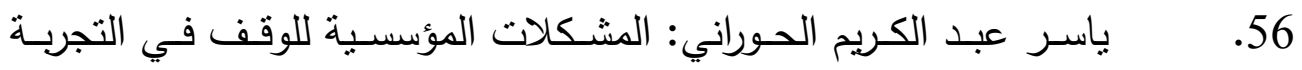
الإسلامية التاريخية مجلة أوقاف، السنة الثامنة، العدد 17، مايو 2008 .

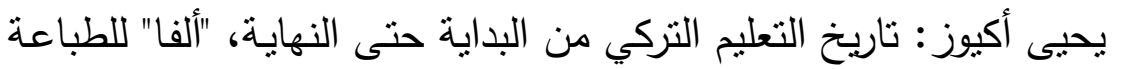

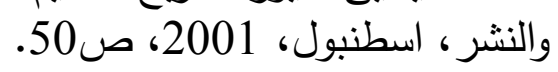

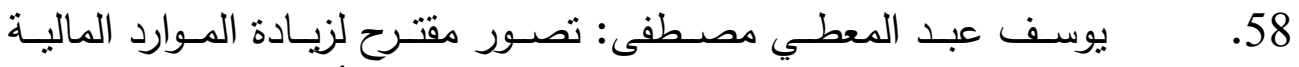
بالجامعات المصرية في ضوء خبرات بعض الجامعات الأجنبية، مجلة التربية- 
الجمعية المصرية للتربية المقارنة والإدارة التعليمية، السنة السابعة العدد 11، مارس

$$
\text { ثانيا : المراجع الأجنبية .312. }
$$

1. Choong Yuen- Onn and et.al: Organizational Commitment: An

Empirical Investigation on the Academician of Malaysia private universities. Business and Economics Research journal, Vol(3), $\mathrm{No}(2), 2012$. .

2. ${ }^{1}$ Hoquel Kazi Enamul and et.al : Service delivery in Higher Education ( $\mathrm{HE})$ : A comparative Study Between Public and Private Universities, Life Science Journal. 10(3),2013.

3. ${ }^{1}$ Lee Molly N.N. and et.al: Case Study: the Effectiveness of Research and Innovation Management at Police and Institutional Levels Combodia, Malaysia. Thailand and Vietnam, In Asa Olsson Lunn Meek, OECD,( W.d).

4. 1 Students' Attitude to Education Loan Repayments: Astructural Modelling Approach, Dissertation of Philosophy, Brunei University, West London, 2011.

5. ( $\left.{ }^{1}\right)$ Ali Dogramaci (2008): Private university initiatives in Turkey: The Bilkent Experience International conference in Higher Education. Technion, Turkey, p.

6. $\left({ }^{1}\right)$ Council of Higher Education Report on Foundation universities. 2007, p. 101.

7. ( $\left.{ }^{1}\right)$ Mukesh Chawla, How much does Turkey Spend on Education? 2005, World Bank.

8. ( $\left.{ }^{1}\right)$ Thomas Heinz, philip Shapira, Juan Rogers \& Jacqueline Senker: Organizational And Instiutional Influences On Creativity In Scientific Research, Research policy, Vo138, Issue 4, 2009.

9. Ahmed Abd Rahman and et.al: Funding Reform In Malaysian Public Universities: Transitions Towards Competitive Funding, Australian Journal Of padc And Applied Sciences.7( 1 0),20 13. 


\section{ILA الجمعية المصرية للقر اءة والمعرفة عضو الجمعية الدولية للمعرفة}

10. Ahmed Abd Rahman and et.al: Funding Reform In Malaysian Public Universities: Transitions Towards Competitive Funding, Australian Journal Of padc And Applied Sciences.7( 10$), 2013$. .

11. 'Ahmed Ibrahim and et.al: Waqf Fund Management in Kuwait and Egypt: Can ${ }^{\wedge}$ Malaysia leams From Their Experience, The International Conference on Masjld. Zakat and Waqf, 1-2 December, Kuala Lumpur, Malaysia, 2014. .

12. Asharf Mohdramili, Mohamed Mostafa Omar: An Over View Of Public Funding For Higher Learning Education In Malaysia And The Prospect Of Waqf Funding, This Study Is Apart Of Research in "Pembentukan Model Baru Wakaf Korprat Di Malaysia, Ministry Of Higher Education (mohe), (w.d).

13. Ashorth, Kenneth; H; The Texas Case Study, Change, Vol. 26, No.6, Nev/Dec, /2004.

14. Associacao Brasilerira De Educacao Adistancia : Distance Education Public Policy And Practice In Higher Education; The Case Study of Malaysia,(part 11), Revista Brasilerira De Aprendizagem Abertae Adistance, Saopaulo, Setember, 2003.

15. Bain, Olga. (2001)The costs of Higher Education to students and parents in Russia: Tuition policy Issues.Peabody Journal of Education .

16. Ben, Jongbloed And Hans, Vossensteyn Keeping Up Performances : An International Survey of Performance - Based Funding In Higher Education, Journal of Higher Education Policy and Management, Vol. 23, No.2, 2001.

17. Brian, Salter, And Others: Managing The Private Finance Intiative, Perspective, Vol. 4, No.3, 2000,

18. Catherine, Beaudty \& Sedki Allaoui : Impact of public and private Research Funding on Scientific production: The Case of Nanotechnology, Research policy, Vol41,2012,

19. Champan, Bruce and chris Ryan (2003). The Access Implications of Income contingent charges for Higher Education: Lessons from Australia Discussion paper No. 463 Center for Economic Policy Research, Australian National university . 


\section{ILA عضو الجمعية الدولية للمعرفف}

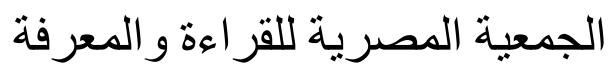

20. Choice Of Malaysian Public University: A Reach model Analysis, International Journal of Applied psychology, 3(1), 2013.

21. Clausen, Tommy \& Fagerberf, Jan \& Gulbrandsen, Maguns: Mobilizing For Change: Astudy of Research Untis in Emerging Scientific Fields, Research poliey, Vol41,Issue 7,2012,.

22. Diedra young (1998): Teacher Moral and Efficacy in Rural Western Australia A paper presented At the Annual conference of Australian Association for Research in Education, South Australia, No. 29, De3 .

23. Fuadah Johari , Mohammed Haji Alias: Potential Of Waqf and Instruments in Contemporary Economic System, available at: www.nuradli.comliecons 2013/ B.4Pdf 17/5/2015. 2:30 pm.

24. Hebel, Sara; Colorado Institutions Seek To Escape Limits On Spending, Chronicle Of Higher Education, Vol.48, No.39, 2002.

25. Hebel, Sara;Virginia Plan Of Fers Fiscol Stability, But The Attached Strings Worrg Colleges, Chronicle Of Higher Education , Vol. 46, No.24, 2000.

26. Holtta, Seppo; The Funding Of Universities In Finland : Towards Goal Oriented Government Steering, European, Journal Of Education, Vol. 33, No.1, 2008.

27. Ismail Shafmar: Antoaneta Serguieva: Investigating Possible Benefits Of Student Loan Backed Securitization In The Context Of The Malaysian Higher Education, Higher Education Journal, Cabell Publishing, USA,Inc, 2009.

28. John Hagan; More Money For More Rope: The Taylor Report and The Funding Debate, Perspectivers, Vol. 6, No.1, 2002.

29. Larocque Norman. (2003) Who should pay? Tuition fees and tertiary education financing in New Zealand, (Wellington, Education Farom..

30. Mohamed Zuraigah and et.al: Acomparative Study Of Waqf Management in Malaysia, 2011 International Conference on Sociality and Economics Development, IpEDer, vol.10, IACSIT Press, Singapore, 2011.p.562.

31. Ramii Asharf Mohd, Mohamed Mostafa Omar: An Over View Of Public Funding For Higher Learning Education In Malaysia And The Prospect Of Waqf Funding, This Study Is Apart Of Research in 


\section{الجمعية المصرية للقر اعة والمعرفة عضو الجمعية الدولية للمعرفة}

"Pembentukan Model Baru Wakaf Korprat Di Malaysia, Ministry Of Higher Education (mohe), (w.d). .

32. Ramii Asharf Mohd, Mohamed Mostafa Omar: An Over View Of

Public Funding For Higher Learning Education In Malaysia And The

Prospect Of Waqf Funding, This Study Is Apart Of Research in

"Pembentukan Model Baru Wakaf Korprat Di Malaysia, Ministry Of

Higher Education (mohe), (w.d).

33. Robert Heorner: Research In Special Education: Scientific Methods and Evidence - Based Practices Education, 2005, P4, www: Uorgon.edu/ Grantmatters/pdf/DR/ Research- in- Sped.

34. Shinichi Yamamoto (2006), 'Academic Research in Japan, The future of academic research - OECD Expert Meeting Vienna.

35. Steering committee for the review of commonwealth state service provision Report on government services 2007, Australia, conberra: productivey commissiony, 2003.

36. The World Bank: Putting Higher Education to Work Skills and Research for Growth in East Asia,'World Bank East Asia and Pacific Regional Report, The World Bank,Washington DC 20433,2012.

37. Varghese N. V.: Incentives and Institutional changes In Higher Education, Higher Education Management and Policy,Vol.16, No. 1, OECD, 2004 .

38. Yaakub Noor Inayah: The Transformation Of The Role Of Waqf in The Higher Learning Education In Malaysia: A New paradigm For Islamic Financial Institutions, $11^{\text {th }}$ Kuala lumper Islamic Finance Forum 2014, Hotel Istana kualalumper city Center, Malaysia, 11-12 November 2014.

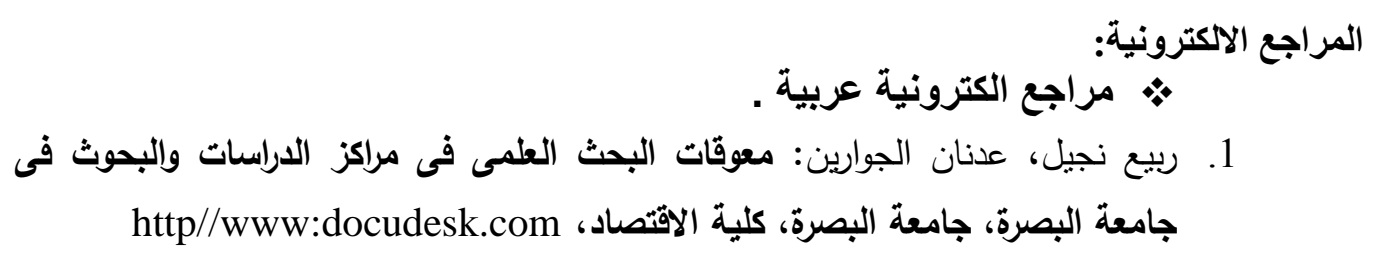


ILA الجمعية المصرية للقر اعة والمعرفة عضو الجمعية الدولية للمعرفة

2. جامعة أم القرى ، معهد البحوث العلمية وإحياء التراث الاسلامي : مرجع سابق ، ص ص .77-75

3. http://www.sauress.com/almadina/340948. 12-10-2016 4. جامعة الملك عبد العزيز.(بدون تاريخ). الكراسى العلمية. معهر البحوث والاستشارات.

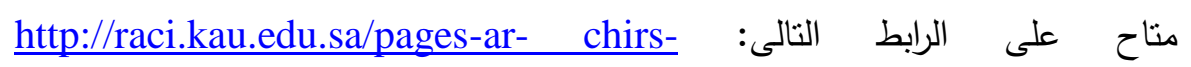
- 'massages.aspx 5. جامعة الملك عبد العزيز.(بدون تاريخ). الكراسى العلمية. معهد البحوث والاستشارات. http://raci.kau.edu.sa/pages-ar- chirs- متاح - 'massages.aspx

6. جامعة الملك سعود.(بدون تاريخ). برنامج كراسى البحث. متاح على الرابط النالي:

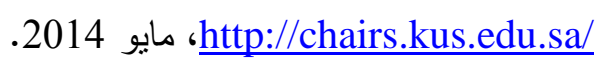

ج 7

8. جامعة الإمام محد بن سعود الإسلامية.(بدون تاريخ). برنامج كراسى البحث. متاح على

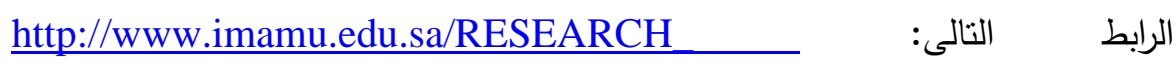
2014. CHAIRS/Pages/default.aspx 9. نبيل السمالوطي: الجامعات ونهضة الأمة. تجربة التعليم الجامعي في تركيا، نموذجا:

10. http://islamirabta.com/index.php?pageshow=shawarticle\&ids9615/7/ $\underline{2011}$.

11. الجامعة الإسلامية بالمدينة المنورة: http:/Www.iu.edu.sa، أبريل 2013.

12. جامعة الملك فيصل. (بدون تاريخ). الكراسى العلمية القائمة بالجامعة. متاح على الرابط http://www.kfu.edu.sa/ar/departments/knowledge التالى: ،22-10-2016Exchange/pages/chairshtescientific1.aspx

13. جامعة أم القرى: 12-11-2015 . 


\section{الجمعية المصرية للقر اعة والمعرفة عضو الجمعية الدولية للمعرفة ال}

\section{4. جامعة الأمير محمد بن فهـ:http://www.pmu.edu.sa، أبريل 2013.

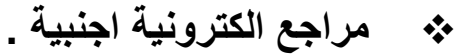

1. The Australian National university, discover ANU, university mission, available at http: // www. Anu. Edu. Au/ discoveranu, 2009.

2. The Australian National university, office of commercialization, about us, available at http: // www. Anu. Edu. Au/ commercialisation / aboutus. Php, 2009.

3. The Australian National university, Marketing \& Communications at ANU, available at http: // www. Anu. Edu. Au / mac/ content/ about, 2009.

4. The Australian National university, marketing \& Communications at ANU, marketing office, available at http: // www. Anu. Edu. Au/ mac/ content/ about/ area/ marketing office/, 2009.

5. The Australian National university, Marketing \& Communications at ANU, Alumni Relations, available at http: // www. Anu. Edu. Au/ mac/ content/ about/ area/ alumni_relations/, 2009.

6. The Australian National University, The ANU Careers Centre, available at http: // www. Anu. Edu. Au/ careers/ index. Php? Page=2., 2009. 